\title{
Projection of truck traffic volumes at interstate permanent automatic traffic recorders
}

Alex M. Sanchez

West Virginia University

Follow this and additional works at: https://researchrepository.wvu.edu/etd

\section{Recommended Citation}

Sanchez, Alex M., "Projection of truck traffic volumes at interstate permanent automatic traffic recorders" (2006). Graduate Theses, Dissertations, and Problem Reports. 1720.

https://researchrepository.wvu.edu/etd/1720

This Thesis is protected by copyright and/or related rights. It has been brought to you by the The Research Repository @ WVU with permission from the rights-holder(s). You are free to use this Thesis in any way that is permitted by the copyright and related rights legislation that applies to your use. For other uses you must obtain permission from the rights-holder(s) directly, unless additional rights are indicated by a Creative Commons license in the record and/ or on the work itself. This Thesis has been accepted for inclusion in WVU Graduate Theses, Dissertations, and Problem Reports collection by an authorized administrator of The Research Repository @ WVU. For more information, please contact researchrepository@mail.wvu.edu. 


\title{
Projection of Truck Traffic Volumes at Interstate Permanent Automatic Traffic Recorders
}

\author{
By \\ Alex M. Sanchez
Thesis submitted to the
College of Engineering and Mineral Resources
at West Virginia University
in partial fulfillment of the requirements
for the degree of
Master of Science
in
Civil Engineering

\author{
David R. Martinelli, PhD., Chair \\ Lloyd. J. French, Ph.D. \\ Ronald W. Eck, Ph.D. \\ Department of Civil and Environmental Engineering \\ Morgantown, West Virginia \\ 2006
}

Keywords: Transportation, Forecasting, Truck Traffic, Traffic Recorders 


\title{
ABSTRACT \\ Projection of Truck Traffic Volumes at Interstate Permanent Automatic Traffic Recorders
}

\author{
Alex M. Sanchez
}

This study documents the development of a methodology and models to forecast truck traffic volumes on Interstate Highways at a selection of Permanent Automatic Traffic Recorder (PATR) sites. The models were developed using data collected over a period nine years (1995 to 2003) from sixteen permanent count stations located throughout the state. Eight sites were ultimately utilized, five along rural interstate highways and the others from urban interstate highways. Model development was based on the time series method, using two techniques: regression analysis and the growth factor technique. Both were analyzed and compared in order to select the most reliable technique to be used in the forecasting procedure. To further understand changes in truck traffic patterns, traffic was grouped according to the FHWA vehicle classification scheme. Models were developed for each site and for every truck classification in these sites as well. Due to the smaller effect of demographic characteristics on interstate highways models; these models were performed using as a predicted variable: the Annual Average Daily Truck Traffic data obtained directly from the counters, and time period as the unique independent variable. Validation was conducted using the coefficient of variation to measure the statistical significance of the results obtained. Further validation of models was conducted by the coefficient of regression, and by comparison between the based trends data with the predicted models. In the course of the study, regression models resulted as the appropriate predictor technique to be used at interstate highways. Models, growth factors and figures are reported by every site and truck classification, detailed tables containing these factors are presented in the report. 


\section{DEDICATION}

This thesis is dedicated to my father Wilder my mother Gladis, my siblings Raul,

Ivan and Graciela, and my grandmother Celia (rests in peace), who always have expressed their love and support. 


\section{ACKNOWLEDGEMENTS}

I would like to express my thanks and gratitude to my advisor and committee, Dr. David Martinelli, Dr. Jim French, and Dr. Ronald Eck, for their guidance throughout this project. Also, express my thanks to the Mid-Atlantic Universities Transportation Center and the West Virginia Division of Highways for their financial support of this project. The author would like to thank my family, friends, and all of those who encouraged and supported me throughout this project. 


\section{TABLE OF CONTENT}

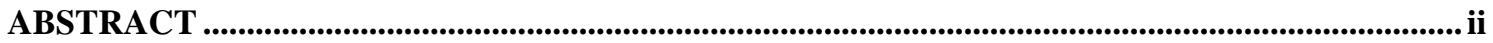

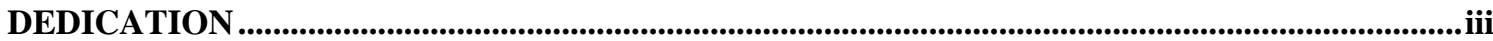

ACKNOWLEDGEMENTS ........................................................................................................................ iv

TABLE OF CONTENT …............................................................................................................................

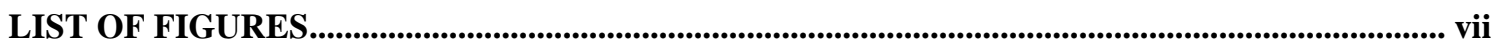

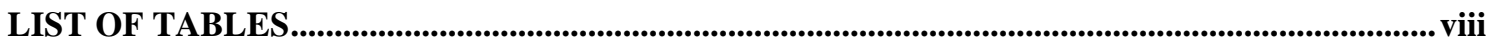

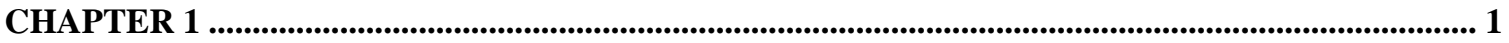

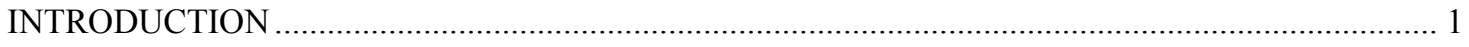

1.1 Background

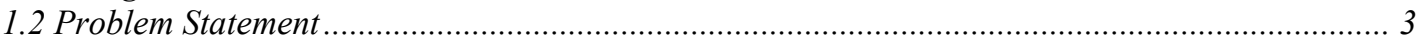

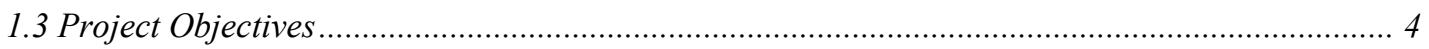

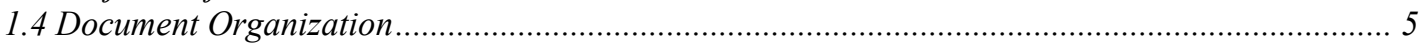

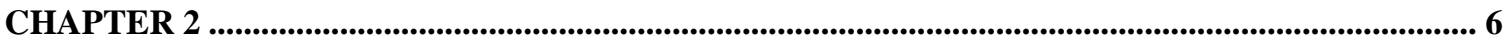

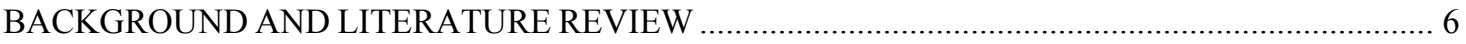

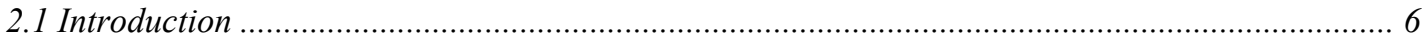

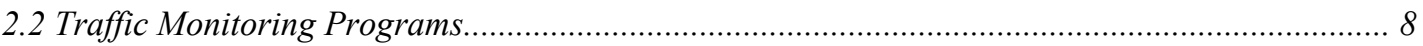

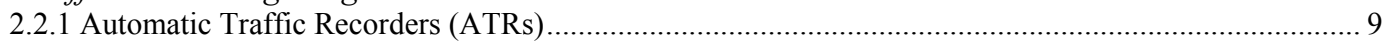

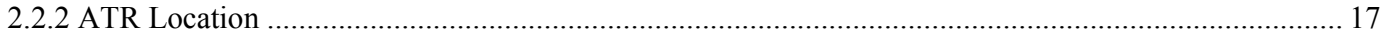

2.3 Current Methods to Forecast Truck Traffic Volumes .............................................................. 17

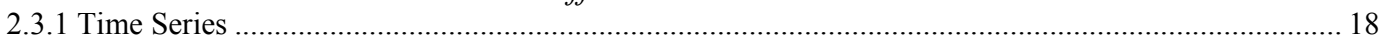

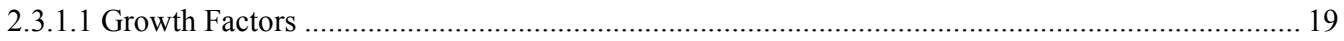

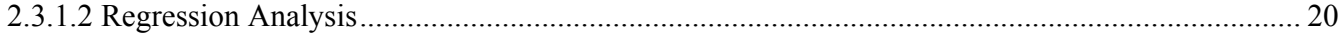

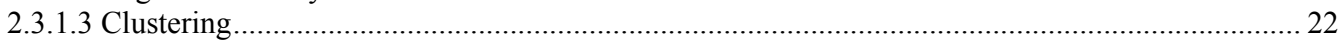

2.4 Computing Annual Average Daily Truck Traffic (AADTT) …………...................................... 24

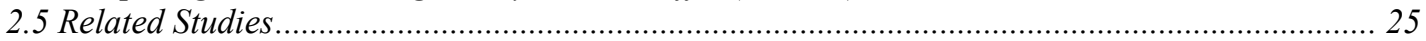

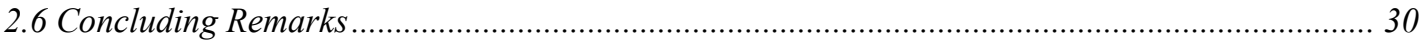

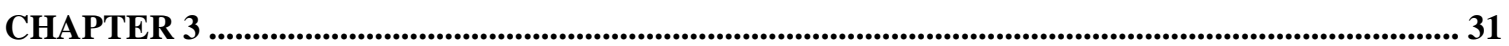

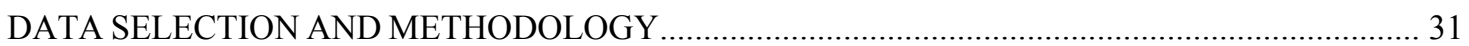

3.1 Type of Data

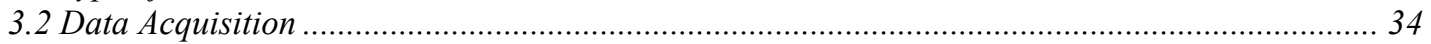

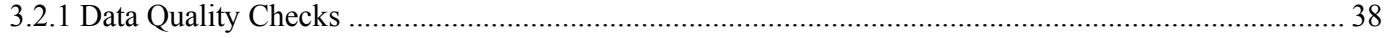

3.3 Estimation of Annual Average Daily Truck Traffic (AADTT) …….......................................... 38

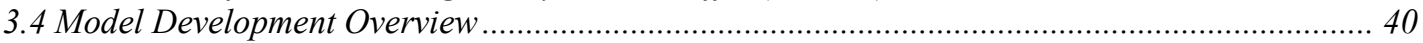

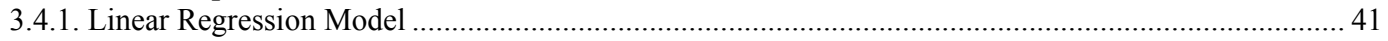

3.4.1.1. Statewide Interstate Highways Growth Rate ......................................................................... 42

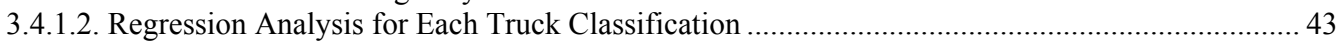

3.4.1.3. Annual Average Growth Rate Weighted...................................................................................... 43

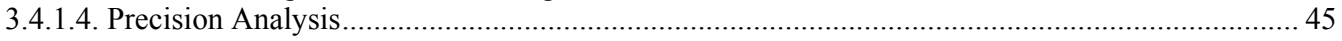

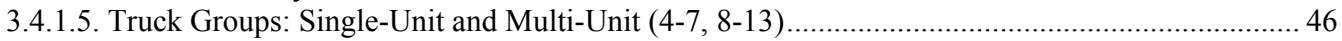

3.4.1.6 Models' Calibration and Validation ....................................................................................... 46

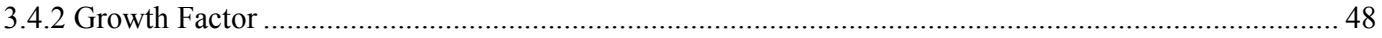

3.4.2.1. Statewide Interstate Highways Growth Rate ............................................................................ 48

3.4.2.2 Growth Factor Method for Each Truck Classification ................................................................. 49

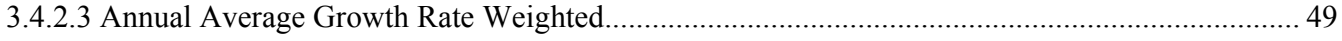

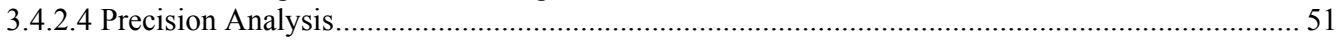

3.4.2.5 Truck Groups: Single-Unit and Multi-Unit (4-7, 8-13)............................................................ 51 


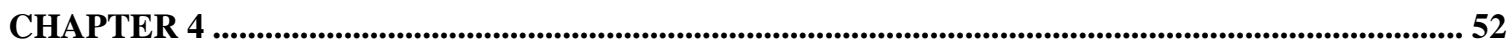

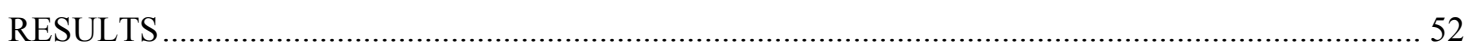

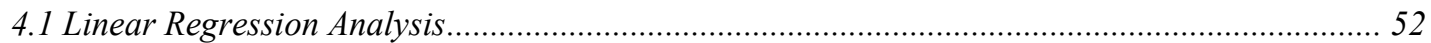

4.1.1. Linear Regression Analysis using AADTT …………………………………………………...... 55

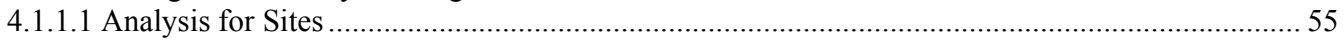

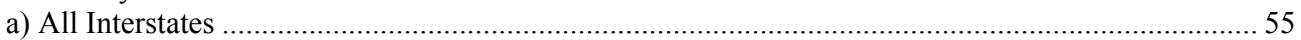

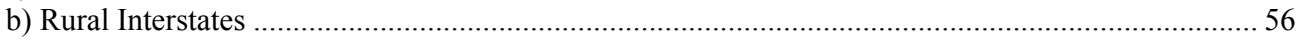

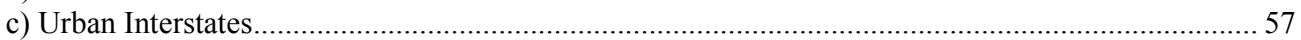

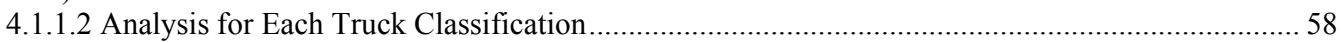

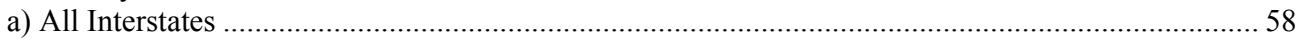

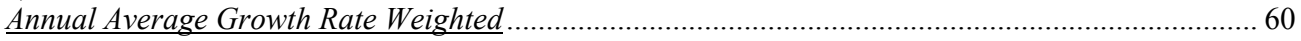

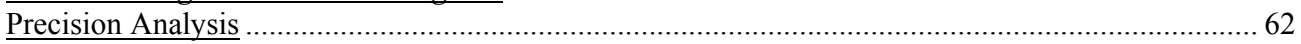

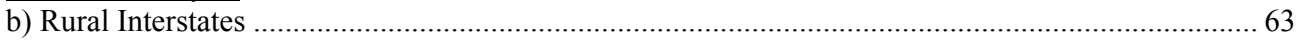

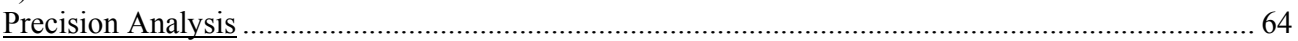

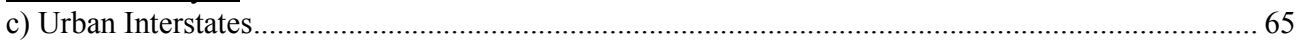

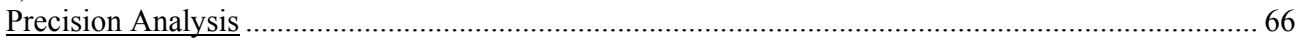

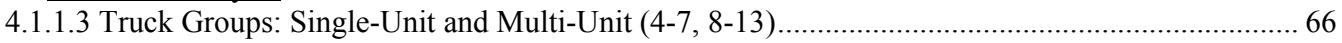

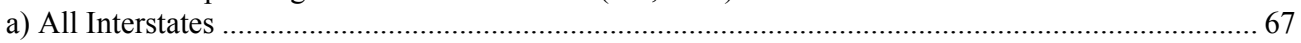

Annual Average Growth Rate Weighted ...................................................................................... 67

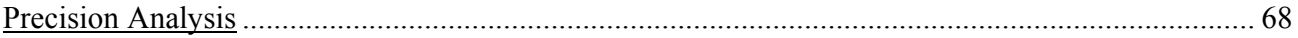

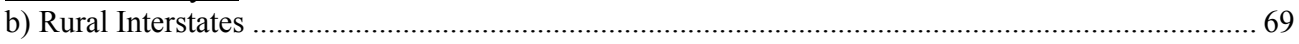

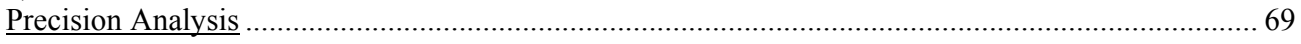

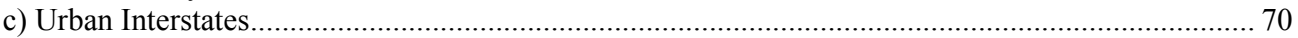

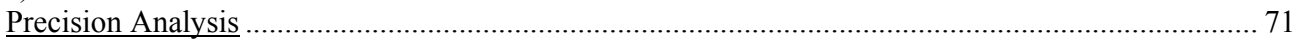

4.1.2. Linear Regression Analysis using Year Averaged AADTTs ............................................................ 71

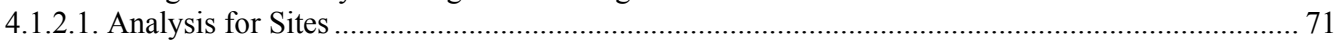

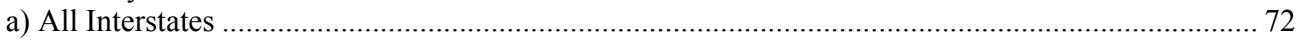

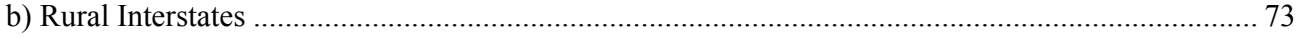

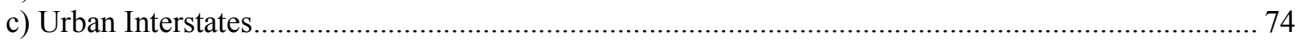

4.1.2.2 Analysis for Each Truck Classification ………………………………………………....... 75

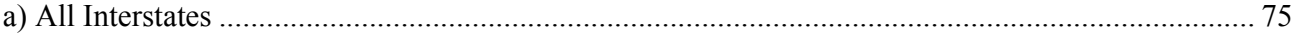

Truck Groups: Single-Unit and Multi-Unit (4-7, 8-13) ……………………………………...... 76

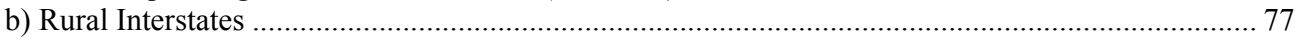

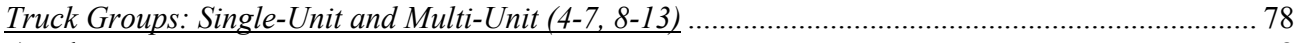

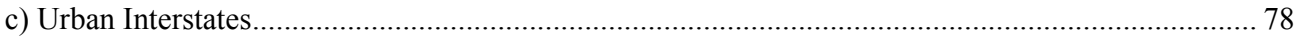

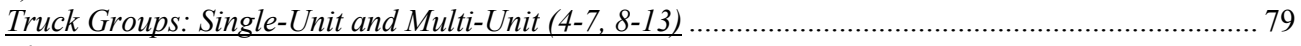

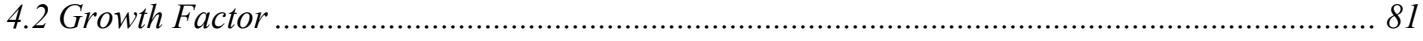

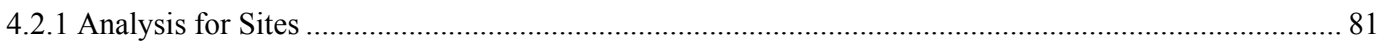

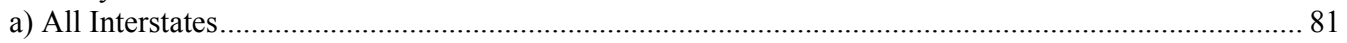

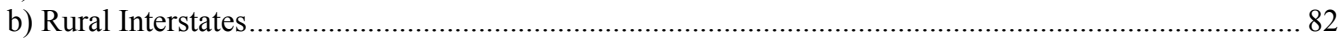

c) Urban Interstates .......................................................................................................................... 83

4.3 Summary: Comparison among Annual Average Growth Rates ................................................. 84

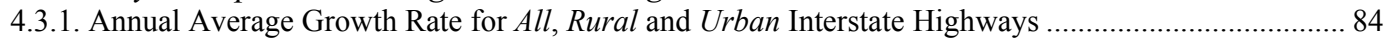

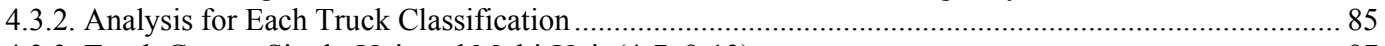

4.3.3. Truck Groups Single-Unit and Multi-Unit (4-7, 8-13) .................................................................... 87

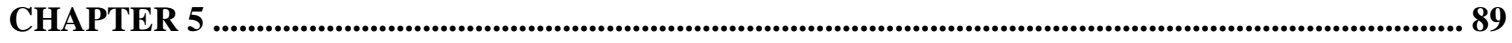

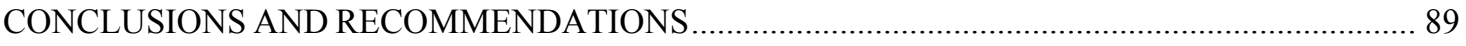

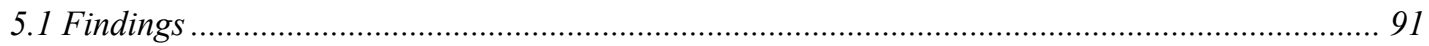

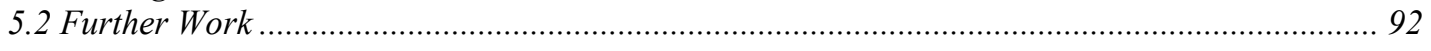

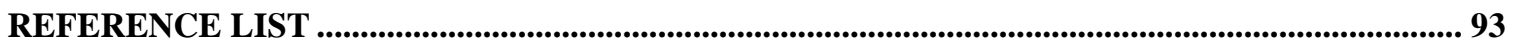

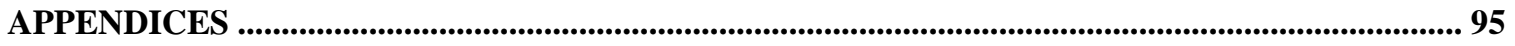

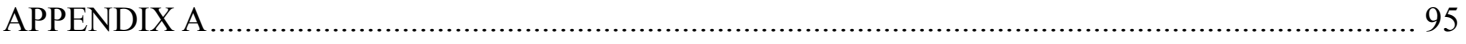

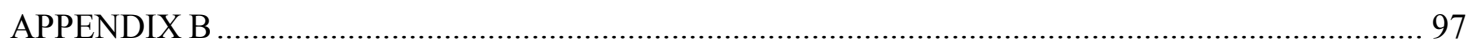

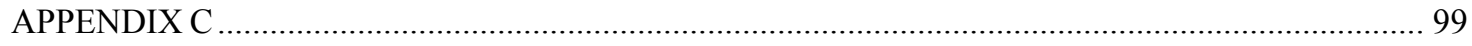

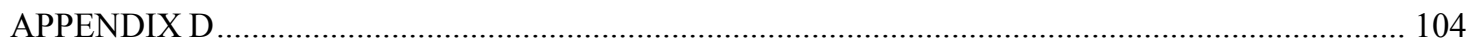




\section{LIST OF FIGURES}

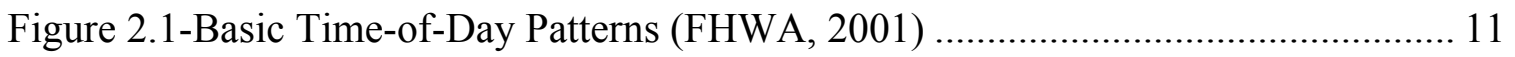

Figure 2.2-Weekday/Weekend Truck Percentage (FHWA, 2001) ................................ 11

Figure 2.3-Typical Day-of-Week Traffic Patterns........................................................ 12

Figure 2.4-Typical Monthly Volume Patterns .......................................................... 12

Figure 3.1 - West Virginia National Highway System ............................................... 33

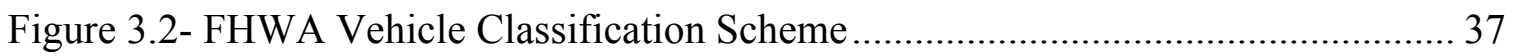

Figure 4.1-Trends at All Interstate Highways ................................................... 72

Figure 4.2-Trends at Rural Interstate Highways ................................................ 73

Figure 4.3 - Trends at Urban Interstate Highways ................................................. 74 


\section{LIST OF TABLES}

Table 3.1 - List of Interstates Permanent Traffic Recorders in West Virginia ................ 32

Table 3.2 - List of Sites used for this Project ............................................................ 32

Table 3.3- FHWA Vehicle Classification Scheme ….................................................. 36

Table 3.4- Annual Average Daily Truck Traffic- Interstate Highways.......................... 39

Table 4.1-Linear Regression Models and Coefficient of Regression for Each Site ...... 52

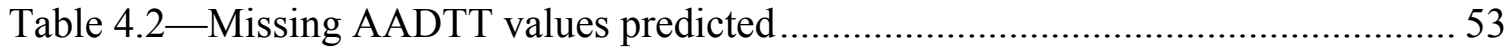

Table 4.3-Average Annual Growth Rates for Each Site .......................................... 53

Table 4.4-Average Annual Growth Rate Weighted-All Interstates .......................... 55

Table 4.5- Average Annual Growth Rate Weighted — Rural Interstates...................... 56

Table 4.6-Average Annual Growth Rate Weighted-Urban Interstates....................... 57

Table 4.7-Annual Average Growth Rate for Each Truck Classification-All Interstates

Table 4.8-Average of AADTTs from 1995 to 2003 for Each Truck Classification and

Site-All Interstates

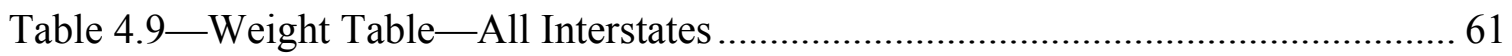

Table 4.10 - Annual Average Growth Rate Weighted —All Interstates ......................... 62

Table 4.11 - Coefficient of Variation (CV) for Each Truck Class-All Interstates ........ 63

Table 4.12 - Annual Average Growth Rate Weighted—Rural Interstate ....................... 64

Table 4.13 - Coefficient of Variation in Every Site-Rural Interstates........................ 65

Table 4.14-Annual Average Growth Rate Weighted-Urban Interstates..................... 65

Table 4.15- Coefficient of Variation in Every Site-Urban Interstates......................... 66

Table 4.16-Annual Average Growth Rates for Single and Multi-Unit Trucks for Each

Site-All Interstates

Table 4.17-Weight Table and Annual Average Growth Rate Weighted for Single and

Multi-Unit Truck-All Interstates

Table 4.18-AADTT for Each Truck Group (Single/Multi-Unit) and Coefficient of

Variation in Every Site-All Interstates.....

Table 4.19-Weight Table and Annual Average Growth Rate Weighted for Single and Multi-Unit Truck—-Rural Interstates 
Table 4.20-AADTT for Each Truck Group (Single/Multi-Unit) and Coefficient of Variation in Every Site-Rural Interstates

Table 4.21-Weight Table and Annual Average Growth Rate Weighted for Single and Multi-Unit Truck-Urban Interstates

Table 4.22 - AADTT for Each Truck Group (Single/Multi-Unit) and Coefficient of Variation in Every Site-Urban Interstates.

Table 4.23 - Linear Regression Models, Growth Rates and Coefficient of Regression $\left(\mathrm{R}^{2}\right)$

for Each Truck Classification—All Interstate Highways ........................................... 76

Table 4.24-Linear Regression Models, Growth Rates and Coefficient of Regression $\left(\mathrm{R}^{2}\right)$

for Each Truck Classification—Single/Multi-Unit Trucks (All Interstates) ................... 77

Table 4.25-Linear Regression Models, Growth Rates and Coefficient of Regression $\left(\mathrm{R}^{2}\right)$ for Each Truck Classification_-Rural Interstate Highways ........................................ 77

Table 4.26-Linear Regression Models, Growth Rates and Coefficient of Regression $\left(\mathrm{R}^{2}\right)$ for Each Truck Classification—Single/Multi-Unit Trucks (Rural Interstates)................ 78 Table 4.27-Linear Regression Models, Growth Rates and Coefficient of Regression $\left(\mathrm{R}^{2}\right)$ for Each Truck Classification-Urban Interstate Highways

Table 4.28-Linear Regression Models, Growth Rates and Coefficient of Regression $\left(\mathrm{R}^{2}\right)$ for Each Truck Classification—Single/Multi-Unit Trucks (Urban Interstates)

Table 4.29-Average Annual Growth Rates Weighted and Coefficient of Variation (CV) for Each Site-All Interstates ..... 81 Table 4.30-Average Annual Growth Rates Weighted and Coefficient of Variation (CV) for Each Site-Rural Interstates

Table 4.31-Average Annual Growth Rates Weighted and Coefficient of Variation (CV) for Each Site-Urban Interstates 83

Table 4.32 - Comparison of Annual Average Growth Rates (Weighted Average, Year Average Analysis and Growth Factor) 84

Table 4.33-Comparison of Annual Average Growth Rate- All Interstate Highways . 85 Table 4.34 - Comparison of Annual Average Growth Rates - Rural Interstate Highways

Table 4.35-Comparison of Annual Average Growth Rates - Urban Interstate Highways 
Table 4.36-Comparison of Annual Average Growth Rates-- All Interstate Highways . 87 Table 4.37-Comparison of Annual Average Growth Rates—Rural Interstate Highways

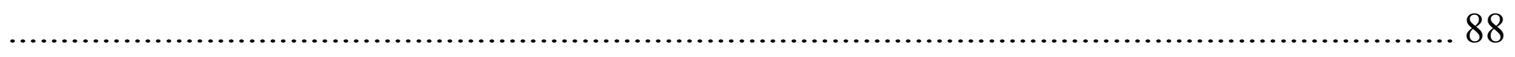

Table 4.38 - Comparison of Annual Average Growth Rates-Urban Interstate Highways 88 


\section{CHAPTER 1}

\section{INTRODUCTION}

\subsection{Background}

Forecasting truck traffic volumes and truck traffic growth rates are necessary in transportation planning, air quality modeling, and geometric design of highways, adding lanes, new roadways projects, intersections, and exits ramps. It is also used to determine the required thickness of pavement based on the number of 18-KIP ESALs that the pavement will be subjected to over the design life.

The U.S. freight transportation network is a vital component to the national economy, moving billions of goods, valued in trillions of dollars. The movement of bulk goods, such as grains, coal, and ores, by rail or barge, still comprises a large share of the tonnage moved on the U.S. freight network. However, lighter and more valuable goods, such as manufactured products, are moved by trucks in an increasing percentage. Until

recently, most goods were stored in warehouses throughout the country and trucks were primarily used to deliver goods to and from these warehouses. Now, goods are more often delivered straight from the factory to the customer, changing the travel pattern of trucks. Interstates provide the highest level of service in the U.S. highway system through high-speed geometrics and high-strength pavements conducive for truck traffic. For this reason, the ability to forecast truck traffic on the Interstate system is valuable in understanding and predicting freight movements in the U.S. 
Understanding that transportation in the U.S. is changing and that future freight activity is important for supplying consumer demand and understanding the nature of the supply chain is critical. For this reason, the USDOT created the Freight Analysis Framework (FAF), a comprehensive database and policy analysis tool, which estimates flows and related freight transportation activity. It also examines geographic relationships between freight movement and infrastructure capacity among states. The FAF was developed from several private and government sources; including: the Transportation Infrastructure and Activity--Commodity Flow Survey, the U.S. International Trade, the National Transportation Statistics, and the Highway Statistics. The FAF provides detailed information on freight flows for motor carrier, rail, water, and air modes and for various commodities; its estimates and forecasts are available for 1998, 2010, and 2020. For example, the FAF estimates that trucks carried about 71 percent of the total tonnage and 80 percent of the total value of U.S. shipments in 1998. By 2020, the U.S. transportation system is expected to handle about 23 billion tons of cargo valued at nearly \$30 trillion.

Because truck traffic volumes as well as their weights play an important role in the highway operation system, it is absolutely essential that States collect truck volume data that describe the changes that exist in travel patterns, aiding in the decision-making processes. Accurate and efficient forecasts of truck traffic are helpful in answering important questions for engineers and planners charged with the construction, maintenance, and operation of the Interstate Highway System: Which roads carry large truck traffic volumes?, and Which roads carry light truck traffic volumes? As mentioned, the main factor in evaluating the deficiency of freight transportation network is truck 
traffic volume. By estimating growth rates of truck traffic volume, we anticipate the improvements of new facilities by combining a future land use plan and understanding the relationship between land use and transportation. Inaccuracies in truck traffic volume forecasts are responsible for the additional labor costs, extra material, and over-design of facilities. Thus, forecasting truck traffic flow in West Virginia is a key tool in understanding the variation in the roadway activity system.

\subsection{Problem Statement}

According to the US Department of Transportation and its Freight Analysis Framework, in West Virginia the principal mode of freight transportation is by rail, 176 million tons in 1998 and expected to be 225 million tons in 2020. The second most common is by truck, which moves most of the "high-value" shipments (103 million tons in 1998 and expected to be 185 million tons in 2020). Therefore, truck traffic on highways in West Virginia is expected to grow throughout the state over the next 20 years. Much of the growth will occur in urban areas and on the interstate highway system. Truck traffic to and from West Virginia accounted for 14 percent of the average annual daily truck traffic (AADTT) on the FAF road network, around 7 percent of truck traffic involved in-state shipments, and 42 percent involved trucks traveling across the state to other markets. About 37 percent of the AADTT were not identified with a routespecific origin or destination.

Research has shown that truck volumes vary over time and space differently than car volumes (Hallenbeck et al., 1997), and these variations can be relatively different 
from one type of truck to another. Furthermore, the truck type characteristics, such as vehicle weights, can change dramatically over time and from location to location, even within a given truck classification. It is therefore vital that each State develop mechanisms within its statewide traffic monitoring program that measure these variations. Due to increased Federal interest, the West Virginia Department of Transportation/Division of Highways (WVDOH) has the need to project truck traffic volumes independently from overall traffic volumes. The proposal to estimate future truck traffic is based on data selected from the Statewide Permanent Automatic Traffic Recorders (PATR).

\subsection{Project Objectives}

The objective of this study is to develop models to estimate the truck traffic volume along interstate highways, applying a methodology that is accurate and can assist transportation professionals in forecasting traffic based on data logged from permanent automatic traffic recorders. To reach the study objective, it is necessary to understand that urban and rural roads have different travel patterns, and also that traffic on Interstate highways behaves differently than non-Interstates. For instance, Interstate highways tend to carry considerably more through traffic than non-Interstate. This research predicted truck traffic volumes and growth rates at interstate highways from historical trends, assuming changes in the growth rate over time. 
The tasks of this study can be outlined as follows:

1. To conduct a literature review to assess the state of the procedures and models that are used to perform truck traffic forecasting.

2. To develop a clean sample of truck traffic data from the WVDOH raw data: gathering and placing raw data in workable form, eliminating errors, discrepancies and improbabilities.

3. To develop truck traffic growth rates based on annual average daily truck traffic trends at individual sites, and for individual truck classification. Sites and truck classes may be grouped according to some combination of area type, functional classification, and geography.

4. To document the findings of this research in a final a report.

\subsection{Document Organization}

The report contains five chapters. The first chapter discusses the need for forecast truck traffic at interstate highways, and identifies the problem, the objective of the study, and the task involved. The second chapter provides a review of previous studies conducted in the same field for other states and the methods used for data collection and analysis. The third chapter explains the methodology adopted and the practical tasks that were executed for the completion of the study. In the fourth chapter, the results are presented. The fifth chapter provides conclusions, recommendations, suggestions obtained from this study; and discusses areas for future improvements. 


\section{CHAPTER 2}

\section{BACKGROUND AND LITERATURE REVIEW}

\subsection{Introduction}

This chapter documents the literature reviewed relating to current methods of forecasting Annual Average Daily Traffic (AADT). Also, these methods can be used to independently analyze the case of truck traffic volumes at Interstate Highways-- Annual Average Daily Truck Traffic (AADTT). The primary source in this literature review is the examination of the Traffic Monitoring Guide, FHWA 2001, and The Guidebook on Statewide Travel Forecasting, FHWA, 1999, since these serve as guidelines for states' traffic monitoring programs. In addition, the literature review includes the examination into how other states' programs have been doing the forecasting process and how they have followed the FHWA recommendations. Furthermore, previous and most recent studies related to this topic are reviewed in this chapter.

Within the methodologies and approaches for estimating growth rates and forecasting future truck traffic, Annual Average Daily Truck Traffic (AADTT) is a key factor to estimate vehicles miles traveled (VMT) on all roadways by local governments. This information is also used by the U.S. Environmental Protection Agency (EPA) to establish conformity with the 1990 Clean Air Act Amendment (Legislation focused on the fuel rather than the vehicles engines to reduce ozone-forming and carbon monoxide

emission from automobiles). Therefore, the forecasting process is vital in providing accurate traffic data to develop traffic growth rates and to estimate truck traffic volumes. 
Traffic data usually comes from different sources such as: Automatic Traffic Recorder (ATR) stations throughout states that constantly record traffic and are considered the most accurate type of traffic data, portable counts, economic and demographic data, county population, county employment, annual population growth rate, and information about traffic directions and peak hour rates (Dixon, 2004). When this information or data is unavailable, the estimates could be made by comparison of highways with similar characteristics. (Zhao and Chung, 2001).

A basic process for estimating AADTT using a sample of traffic count data is as follows:

1. To obtain data for any type of traffic count.

2. To develop a clean sample of traffic volume.

3. To develop truck traffic growth rates model based on AADTT.

4. To group sites with some similar characteristics to improve the prediction of traffic.

Truck traffic data usually comes from traffic monitoring programs from states, which gather, handle, and analyze traffic data. 


\subsection{Traffic Monitoring Programs}

Traditionally, the major goal of traffic monitoring programs is the development of factors to estimate annual average daily traffic. Recently, monitoring truck traffic has emerged as an important application of traffic monitoring. Usually, truck traffic is estimated as a percentage of the number of vehicles traveling. Some highways carry the same traffic but with a large difference in truck traffic volume; therefore, it is necessary to be able to monitor all of these traveler differences in order to make correct decisions about the design, operation, and maintenance of roadways. It is important that each State implement a statewide traffic monitoring program to analyze and report these variations. One of the most important points in monitoring programs is the necessity to collect and manage data to produce analyses. To accomplish this goal, state programs have the necessity to measure different time scales: time of day, day of week, and season (month) of the year. Furthermore, location is essential in order to further understand the variation of truck traffic. The cost of monitoring programs could be excessive for the state DOT budgets; therefore, an adequate number and location of continuous counters are needed to reduce the cost of programs and to obtain quality information regarding the various truck traffic patterns in the highway system. The Traffic Monitoring Guide highlights that:

\section{"A State that recognizes that these data collection efforts exist and is able to cost- effectively capture, summarize, and use these data can significantly improve the quality of its traffic monitoring information at relatively low marginal cost”.}

Thus, a well-designed traffic monitoring program consists of a modest number of permanent data collection sites and large number of short duration data-collection efforts 
(FHWA, 2001). Currently, there are varieties of traffic collector devices commercially available, but the most common in use today for traffic engineers is automatic traffic recorders (ATRs).

\subsubsection{Automatic Traffic Recorders (ATRs)}

Automatic traffic recorders are loop detectors, which have been used for many years to monitor traffic at specific locations. The ATRs collect data 24 hours a day, 365 days annually, for each lane. The equipment records traffic volumes as total and as directional traffic for each station. In addition, the equipment collects traffic volumes by vehicle classification (13 classes) and unclassified (Classes 14 and 15), weight-in-motion (determines vehicle weights while vehicles are moving), and speed data in 5-mph increments. The data also include date, time, locations, site number and direction. Automatic Traffic Recorder data are commonly stored on site as hourly volumes by lane and are downloaded periodically (daily, weekly, or monthly) to a central location. At the central location, the data are checked for quality, summarized, and stored for later use. In other cases, the data are stored but are not reported or made available in a useable form to other data users. Some ATRs may suffer periods of downtime due to problems with the equipment, communication difficulties, and power failures. This may result in hours or days of missing data that consequently introduce biases in the factor computation, particularly when blocks of data are lost (FHWA 2001). Making this information available was the first objective in the course of this project. Raw data was handled and placed in a usable form and divided in workbooks: by lane, by direction, by hour, by day, and by month. A sample of raw data from Automatic Traffic Recorders is shown, and the 
procedure used to organize raw data is described in the next chapter. Among the values commonly reported from ATRs are the following:

- Annual average daily traffic at the site (AADT)

- Annual average weekday traffic at the site (AAWDT)

- Seasonal adjustment factors

- Day-of-week adjustment factors

These values allow project engineers to analyze and to establish truck traffic patterns present in the highway system. The TMG shows truck traffic patterns by time of day, day of week, and season during the year as is illustrated by Figures 2.1, 2.2, 2.3 and 2.4. 


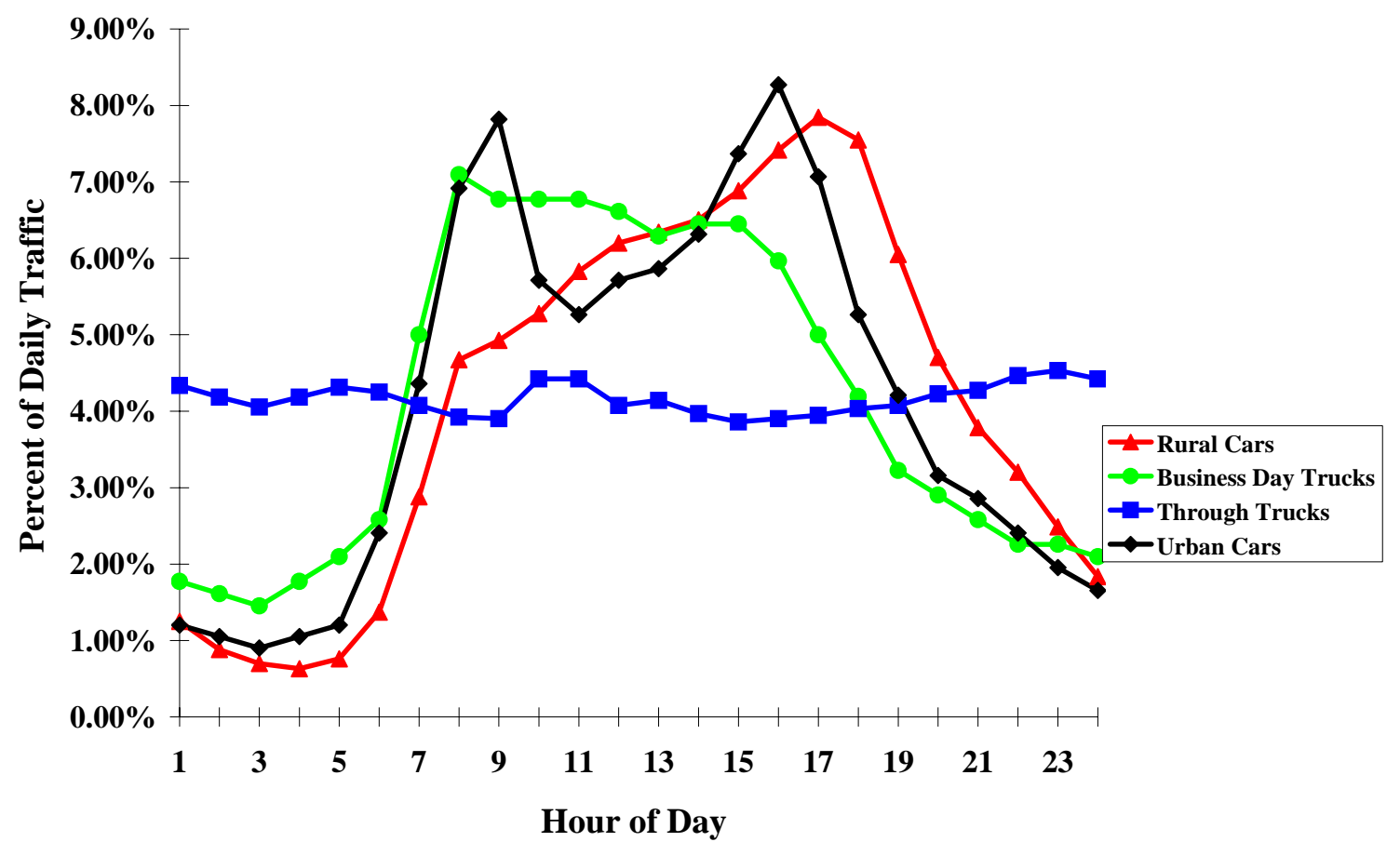

Figure 2.1-Basic Time-of-Day Patterns (FHWA, 2001)

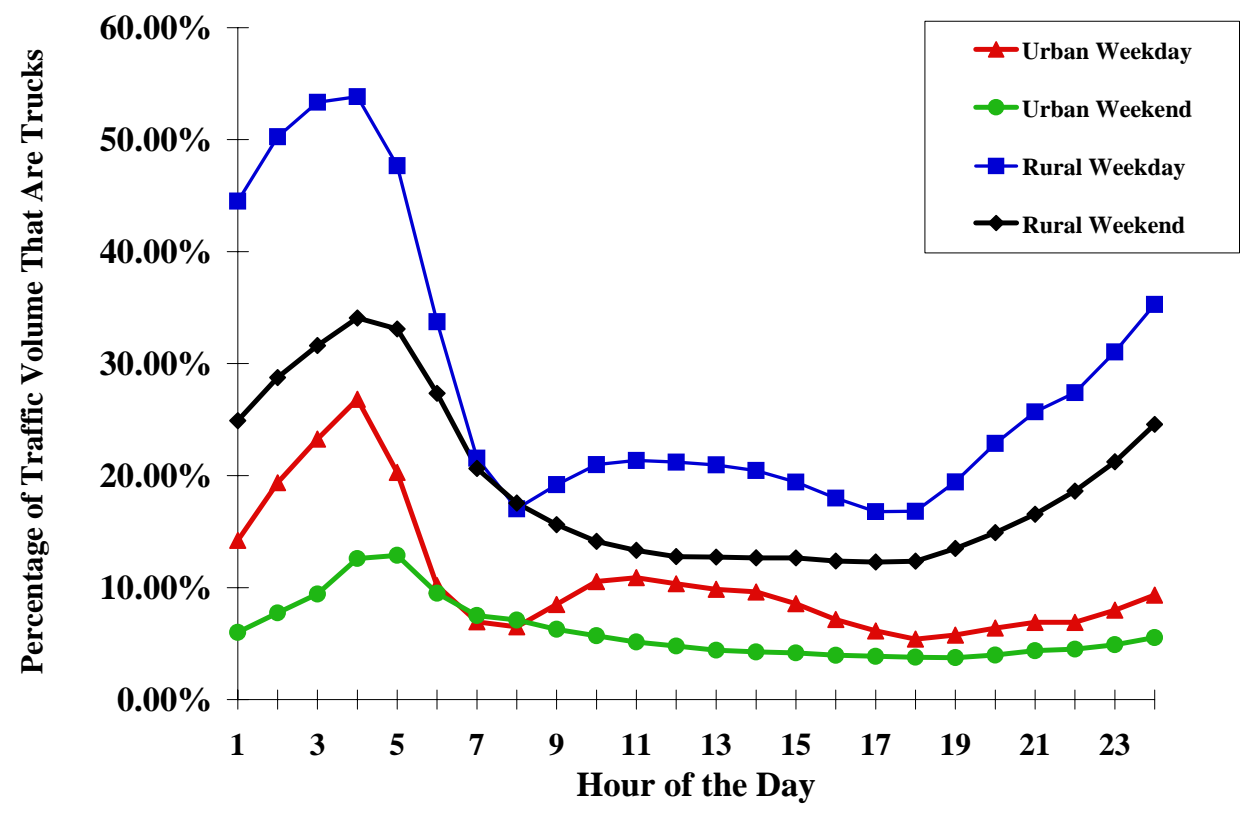

Figure 2.2-Weekday/Weekend Truck Percentage (FHWA, 2001) 


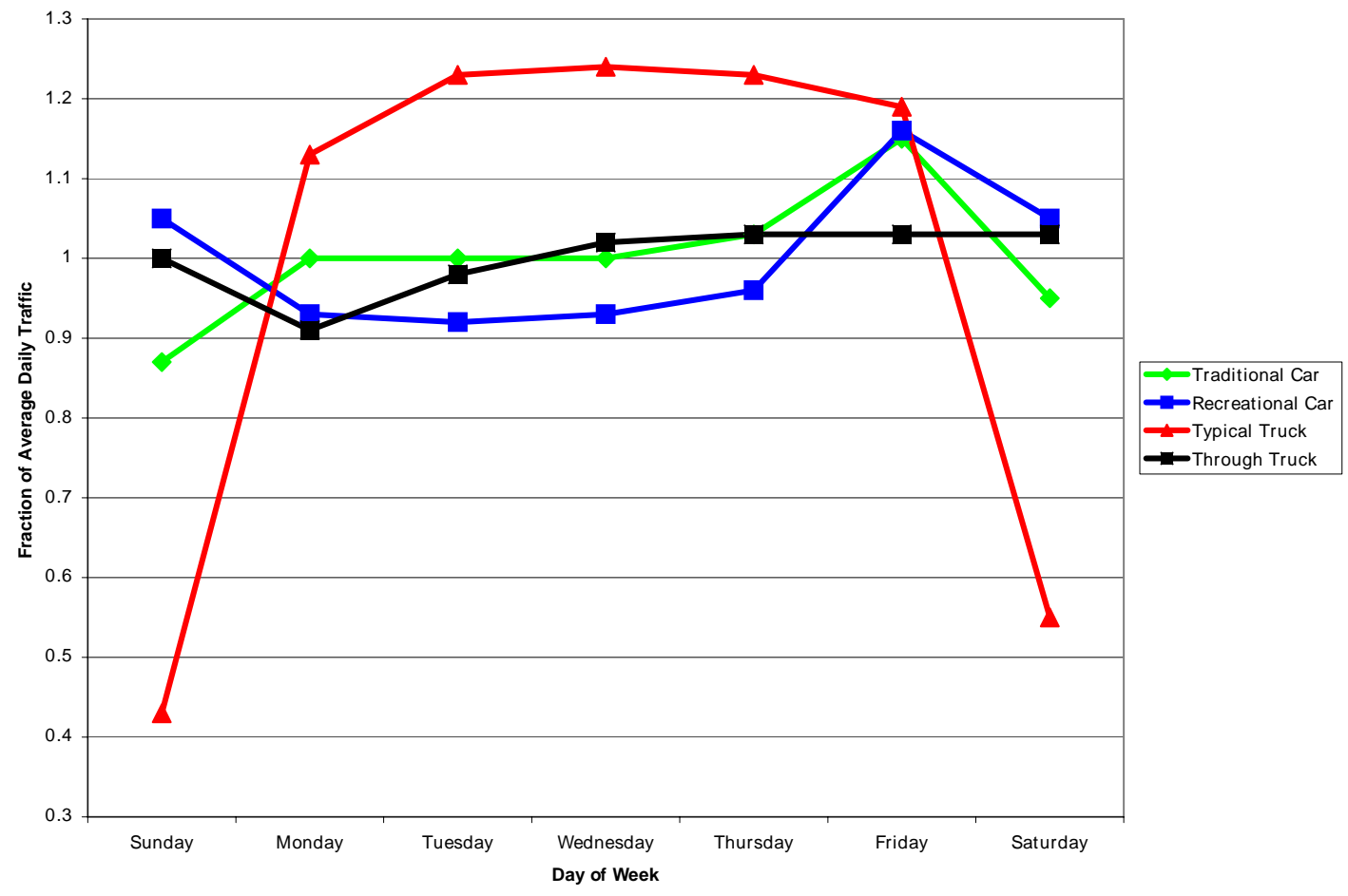

Figure 2.3-Typical Day-of-Week Traffic Patterns

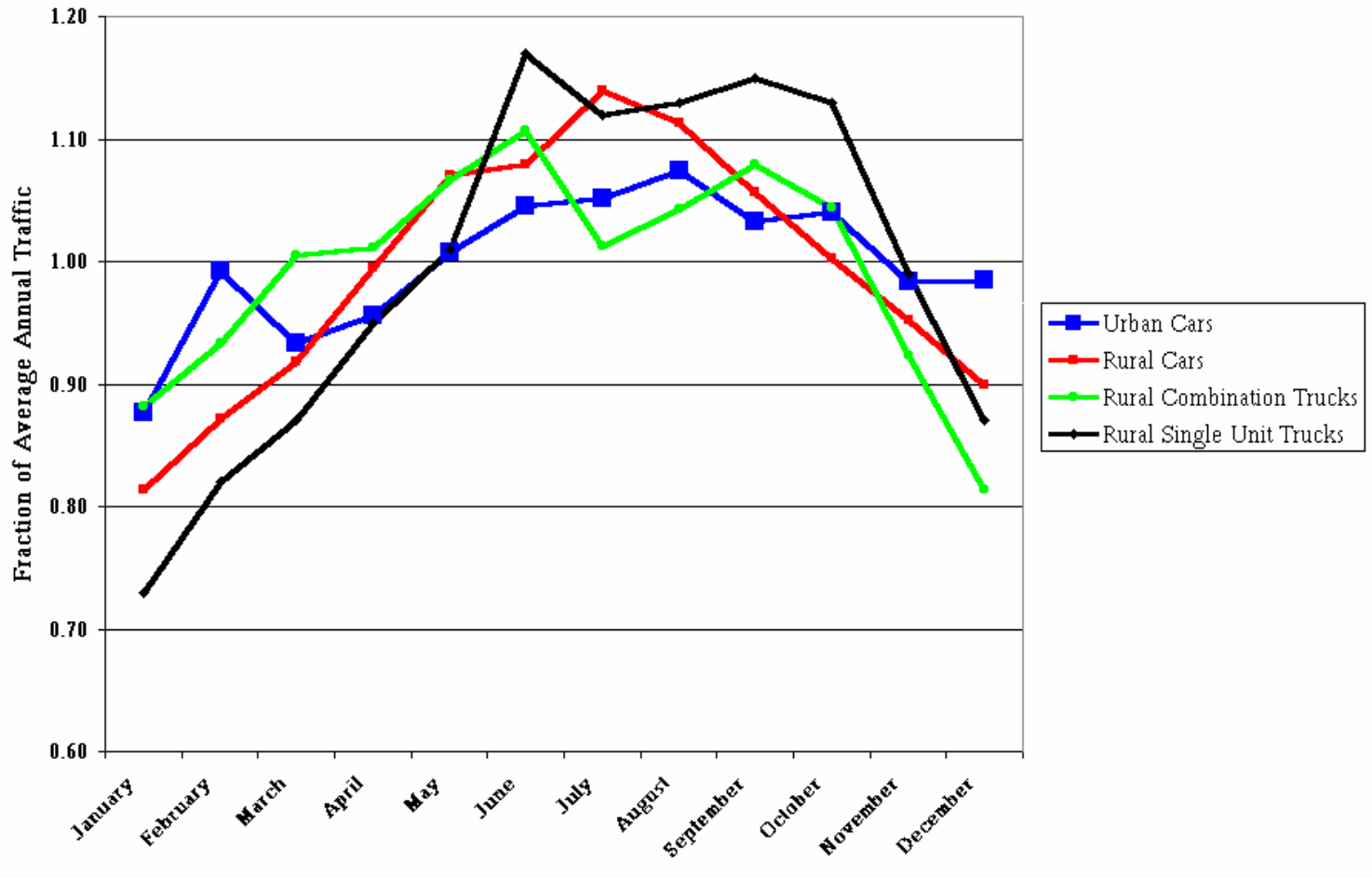

Month of the Year

Figure 2.4-Typical Monthly Volume Patterns 
Sample Data- Output data from Interstate Permanent Automatic Traffic Recorder--WV (Site 47-January 1, 2003)

DISTRIBUTION OF VEHICLE CLASSIFICATIONS BY HOUR OF DAY

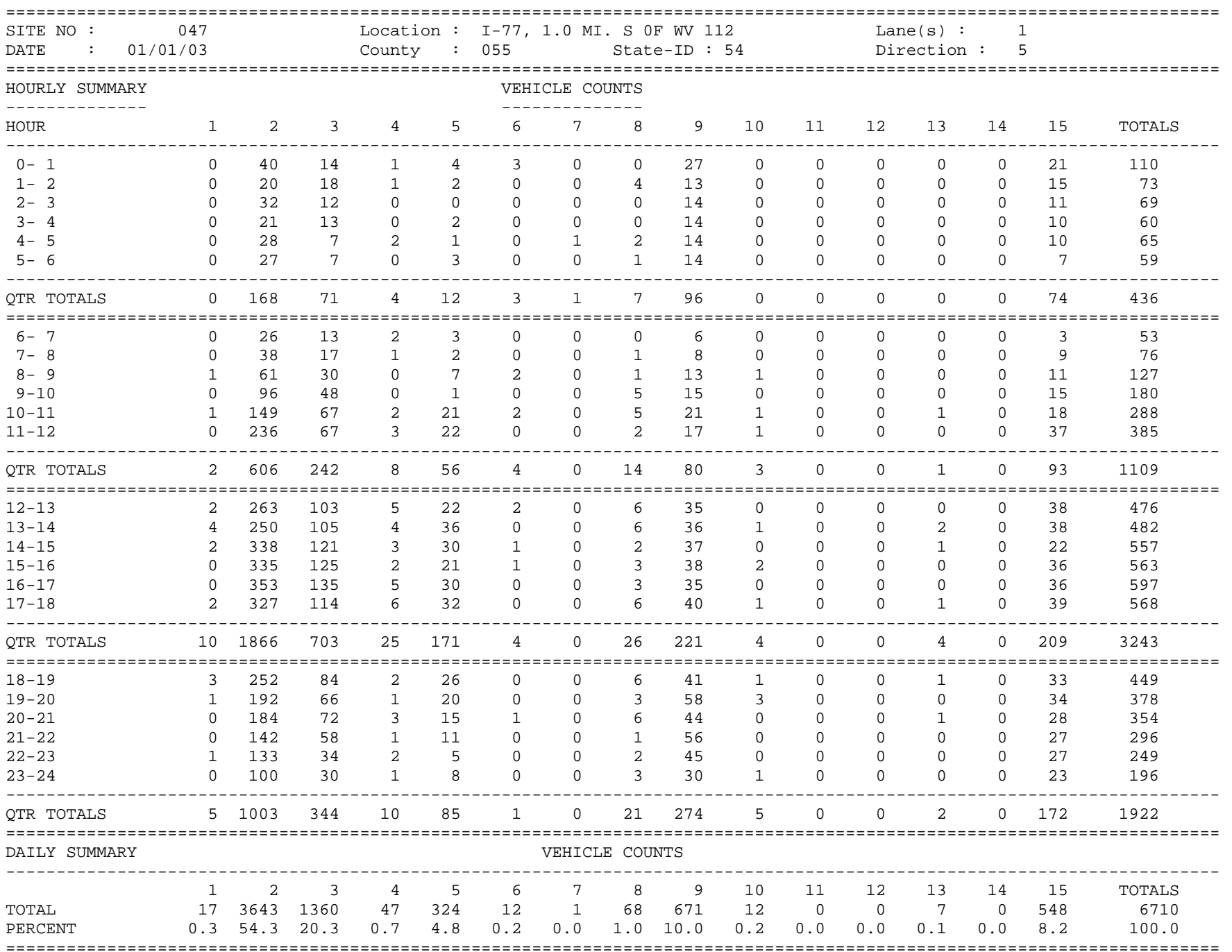


DISTRIBUTION OF VEHICLE CLASSIFICATIONS BY HOUR OF DAY

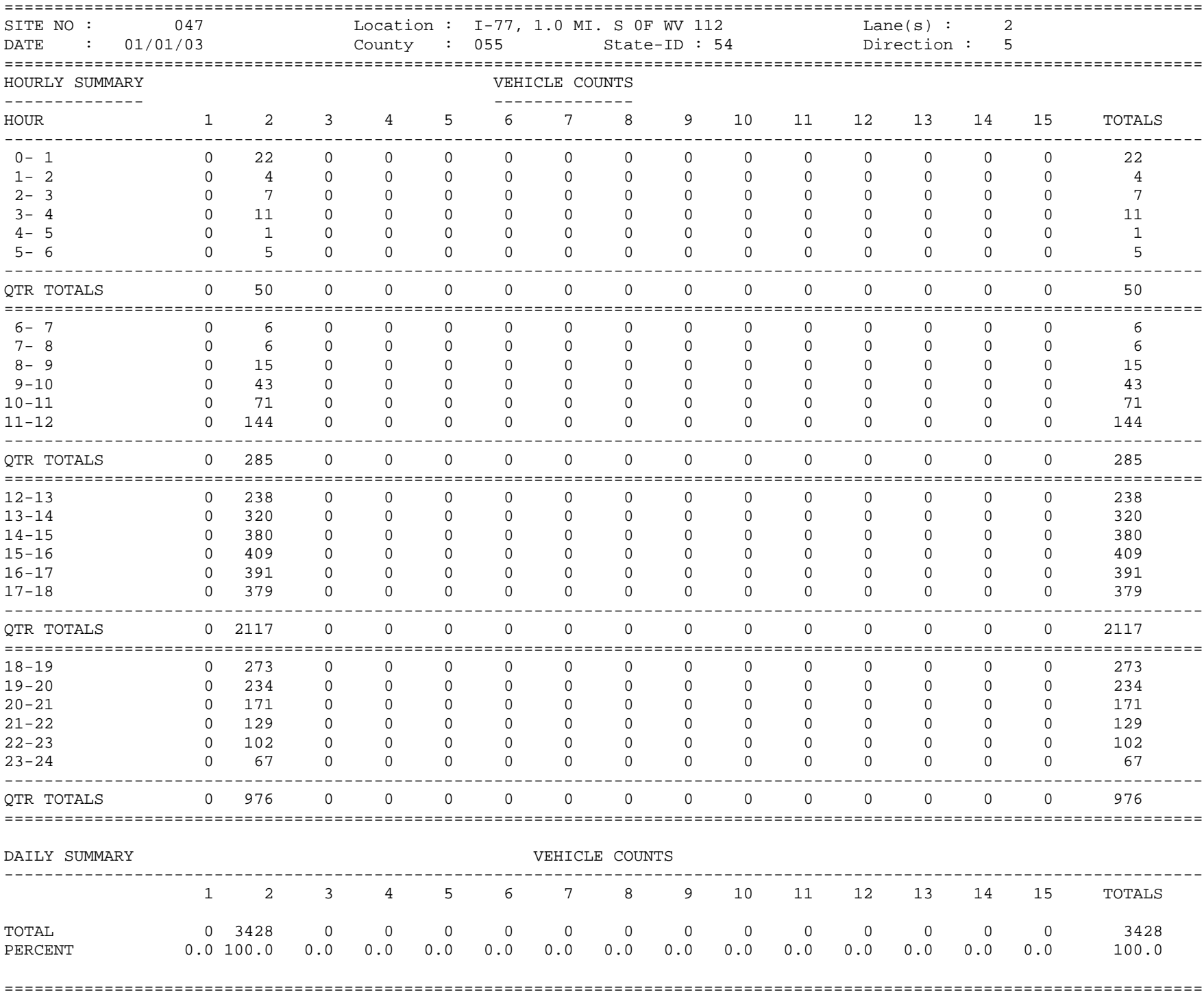


DISTRIBUTION OF VEHICLE CLASSIFICATIONS BY HOUR OF DAY

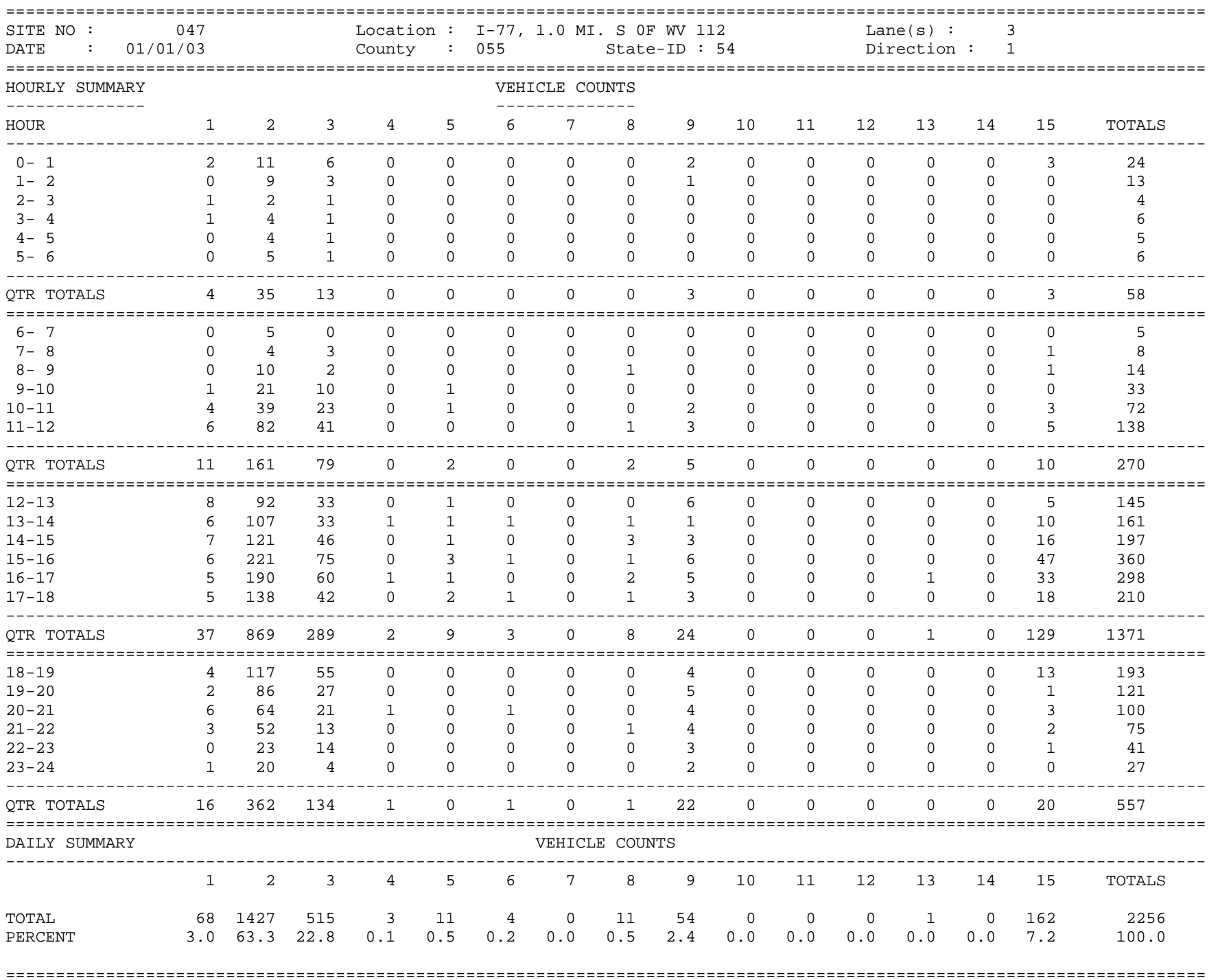


DISTRIBUTION OF VEHICLE CLASSIFICATIONS BY HOUR OF DAY

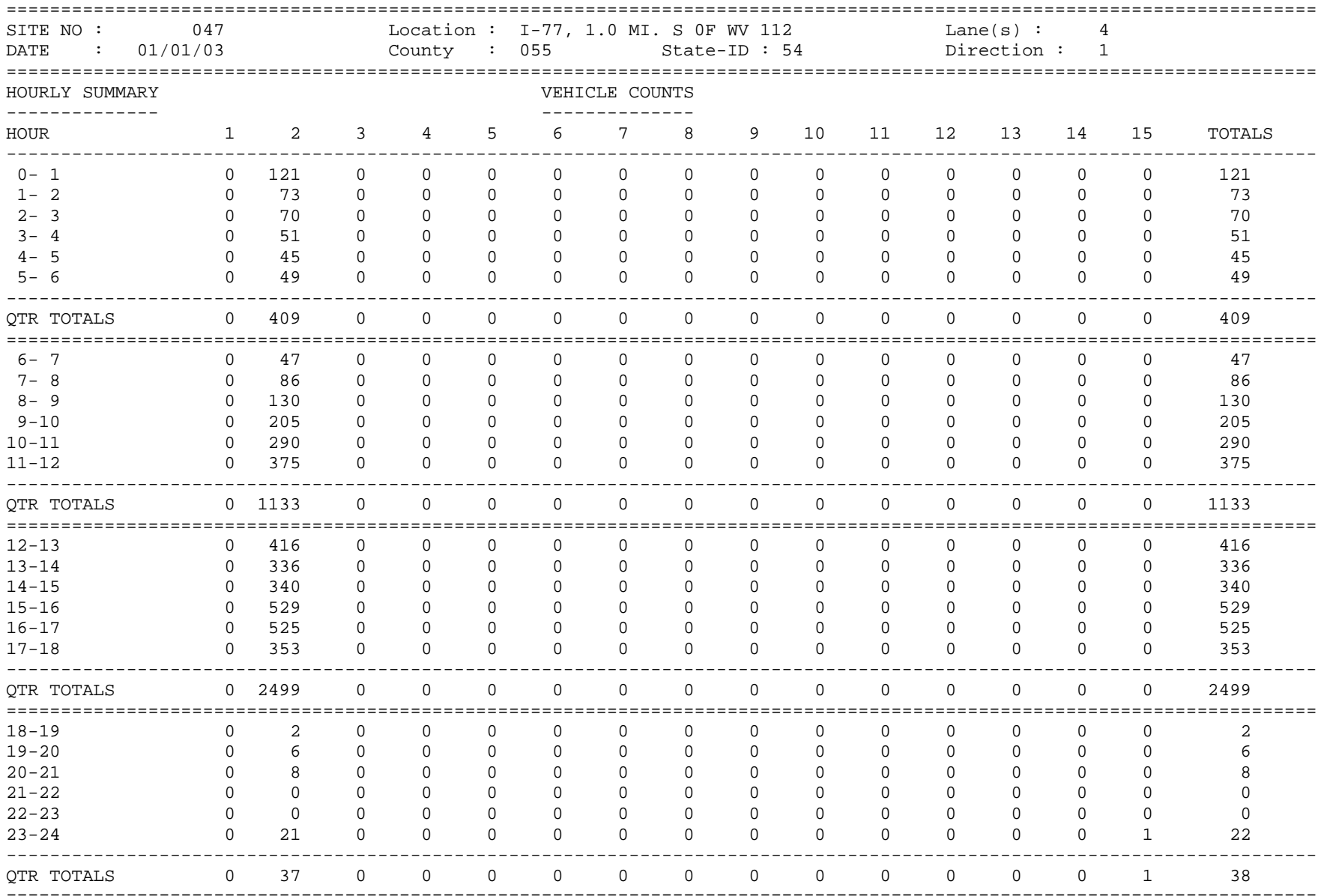

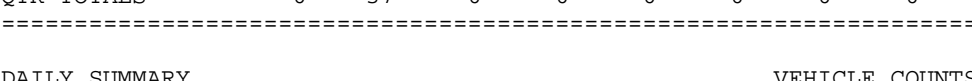

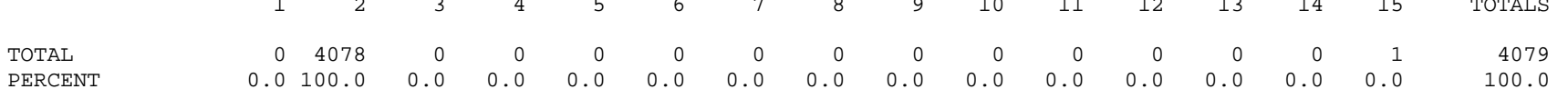




\subsubsection{ATR Location}

The ATR location consists of induction loops embedded in the pavement for each traffic lane, a cabinet mounted on concrete off the road with the recording unit, modem, battery, and solar panel. A phone line is run into the cabinet. The Traffic Monitoring Guide states that locations of ATR sites that were initially selected may no longer be true or applicable; but the fact that a long history of data exists at these locations provides a reason for the continuing efforts to collect data at those locations. Recommended steps for selecting continuous count locations are the following: determine what continuous data collection is still needed for specific projects by determining the available funding, prioritize the "specific" project locations, and place counters at the "specific" project locations for which funding exists (FHWA, 2001).

\subsection{Current Methods to Forecast Truck Traffic Volumes}

Most recent technical papers and government reports do not establish a unique conclusion about the best method to estimate traffic growths using AADTT. Growth factors can be best estimated at a specific location when a continuous ATR is available, assuming that the ATR data is reliable and that the differences found from year to year can be attributed to growth. However, it is well known that volumes at a single location can be affected by different factors (new roads facilities, land developments), thus, growth factors computed from the limited number of ATRs operated by a State highway agency can be easily biased. In addition, whether the same count locations are used continually over time to compute growth, errors at any one given location due to the inaccuracy of the AADT estimate are self-correcting (FHWA, 2001). The point of the above discussion is to emphasize that there is not a best procedure that is applicable in all 
cases due to the bias in data available; therefore, an alternative is to use all the tools available to examine the growth issue from several perspectives.

\subsubsection{Time Series}

Time series forecasting methods assume that past trends will continue into the foreseeable future. With this assumption, the past data can be used to forecast AADTT volumes to a specified year in the future. The Guidebook on Statewide Travel Forecasting by the Federal Highway Administration, 1999, states that time series models must be used with care because these methods use past data and cannot anticipate an unpredictable or random event that could affect the traffic volumes. Some research used time series to predict vehicle traffic volume and also to establish traffic patterns. Some independent variables are used in the models such as economic variables or time period. Traffic patterns can be established by the time series method; for example, between population and vehicle traffic such as: "higher traffic growth in high-growth counties," or "traffic volumes increase but population decrease over the same period of time," in this case, it is difficult to forecast because this trend is atypical (Dixon, 2004). Similar patterns for freight traffic were established: as the economy grows, the road freight task grows even quicker (Gargett and Cosgrove, 2003).

Conducting separate studies from interstate and non-interstate are the best suited to forecast vehicle traffic because of the different demographic characteristic between them. Interstate highways have less of a cause-effect relationship between demographic variables than non-interstate. Therefore, truck traffic could be projected using growth 
rates determined from historical trends and assumed changes in the growth rate over time based on expectations that interstate travel will continue to increase at a higher rate than non-interstates. (Barrett et al, 2001). A recent research project by Rebovich (2004) establishes the time series analysis as best suited for short-term forecasts when there are limited time and resources available to build and calibrate a behavior model. The simplicity of this method produces rapid forecasts for individual facilities based on historic trends, typically requiring less and offering more simplistic approaches than other forecasting approaches. Rebovich (2004) suggests that trend analysis methods display great potential for model development in West Virginia because this model is flexible. According to The Guidebook on Statewide Travel Forecast, time series methods are divided into two techniques: growth factors and linear regression analysis.

\subsubsection{Growth Factors}

Currently, some states calculate the annual growth rate as a factor which represents the average percent increase in AADTT volume per year; these factors are calculated using the following equation:

(Equation 2.1)

$$
g=\sqrt[n]{\frac{A A D T_{t}}{A A D T_{t-n}}}-1
$$

(Dixon, 2004) 
Where:

g: annual growth rate

$n$ : number of years between the most recent (AADT) and the past (AADTn)

volumes

AADTt: AADT volume recorded during the most recent year $t$;

$A A D T_{t-n:}$ AADT volume recorded $n$ years prior to the year $t$

The above equation is somewhat similar to those used to calculate compound interest. A positive growth factor means that truck traffic will increase over time. The disadvantage of this method is that it generates forecasting errors if the annual growth rates have not been updated regularly (Dixon, 2004). Also, the input in this method is based on information from two years, instead of using the whole information available,

which might create some inaccuracy in the forecast process. The advantage of this method, and the reason why it is widely used for many states to forecast AADT volumes, is that the technique is relatively simple. This method assumes that the past trends in percent increase in traffic volume each year will continue into the future.

\subsubsection{Regression Analysis}

Linear regression can extrapolate trends in annual average daily truck traffic into the future. It uses past trends in data, but it can also incorporate the relationship between economic and demographic variables and the traffic growth pattern. A general example of a linear regression equation is: 
(Equation 2.2)

$$
Y=a_{0}+a_{1} . x_{1}+a_{2} . x_{2}+\ldots a_{n} . x_{n}
$$

Where:

Y: Criterion variable, variable we want to predict.

a1 a2,...an: Regression coefficients (slope)

a0: Regression constant (intercept)

$X$ : predictor variable

These equations are used to forecast the AADTT values, and the accuracy of the projections is influenced by several factors. One of these factors is the time period of the forecast. As the amount of time between the base year and projection year increases, the accuracy of the forecast decreases. Usually, variables are chosen on the basis of causal relationship to the traffic volume and high R-square values. There is not a single method for determining whether an independent variable should be included in the equation. Usually, variables are chosen on the basis of causal relationship to the traffic volume and high R-square values. Variables should be chosen according to how much they explain the dependent variable (AADTT); in other words, they should be chosen for their unique contribution to the model. Often, when there are many variables to be included in a model, the use of a step-wise procedure to chose variables is conducted or statistical software are left to select the set that best explains the dependent variable, as measured by R-square. For instance, the research by Zhao and Chung, (2001), used multiple regression analysis with up to six independent variables in their models such as number of lanes, functional classification, and population. The inclusion of these variables in the four models performed found a good relationship between the dependent and independent 
variables with coefficients of regression $\left(\mathrm{R}^{2}\right)$ between 0.66 and 0.83 . Furthermore, variables should be selected based on their ability to be obtained in order to be used in future forecasting and for their cost to be obtained. Variables might be changing over the time generating inaccuracy in predictions. For example, a model with two independent variables, population and employment, might predict the amount of traffic on an interstate highway; however, changes in any of these variables due to recession in the state may generate that the model lose its ability to predict traffic volume.

\subsubsection{Clustering}

Frequently, the first step in developing regression analysis in traffic volume prediction is sorting the data into groups with similar characteristics. The stations that are most similar are grouped together. Several methods of clustering transportation data exist. The Federal Highway Administration has set up functional classes for different types of roadways, which are documented in the Highway Performance Monitoring System Field Book. In addition, Garger and Bayat-Mokhtari, (1986), recommend divide highways in different groups, which are outlined below:

- Dividing roadways into sections that have a homogeneous traffic volume,

- Grouping the data by similar characteristics.

- FHWA functional class,

- Primary functional use such as recreational, local travel, or commercial,

- Land use of the county in which the roadway section lies,

- Population of the county in which the roadway section lies, and

- Type of terrain. 
After executing the cluster procedure, a regression analysis may be performed with these groups of data. An important feature of clustering the data is the decrease in the coefficient of variation. FHWA recommends, in the Traffic Monitoring Guide, that the absolute precision of estimates be within 10 percent. Equation 2.3 shows the relationship between the coefficient of variation and the absolute precision. Because of the small number of sites available in this research, the difference between the coefficient of variation and the absolute precision were slight; therefore, only the coefficient of variation is present in all of our results in chapter four.

(Equation 2.3)

$$
D=T_{1-d / 2, n-1} \frac{C}{\sqrt{n}}
$$

Where:

$$
\begin{aligned}
& D=\text { precision interval as a proportion or percentage of the mean } \\
& C=\text { coefficient of variation of the factors. } \\
& n=\text { number of locations } \\
& T=\text { value of Student's } T \text { distribution with 1-d/2 level of confidence and } n-1 \\
& \text { degrees of freedom } \\
& d=\text { significance level }
\end{aligned}
$$

The recommended coefficient of variation depends on the number of locations. Note that a percentage is equal to a proportion times 100 , i.e., 10 percent is equivalent to a proportion of $1 / 10$. The basic assumption made in the procedure is that the existing locations are equivalent to a simple random sample selection. Very tight precision requires large sample sizes, which means expensive programs due to the traffic data 
required. Very loose precision reduces the usefulness of the data for decision-making purposes. Traditionally, traffic estimates of this nature have been thought of as having a precision of \pm 10 percent. A precision of 10 percent can be established with a high confidence level or a low confidence level (FHWA, 2001). The higher the confidence level desired, the larger the sample size required. Furthermore, the precision requirement could be applied individually to each group in the clustering process. The Traffic Monitoring Guide refers:

"The reliability levels recommended are 10 percent precision with 95 percent confidence, 95-10, for each individual seasonal group, excluding recreational groups where no precision requirement is specified".

\subsection{Computing Annual Average Daily Truck Traffic (AADTT)}

The Traffic Monitoring Guide, 2001 provides two procedures to estimate AADTT for continuous count locations. These two procedures are:

- A simple average of all days

- An average of averages (the AASHTO method).

In the first of these techniques, annual average daily traffic (AADT) is computed as the simple average of all 365 days in a given year. When days of data are missing, the denominator is simply reduced by the number of missing days. This approach has the advantage of being simple and easy to program. The AASHTO procedure is based on three steps: first, average monthly days of the week are computed; second, all the 84 values (12 months by 7 days) are averaged to obtain the seven average annual days of the week; finally, these seven values are averaged to obtain the AADTT. This method 
accounts for missing data because the procedure is weighting each day of the week the same, and each month the same, regardless of how many days are actually present within that category.

The resulting two versions of AADTT are very close to each other. The study by Wright, Hu, et al., (1997), indicates that the differences are so small as to be unimportant. The "simple average" method is certainly easier to compute. However, where data is likely to be missing, the AASHTO method will provide a more reliable and accurate value. For our purpose on this research, the first method was used due to its simplicity and for the very slight difference between both methods.

\subsection{Related Studies}

Many state programs have been using automatic traffic recorder stations (ATR), recording data for more than 20 years. Different methods are established in every state. Some use statewide data being more statistically significant than county-level to estimate AADTT. Statistical analysis is commonly conducted as well as analysis of the relationship between AADTT (on rural and urban interstate highways) and time period. Recently, transportation centers and departments of transportation have taken interest in improving methods to predict truck traffic.

In the research by Zhao and Chung entitled "The Estimation of Annual Average Daily Traffic in a Florida County Using GIS and Regression”, 2001, four multiple 
regression models for estimating AADT on non-expressway roads have been developed, and up to six predictors have been used in the final models.

1. Functional classification

2. Number of lanes

3. Direct access from a count station to expressway access points

4. Accessibility to regional employment in Broward County

5. Employment in a variable-sized buffer around a count station

6. Population in a variable-sized buffer around a count station

The four models had a strong relationship between AADT and the independent variables; variables were selected using the stepwise procedure. The models were checked for multi-collinearity, and outliers were diagnosed. The models were able to explain $66 \%$ to $83 \%$ of the total variability depending on the variables used $\left(\mathrm{R}^{2}\right.$ between 0.66 and 0.83 ).

Findings:

- Generally, the more variables used, the better a model's performance.

- The model data are typically available and relatively easy to process.

- Functional class and number of lanes prove to be the most significant predictors.

- Model testing has already shown that functional classes are not consistently correlated with AADT. However, the model that does not use any information related to functional classes has the worst performance. 
- Land use variables that are determined based on functional classes significantly improve the models although they are not as strong predictors as functional class.

$>$ The research by Hallmark and Lamptey entitled Shauna "Evaluation of Different Methods to Calculate Heavy-Truck VMT", 2004, evaluates and compares methods to calculate heavy-truck AADT and, subsequently, VMT. The data was provided for the Iowa DOT to estimate AADT for two different truck groups (single-unit and multiunit). Data were collected for all the thirteen classes of the FHWA vehicle classification scheme. Three methods were conducted; the first method developed monthly and daily expansion factors for each truck group. Truck AADT was calculated by applying truck expansion factors to short-term counts. In the second method, general expansion factors for all vehicles were performed using continuous counts stations, and truck percentages were based on the annual percentage of trucks for each group from continuous count stations. Similar to the third method, the second method employs daily truck percentages from the short-term counts. The presence of missing data due to equipment and communication problems and power failures might produce bias during the data analysis procedure. To overcome missing data, the Iowa DOT employs historical methods. They analyze data from previous years for the same period in which data are missing in the current year to help make projections to fill in the missing data. For instance, if data collected at an ATR station on a Monday in October 2002 are missing from $1 \mathrm{pm}$ to $3 \mathrm{pm}$, data for the same period in previous years, such as 1999,2000 , and 2001, are used to extrapolate the missing hours. In a case where an ATR station is missing data over a long period of 
time, the entire data from that station are excluded from the factor computation. The study concludes that significant variation exists in the temporal and seasonal patterns of heavy trucks as compared to passenger vehicles. This suggests that the use of aggregate expansion factors fails to adequately describe truck travel patterns.

The research by Gargett and Cosgrove entitled "Predicting Traffic Growth in Australian cities", 2004, reports a relationship with the economic activity to estimate truck traffic. The truck traffic growth framework that explains truck traffic (truck kilometers traveled or vkt) is the following:

(Equation 2.4)

$$
\text { Truck Traffic }(v k t)=\frac{\text { Road Freight Task }}{\text { Average Load per Truck }}
$$

Road freight task is defined as a measured in total tonne-kilometres, which is the product of average load and total kilometers for each vehicle type. To further understand the relationship, it is better to think of truck traffic as the product of numbers of vehicles multiplied by the yearly average $\mathrm{km}$ they each perform. The influences of the technological shift and the economy affect this relationship and can be illustrated as below:

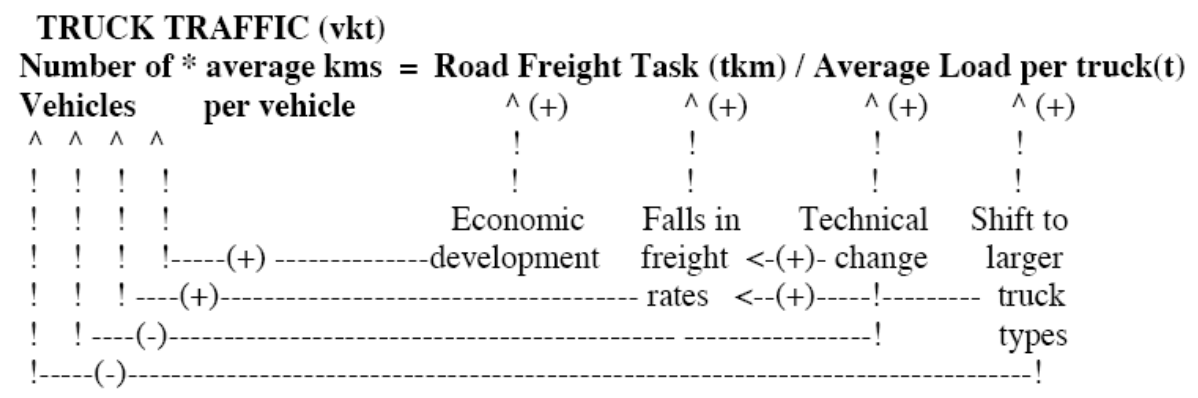


These influences of the truck traffic flow on the economy can be outlined as below:

- As the economy grows, the road freight task grows even quicker.

- The shift to larger vehicles makes possible larger loads and therefore less traffic, but at the same time makes possible lower real freight rates which causes additional demand for freight transport.

- In general, technological change has a similar "double-edged" effect on truck traffic.

The research by Barrett, Graves, Allen and Pigman entitled "Analysis of Traffic Growth Rates", 2001, presents methods applied to estimate traffic growth. Logarithmic and regression equations were developed to explain the relationship between two collectors and local roads, and an analysis of linear regression was used to represent changes in ADT and to develop growth rates by functional class. In addition, it shows the analysis of a general traffic growth rate as an averaged growth rate. Given the important influence of interstate highway travel in many counties, the research divided roadway into two categories for forecasting purpose - interstates and non-interstates. Also it establishes that, for interstate highways, the relationship between county; level demographic variables and traffic are much less cause-andeffect in nature than non-interstate travel. Therefore, traffic is projected using growth rates determined from historical trends and assumed changes in the growth rate over time. These changes are based on the expectation that interstate travel will continue to increase at a higher rate than non-interstate. The regression model used time period as 
an independent variable and 18-year traffic data were used to predict statewide VMT. Some findings are the following:

- Interstates VMT annual growth rate of $4 \%$

- Interstates VMT has increased at a higher annual rate, by $1 \%$ or more than non-interstates VMT.

\subsection{Concluding Remarks}

In summary, current research and state guidelines emphasize the need to forecast truck traffic separated from the usual vehicle traffic. A good recommendation is grouping sites by similar characteristics such as functional class, rural/urban characteristics, axles, and single-unit/multi-unit truck vehicles. Also, separate forecasts should be performed for interstates and state highways due to the differences in demographic characteristics. A good procedure after the data is collected for the 13 FHWA vehicle classifications is dividing it into two categories: single-unit vehicles (4 - 7 classes) and multi-unit vehicles (8-13 classes). Finally, for interstate highways, the demographic characteristics are less influential than non-interstate highways. Therefore, forecasting truck traffic at interstate highways using time period as a unique independent variable makes the forecast process much more flexible and less expensive to be used in the future. 


\section{CHAPTER 3}

\section{DATA SELECTION AND METHODOLOGY}

\subsection{Type of Data}

For the purpose of this project, nine years of data from 1995 to 2003 were used. The West Virginia Department of Transportation collected traffic volume and vehicle classification data continuously at 52 statewide permanent counter locations with sixteen of these counters located at Interstate Highways. Locations and characteristics of these sites are shown in Table 3.1. These stations are Permanent Automated Traffic Recorders devices (PATR), which are embedded in the roadway, counting and recording traffic that passes over these devices continuously throughout the year. They can record information such as vehicle type, weight, speed, and number of vehicles. The type of a permanent counter used in West Virginia, and typically in the United States, is an arrangement of inductive loops installed in the pavement. However, not all the sites were used in the course of this project, only sites where data was available for more than one week were selected. During the process to select the final data, eight sites were obtained and are shown in Table 3.2. These eight sites were the final data, and the completed project is based on these selected sites. 
Table 3.1 - List of Interstates Permanent Traffic Recorders in West Virginia

\begin{tabular}{|c|c|c|c|c|}
\hline Site Number & Location & Description & $\begin{array}{c}\text { Functional } \\
\text { Class }\end{array}$ & $\begin{array}{c}\text { Number of } \\
\text { Lanes }\end{array}$ \\
\hline 1 & I-64 & 1.2 miles west of WV 20 & 1 & 4 \\
\hline 2 & I-64 & 1.5 miles west of CO 60/89 & 11 & 4 \\
\hline 3 & I-77 & 2.2 miles north of CO 15 & 1 & 4 \\
\hline 401 & I-77 & NB 1.2 miles south of WV 14 & 1 & 3 \\
\hline 402 & I-77 & SB 1.2 miles south of WV 14 & 1 & 3 \\
\hline 5 & I-79 & 0.8 miles north of US 19 & 1 & 4 \\
\hline 6 & I-79 & 0.2 miles south of WV 131 & 1 & 4 \\
\hline 26 & I-64 & 1.5 miles east of US 52 & 11 & 4 \\
\hline 27 & I-64 & 2.2 miles west of WV 622 & 11 & 4 \\
\hline 29 & I-70 & 4.0 miles west of CO 41 & 11 & 4 \\
\hline 30 & I-77 & 2.2 miles south of WV 3 & 11 & 4 \\
\hline 39 & I-64 & 2.5 miles west of WV34 & 1 & 4 \\
\hline 42 & I-64 & 1.7 miles south of WV 114 & 11 & 4 \\
\hline 47 & I-77 & 1.0 miles south of WV 112 & 1 & 4 \\
\hline 50 & I-81 & 1.6 miles south of WV 44 & 1 & 4 \\
\hline 53 & I-68 & 1.0 miles west of WV 26 & 1 & 4 \\
\hline
\end{tabular}

Table 3.2 - List of Sites used for this Project

\begin{tabular}{|c|c|c|c|c|}
\hline $\begin{array}{c}\text { Site } \\
\text { Number }\end{array}$ & Location & Description & $\begin{array}{c}\text { Functional } \\
\text { Class }\end{array}$ & $\begin{array}{c}\text { Number of } \\
\text { Lanes }\end{array}$ \\
\hline 1 & I-64 & 1.2 miles west of WV 20 & 1 & 4 \\
\hline 5 & I-79 & 0.8 miles north of US 19 & 1 & 4 \\
\hline 26 & I-64 & 1.5 miles east of US 52 & 11 & 4 \\
\hline 29 & I-70 & 4.0 miles west of CO 41 & 11 & 4 \\
\hline 42 & I-64 & 1.7 miles south of WV 114 & 11 & 4 \\
\hline 47 & I-77 & 1.0 miles south of WV 112 & 1 & 4 \\
\hline 50 & I-81 & 1.6 miles south of WV 44 & 1 & 4 \\
\hline 53 & I-68 & 1.0 miles west of WV 26 & 1 & 4 \\
\hline
\end{tabular}




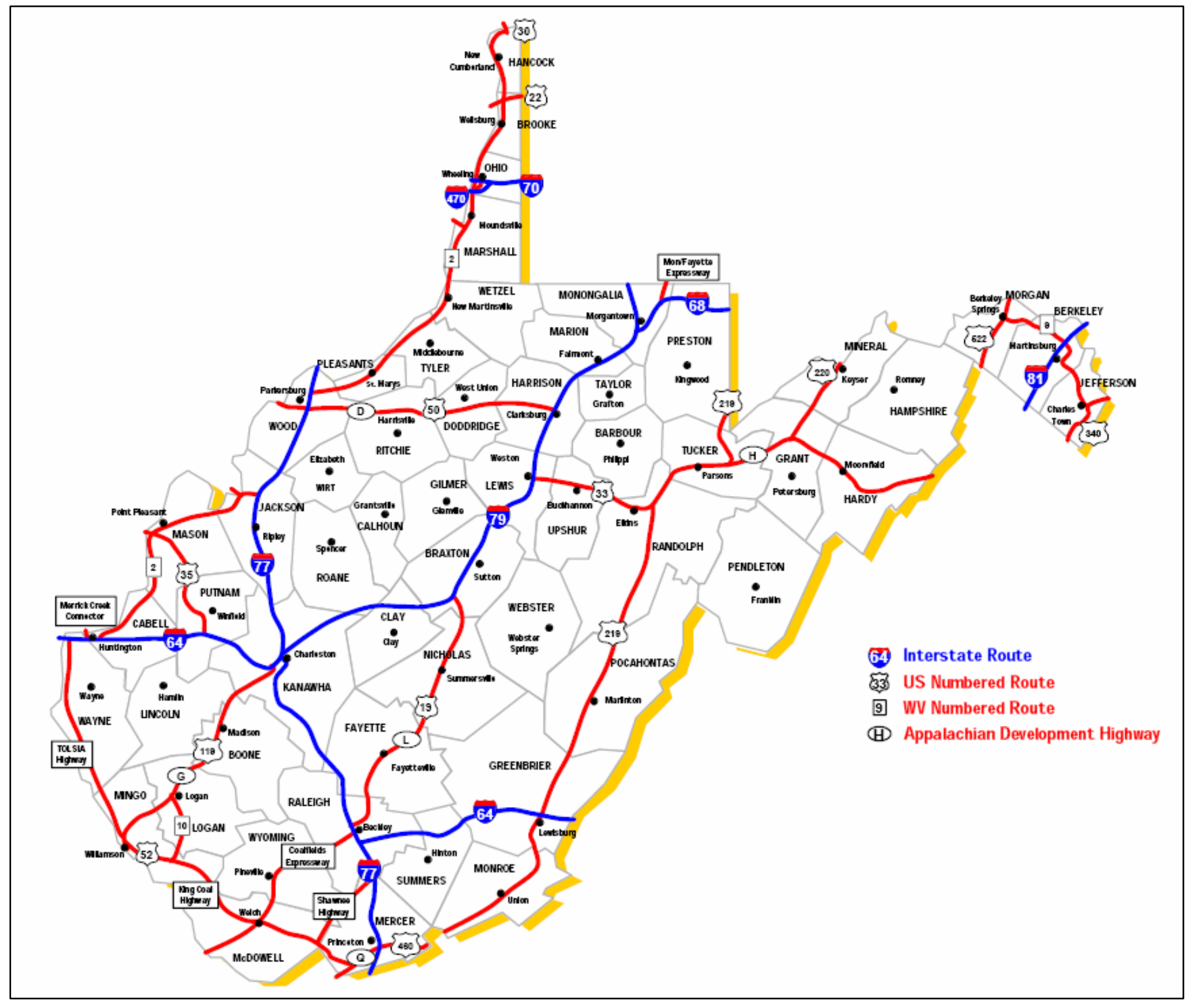

Figure 3.1- West Virginia National Highway System 


\subsection{Data Acquisition}

The first step in this project was to acquire the data and to perform usable spreadsheets to facilitate the data provided by the West Virginia Department of Transportation. Data provided could only be read by a DOS program called "Reporter" which also was provided. The default extension of the raw data is the year in which they were recorded (e.g. *.95,*.96, *.97, etc.). This is how Permanent Automatic Traffic Recorders save the information throughout the years. The Reporter program allows saved data to be recorded as a document extension (*.doc) or CSV. Opening every site for every year, the data can be converted to a document extension (.doc). After the files are completely saved in *.doc extension, they may be opened using any word editor such as notebook, WordPad or MS Word. As the data is delimited by spaces (*.doc extension), it also can be opened using MS Excel completely in some cases, while in others the restriction of the maximum number of rows in an MS Excel file is present (MS Excel only supports 65,536 rows in one workbook). Therefore, in cases where the number of rows exceeds this limit, the procedure is divided into two parts in order to open it using MS Excel without losing data.

Some of the data in the files generated by the counters is not useful for this study, such as travel speed, weight, and garbage data or data without a meaning. Therefore, all this information was not considered in the spreadsheets. The most common method to separate unusable data from a workbook is using an MS Excel macro. A macro is a small program created in MS Excel, which has the purpose of separating information. Information related to vehicle counts, for every hour during a day for the 365 days during the year, and vehicle classification between 4 and 13 (truck classes) was required in this 
study. Stations report vehicle classification and counts for both directions of travel throughout the year, functional classes considered were in accordance with the Traffic Monitoring Guide (FHWA, 2001). FHWA classifies vehicles into 13 categories based on their number of axles, length, weight etc. Table 3.3 shows the FHWA vehicle classification scheme. Finally, after the data was placed in one excel workbook, it was divided in five different workbooks in the same spreadsheet: by lane, by direction, by hour, by day, by month. The workbook "by day" was used to estimate the Annual Average Daily truck Traffic (AADTT) for each site and year. 
Table 3.3- FHWA Vehicle Classification Scheme

\begin{tabular}{|c|c|}
\hline \multirow{2}{*}{ Class 0} & n. \\
\hline & Vehicles which do not activate the system sensors are also unclassified. \\
\hline Class 1 & $\begin{array}{l}\text { Motorcycles. All two- or three wheeled motorized vehicles. This category } \\
\text { includes motorcycles, motor scooters, mopeds, and all three-wheel } \\
\text { motorcycles. }\end{array}$ \\
\hline Class 2 & $\begin{array}{l}\text { Passenger Cars. All sedans, coupes, and station wagons manufactured } \\
\text { primarily for purpose of carrying passengers. }\end{array}$ \\
\hline Class 3 & $\begin{array}{l}\text { Other two-axle, four-tire single units. Included in this classification are } \\
\text { pickups, vans, campers, and ambulances. }\end{array}$ \\
\hline Class 4 & $\begin{array}{l}\text { Buses. All vehicles manufactured as traditional passenger-carrying buses } \\
\text { with two axles and six tires or three or more axles. }\end{array}$ \\
\hline Class 5 & $\begin{array}{l}\text { Two-Axle, Single Unit Trucks. All vehicles on a single frame including } \\
\text { trucks, camping and recreation vehicles. }\end{array}$ \\
\hline Class 6 & $\begin{array}{l}\text { Three Axle Single Unit Trucks. All vehicles on a single frame including } \\
\text { trucks, camping and recreational vehicles. }\end{array}$ \\
\hline Class 7 & $\begin{array}{l}\text { Four or more Axle Single Unit Trucks. All vehicles on a single frame with } \\
\text { four or more axles. }\end{array}$ \\
\hline Class 8 & $\begin{array}{l}\text { Four or Less Axle Single Trailer Trucks. All vehicles with four or less } \\
\text { axles consisting of two units, one of which is tractor or straight truck } \\
\text { power unit. }\end{array}$ \\
\hline Class 9 & $\begin{array}{l}\text { Five-Axle Single Trailer Trucks. All five-axle vehicles consisting of two } \\
\text { units, one of which is a tractor or straight truck power unit. }\end{array}$ \\
\hline Class 10 & $\begin{array}{l}\text { Six or More Axle Single Trailer Trucks, consisting of two units, one of } \\
\text { which is a tractor or straight truck power unit. }\end{array}$ \\
\hline Class 11 & $\begin{array}{l}\text { Five or Less Axle Multi-Trailer Trucks, consisting of three or more units, } \\
\text { one of which is a tractor or straight truck power unit. }\end{array}$ \\
\hline Class 12 & $\begin{array}{l}\text { Six Axle Multi-Trailer Trucks. All six-axle vehicles consisting of three or } \\
\text { more units, one of which is a tractor or straight truck power unit }\end{array}$ \\
\hline Class 13 & $\begin{array}{l}\text { Seven or More Axle Multi-Trailer Trucks. All vehicles with seven or more } \\
\text { axles consisting of three or more units, one of which is a tractor or straight } \\
\text { truck power unit }\end{array}$ \\
\hline
\end{tabular}




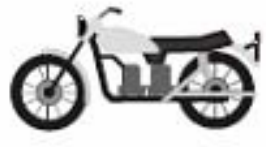

1: Motorcycles

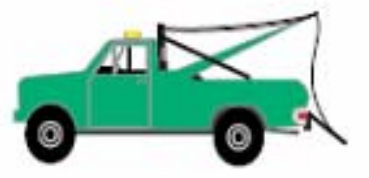

5: 2 Axle - 6 Tire Single Unit 6:3 Axle Single Unit

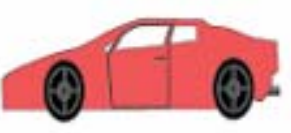

2: Automobiles

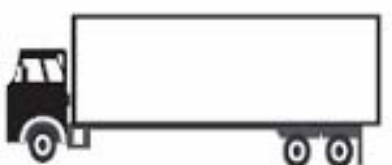

이

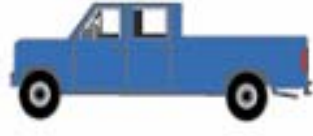

3: 2 Axle - 4 Tire Single Unit

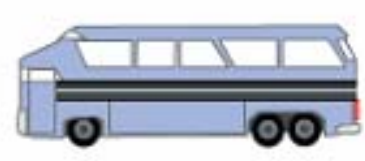

4: Buses

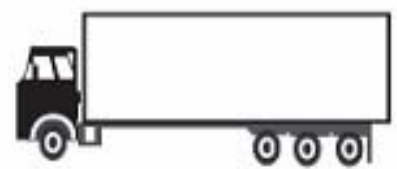

7: 4+ Axle Single Unit

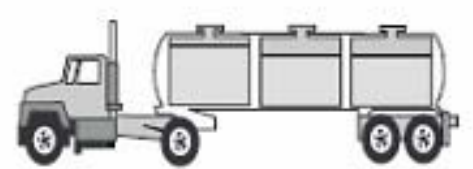

8: 4 or Less Axle Single Trail

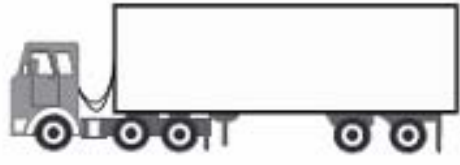

9: 5 Axle Single Trailer

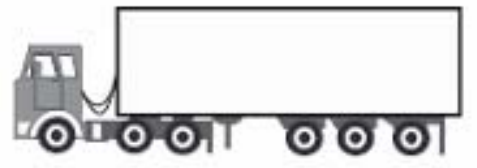

10: 6 or More Axles Single Trailer

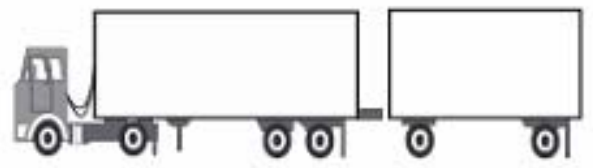

11: 5 or Less Axles Multi Trailer

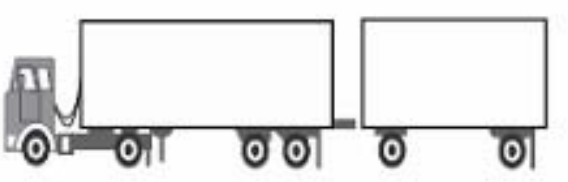

12: 6 Axle Multi Trailer

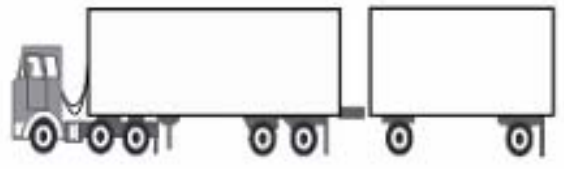

13: 7 or More Axles Multi Trailer

Figure 3.2- FHWA Vehicle Classification Scheme 


\subsubsection{Data Quality Checks}

Previously, to obtain the final data, the data was tested for outliers, discrepancies, and for inconsistent values. Data was tested following the methodology described below:

- Simple observation was used to look for errors and outliers. Data distant as defined below from the usual truck traffic volumes was erased. During the data acquisition procedure, sites were found with the presence of: no data at all, missing data, or unreasonably large or small numbers not according to the normal truck traffic volume in a site or highway analyzed. These values were considered errors and removed from the final data.

- Data between the mean plus or minus two times the standard deviations (u $\pm 2 \sigma$ ) was kept, and data out of this range was considered to be outliers and was erased.

\subsection{Estimation of Annual Average Daily Truck Traffic (AADTT)}

After the removal of discernible errors and discrepancies in the data, AADTTs were computed for each site and year. According to the FHWA, Traffic Monitoring Guide, 2001, there are two methods to estimate AADTT. The method selected in this study was the first one explained in the Literature Review, a simple average of all days.

A simple average was made in this method for all 365 days in the year. In cases of missing data, the denominator was adjusted accordingly by subtracting the number of missing days from 365. This method was selected because of its simplicity and also due 
to the small and insignificant differences in results between the two methods. (Wright, $\mathrm{Hu}$, et al). In this analysis the workbook "by day" was analyzed using the total number of vehicles between classifications 4 and 13. Results of AADTT estimation are shown in the Table 3.4.

Table 3.4- Annual Average Daily Truck Traffic- Interstate Highways

\begin{tabular}{|c|c|c|c|c|c|c|c|c|c|c|c|}
\hline Route & Class & Site & $\mathbf{1 9 9 5}$ & $\mathbf{1 9 9 6}$ & $\mathbf{1 9 9 7}$ & $\mathbf{1 9 9 8}$ & $\mathbf{1 9 9 9}$ & $\mathbf{2 0 0 0}$ & $\mathbf{2 0 0 1}$ & $\mathbf{2 0 0 2}$ & $\mathbf{2 0 0 3}$ \\
\hline I-64 & Rural & SITE 01 & & 1813 & 1782 & 1730 & & 1299 & & & \\
\hline I-79 & Rural & SITE 05 & 2325 & & & 3136 & & & & 3145 & 3089 \\
\hline I-64 & Urban & SITE 26 & 3310 & 3880 & & & 4928 & 5090 & 4764 & & 4912 \\
\hline I-70 & Urban & SITE 29 & & 7101 & 7005 & 7733 & 8384 & 6852 & 8503 & 8424 & 8562 \\
\hline I-64 & Urban & SITE 42 & & 3740 & 4005 & 3358 & & & & 6797 & 7150 \\
\hline I-77 & Rural & SITE 47 & & 2262 & & & 2462 & 2928 & & 2142 & 2936 \\
\hline I-81 & Rural & SITE 50 & & & 5013 & 5440 & 7670 & & & & 11805 \\
\hline I-68 & Rural & SITE 53 & 1736 & & 1046 & 863 & & & & & 2576 \\
\hline
\end{tabular}

AADTT in Table 3.4 were used to developed models as is explain afterwards. 


\subsection{Model Development Overview}

The following is a summary of the different approaches used to develop models based on Annual Average Daily Truck Traffic. As explained in the Literature Review, because of the type of data available and the flexibility of this method, the most reliable method with great potential to be used in West Virginia is the Time Series Method (Rebovich, 2004).

The first approach was regression analysis, as described in the Literature Review. Because of the small cause-effect of demographic variables in the relationship with vehicle traffic on Interstate Highways, those variables were discarded in the course of this project. Therefore, time period was selected as a unique independent variable to be in all models performed. The advantage of regression analysis is the use of all the data available and the simplicity of this method to produce rapid forecasting for individual facilities based on historic trends, requiring less data and offering more simplistic approaches than other forecasting approaches. The disadvantage of this method is that independent variables might change over the time (new or changes in land developments in the area of study), decreasing the predicting ability of the model. During the course of this project, exponential and linear regression analyses were performed using the time period as the independent variable. Since the coefficient of regression $\left(\mathrm{R}^{2}\right)$ was lower in the exponential regression analysis than in the linear analysis, exponential analysis was discarded from the research, and only linear regression analysis was reported in this study. Therefore, a linear form was established to all the models using time period as a

unique independent variable. Linear regression analysis was performed to estimate a 
model for statewide interstate highways, models for rural and urban areas, and for each truck classification. In addition, grouping truck classes according to their number of axles (single and multi-unit vehicles), and the inclusion of a weighted analysis, weighted according to the number of trucks passing in each group (all, rural, urban) per day, was performed to improve the prediction of the models. Precision analysis was performed to test the sample size in the models and their predicting ability.

The second approach was conducted using the growth factor technique, representing as a percentage the increase of AADTT per year. The advantage of this method is its simplicity, assuming past trends in percent increase in traffic volume each year will continue into the future. The disadvantage is that no more than two years of AADTT can be used as an input data instead of used the whole data available over the years. Similar to linear regression analysis, analysis by grouping truck classes and weighted annual average truck traffic growth rates was performed. Finally, a contrast between the two techniques was conducted in order to confirm what the stronger predictor is.

\subsubsection{Linear Regression Model}

Linear Regression analysis models have the form of a straight line, $y=\beta x+c$, where " $y$ " is the resulting of Annual Average Daily Truck Traffic (AADTT), " $x$ " is the year of prediction, called predictor variable, and " $\beta$ " and "c" are regression coefficients. The slope term of the linear regression " $\beta$ " may be utilized to calculate a growth rate for the grouping of stations. The slope represents the average change in AADTT between each year throughout the history of the station. This slope may be utilized in conjunction 
with a single year, AADTT, to determine an individual growth rate. Growth was defined as the slope of the regression line divided by the predicted AADTT, 2003 year, which is the last year available, multiplied by 100 in this project. The resulting growth rates were expressed as a percentage for the purpose of this project.

(Equation 3.1)

$$
\text { Growth Rate }=\frac{\text { Slope }}{\text { Estimate }(2003 \text { year })} \times 100 \%
$$

Using Table 3.4, regression analysis was performed to develop a model for every site; therefore, the missing values of AADTT were estimated and are shown in the next chapter in Table 4.2. The next step is to estimate overall growth rates for all interstate highways, which include rural and urban roads. Also, separate studies were conducted for rural and urban settings.

\subsubsection{Statewide Interstate Highways Growth Rate}

Statewide Interstate Highway Growth Rate is defined as the average growth rate for all Interstate Highways in West Virginia. It was obtained from regression analysis of all sites in a sole group, plotting the whole information (AADTT vs. Years) in a graph, and then conducting a linear regression analysis based on the average of AADTT for each year. Furthermore, to estimate their growth rate, sites were separated into two groups: rural and urban interstates. 


\subsubsection{Regression Analysis for Each Truck Classification}

Regression analysis was performed for every single truck classification according to the Federal Highway Administration vehicle classification scheme. Vehicle classifications between 4 and 13 were considered trucks. Thus, the models for each truck classification were obtained as well as their growth rates.

\subsubsection{Annual Average Growth Rate Weighted}

Using linear regression analysis, the truck traffic growths rates were determined (in percentage) for all interstates sites, distinguishing between rural and urban. These values were used to estimate the annual average growth rate weighted by multiplying the growth rates by their weight; weight was calculated according to the number of trucks passing in each group (all, rural, urban) per day based on data in Table 4.2. The weight for each site is the sum of AADTT for one site in the course of the years (sum of AADTT for $1995,1996, \ldots 2003$ for one site) divided by the total sum of AADTT from the all sites in the study. The weight was calculated for the eight sites in the study (Site01, Site05, ...., Site53) as well as for each group of sites formed (e.g. urban, rural). Therefore, in the case of using all sites, eight values of AADTT(i) were obtained as well as the sum of these values $\mathrm{AADTT}_{(\mathrm{T})}=\mathrm{AADTT} 01+\mathrm{AADTT}_{0}+\ldots . \mathrm{AADTT} 53$. Therefore, the weight

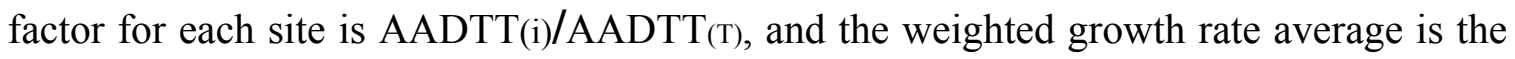
sum product between the growth rate and the weight factor for each site: 
(Equation 3.2)

Weighted Growth Rate Average $=\sum$ Growth Rate(\%)(i) $\times \frac{\operatorname{AADTT}(\mathrm{i})}{\operatorname{AADTT}(T)}$

Observe that $\sum A A D T T(i) / A A D T T_{(T)}$ for all the sites in a group of the study (e.g. all, rural, urban) is equal to one.

In the case of the growth rate of each truck classification, weight factors were calculated according to the following explanation: Considering one truck classification (e.g. TC4), and the eight sites in study, the weight was calculated taking the average of AADTT during the years of study $(1995,1996, \ldots 2003)$ in each site. In the analysis of all sites, eight values of AADTT(TC4)(i) were obtained as well as their sum:

$\operatorname{AADTT}(\mathrm{TC} 4)(\mathrm{T})=\operatorname{AADTT}(\mathrm{TC} 4)(01)+\mathrm{AADTT}(\mathrm{TC} 4)(05)+\ldots .+\mathrm{AADTT}(\mathrm{TC} 4)(53)$

Therefore, the weight factor for one site " $i$ " at a specific truck classification is AADTT(TC4)(i)/AADTT(TC4)(T). The weighted growth rate averaged for this truck classification is the sum product between the growth rate for this truck class at one site and its weight factor.

Weighted Growth Rate Average $=\sum$ Growth Rate $(\%)(\mathrm{TC} 4)(\mathrm{i}) \times \frac{\operatorname{AADTT}(\mathrm{TC} 4)(\mathrm{i})}{\operatorname{AADTT}(T C 4)(T)}$

It is important to note that the average of AADTT was taken for each truck classification during the years instead of the sum of the AADTT. The weight was calculated in this manner because of missing data in some years at various sites, which 
make it impossible to have AADTT for the same years to calculate the sum of AADTT. For example, whether in a site (e.g. site 01), information is available in the years: 1995, 1996, 2001, and 2003, and in other site (e.g. site05) only the years 1997, 1998, and 2003. The approach used, was taken the average of AADTT in Site01 and Site05 instead of taking the sum of AADTT during the years available. This analysis increases the precision of the weight analysis conducted in the study.

\subsubsection{Precision Analysis}

Based on the AADTT, the precision analysis was performed to every site in the course of the years instead of using growth rates calculated for each site and truck classification. Precision analysis was performed by determining the coefficient of variation from the AADTT in every site for each group in the analysis. The coefficient of variation is the result of dividing the standard deviation by the mean of the AADTT for the groups used in the analysis. A coefficient of variation around $10 \%$ was considered acceptable for the purpose of this project. In all of the calculations, special care was taken to check the coefficient of variation $(\mathrm{CV})$, which measures the precision of the factors, telling how precisely the AADTT performed the data. The higher the precision, the lower the percentage; therefore, data collected consistently should hypothetically have a Coefficient of Variance equal to zero percent. A group of data could have a low coefficient of variation (say $10 \%$ or better) which is highly desirable; however, they still

may not have accurate test results. This means that they repeatedly made the same mistake in collecting data. For example, precision of $53.00 \%$ probably means that some of the data could be considered as outliers. Therefore, collecting plenty of data helps to eliminate outliers and still have enough data points to average. 


\subsubsection{Truck Groups: Single-Unit and Multi-Unit (4-7, 8-13)}

As shown during the project, groups with different characteristics were made, such as rural and urban interstates. However, to better improve the results, another grouping analysis was performed by grouping truck classes according to their number of axles. Vehicle classification between 4 and 7, which include buses, recreational vehicles, two-axle, three axle and four or more axle single-units trucks were combined. Another group, between classes 8 to 13 , comprised of two unit truck vehicles, such as tractors with a power unit, or trailers with two or more units.

\subsubsection{Models’ Calibration and Validation}

According to the FHWA Guidebook on Statewide Travel Forecasting, the adjustment or setting of parameters on forecasting models to assure that the models match existing travel behaviors is called "calibration". In addition, it is important that a forecast model be compared with a known traffic count to assure in some percentage that future year forecasts are valid. The preferred calibration techniques use statistical methods, such as linear regression, analysis of variation, and maximum likelihood estimation. However, the most common calibration technique is "Ordinary Least Squares" (Linear Regression), being the primary method for calibrating statewide travel demand models (FHWA, 1999). This method works by finding the "best curve" through the data that minimizes the sums of squares of the residuals. The following equation is an example of a linear equation model that estimates AADTT. 
(Equation 3.3)

$$
A A D T T=a_{0}+a_{1} \cdot x_{1}+a_{2} \cdot x_{2}+\ldots \ldots a_{n} \cdot x_{n}
$$

In a linear equation model, the parameters are analyzed using standard regression techniques, to find the "best fit" straight line to a set of data that should follow a linear trend to describe AADTT as a function of the parameters. In this study, "time period" was used as unique independent variable in all models (e.g. X1 = the year to predict AADTT, $X 2, X 3 . . X n=0$ ). Parameters $a_{0}$ and $a_{1}$ are developed in order to minimize the error sum of squares, which is the difference between the observed AADTT in a specific year and the AADTT predicted by the model at the same year. In other words, the "best" line is performed by minimizing vertical deviations between the points and the line. The procedure to estimate the parameters were made using MS Excel, which uses the least square procedure to estimate the parameters. Finally, in order to demonstrate that the relationship simulated has some degree of accuracy and consistency, the forecasted models should be evaluated for reasonableness. For instance, the most current AADTT could be compared to those generated by the model, and large differences in volume (higher than 10\%) should be further evaluated in an effort to explain the disparity. If valid explanations for the differences cannot be determined, then either the model or the trend volumes may not be appropriate for use. The differences between real and predicted AADTT conducted to the last year of AADTT available is reported in Appendix C. 


\subsubsection{Growth Factor}

As described in the literature review, the following equation was used to estimate growth rates using the beginning and ending year. These years were taken as historical data, using the first year available and the last one available and also using the most recent years available to calculate current growth rate.

(Equation 3.4)

$$
\text { Growth Rate }=\left(\frac{\text { EndingYear }}{\text { BeginningYear }}\right)^{\frac{1}{\# \text { Hears }}}-1
$$

Therefore, two types of compound growth rates were estimated, historical and current growth rates. The first one was conducted by using the last and first year of AADTT available, and the equation above. The other is the current growth rate which is calculated using the last two years available. This growth factor analysis was conducted using Table 3.4; also this analysis was conducted for each truck classification. Tables and results are shown in the next chapter.

Because of missing data, the methodology to estimate current growth rates was conducted by using the last two years available with one year gap between them as an optimum gap. For example, whether 2001 and 2003 were used, but data in 2001 was not available, data from the most recent year was utilized.

\subsubsection{Statewide Interstate Highways Growth Rate}

Similar to linear regression analysis a statewide interstate highway growth rate study was conducted. It was performed using only two years of the most recent years of 
data and Equation 3.4. The growth rates in percentage for all, rural, and urban interstates was estimated.

\subsubsection{Growth Factor Method for Each Truck Classification}

By the same method used for regression analysis, growth rates were estimated for every single truck classification.

\subsubsection{Annual Average Growth Rate Weighted}

The weight for each site and truck classification was estimated differently for regression analysis. It was estimated by using the two years, which determined the growth rate. Therefore, the weight for each site is the sum of AADTT for one site in these two years (e.g. if 2001 and 2003 were used to estimate the growth rate, the sum of their AADTT was used for this site) divided by the total sum of AADTT used to calculate the growth rates in all the sites. The weight was calculated for the total sites in the study as well as for the group of sites (e.g. rural, urban sites).

In the analysis of all sites, the sum of AADTT in each site in the course of the years was calculated. Therefore, eight values of AADTT(i) were obtained as well as the sum of these values: $\operatorname{AADTT}(\mathrm{T})=\operatorname{AADTT}(01)+\operatorname{AADTT}(05)+\ldots . . \mathrm{AADTT}(53)$. Thus, the weight factor for each site is $\operatorname{AADTT}(\mathrm{i}) / \operatorname{AADTT}(\mathrm{T})$, and the weighted growth rate average is the sum product between the growth rate and the weight factor for each site. 
Weighted Growth Rate Average $=\sum$ Growth Rate $(\%)(\mathrm{i}) \times \frac{\operatorname{AADTT}(\mathrm{i})}{A A D T T(T)}$

Observe that $\sum A A D T T(i) / A A D T T_{(T)}$ for the sites in the group of the study (e.g. all, rural, urban) is equal to one.

In the case of the growth rate of each truck classification, weight factors were calculated according to the following explanation: Considering one truck classification (e.g. TC4), and the eight sites, the weight was calculated summing the two AADTT used to estimate the growth rate in each site divided by the total sum of all AADTT used to estimate the growth rates in all sites for the same truck classification. In the analysis of all sites, eight values of AADTT(TC4)(i) were obtained as well as their sum:

$\operatorname{AADTT}(\mathrm{TC} 4)(\mathrm{T})=\mathrm{AADTT}(\mathrm{TC} 4)(01)+\mathrm{AADTT}(\mathrm{TC} 4)(05)+\ldots .+\mathrm{AADTT}(\mathrm{TC} 4)(53)$

Therefore, the weight factor for one site " $i$ " at a specific truck classification is AADTT(TC4)(i)/AADTT(TC4)(T). The weighted growth rate averaged for this truck classification is the sum product between the growth rate for this truck class at one site and its weight factor.

Weighted Growth Rate Average $=\sum$ Growth Rate $(\%)(\mathrm{TC} 4)(\mathrm{i}) \times \frac{\operatorname{AADTT}(\mathrm{TC} 4)(\mathrm{i})}{\operatorname{AADTT}(T C 4)(T)}$ 


\subsubsection{Precision Analysis}

This analysis is somewhat similar to the one performed in regression analysis. It was based on the AADTT, which determined the growth rate in each site or truck classification instead of using growth rates.

\subsubsection{Truck Groups: Single-Unit and Multi-Unit (4-7, 8-13)}

This analysis is similar to the one used for regression analysis. 


\section{CHAPTER 4}

\section{RESULTS}

\subsection{Linear Regression Analysis}

Linear regression analysis was conducted for each site to understand the relationship between AADTT and the independent variable-- time period. This relationship was measured by the coefficient of regression $\left(\mathrm{R}^{2}\right)$. Coefficients of Regression greater than 0.60 were considered acceptable for the purpose of this project. Regression models for each site and their respective coefficients of regression are shown in Table 4.1.

\section{Table 4.1-Linear Regression Models and Coefficient of Regression for Each Site}

\begin{tabular}{|c|c|c|c|c|c|}
\hline Route & Class & Site & $\begin{array}{c}\text { Number of } \\
\text { Lanes }\end{array}$ & Model & $\mathbf{R}^{2}$ \\
\hline I-64 & Rural & SITE 01 & 4 & $\mathrm{Y}=-132 . \mathrm{X}+265131$ & 0.88 \\
\hline $\mathrm{I}-79$ & Rural & SITE 05 & 4 & $Y=86 . X-168131$ & 0.63 \\
\hline I-64 & Urban & SITE 26 & 4 & $Y=204 . X-403402$ & 0.75 \\
\hline $\mathrm{I}-70$ & Urban & SITE 29 & 4 & $Y=215 . X-423024$ & 0.51 \\
\hline $\mathrm{I}-64$ & Urban & SITE 42 & 4 & $\mathrm{Y}=551 . \mathrm{X}-102921$ & 0.90 \\
\hline $\mathrm{I}-77$ & Rural & SITE 47 & 4 & $Y=53 . X-102921$ & 0.15 \\
\hline $\mathrm{I}-81$ & Rural & SITE 50 & 4 & $\mathrm{Y}=1170 . \mathrm{X}-2331111$ & 0.98 \\
\hline I-68 & Rural & SITE 53 & 4 & $Y=146 . X-290031$ & 0.41 \\
\hline
\end{tabular}

Table 4.1 shows coefficients of regression, these coefficients are greater than 0.6 in five sites with lower values in Site 29, Site 47 and Site 53. These models were used to estimate the missing values in Table 3.4. In addition, these models were used to estimate AADTTs for the last year in the study (year 2003) in order to predict the growth rate for each site by dividing the slope of the regression model by the estimation of the year 2003 . 
Table 4.2 shows a complete table with the AADTTs predicted by the regression models, and Table 4.3 shows the growth rates for each site.

Table 4.2-Missing AADTT values predicted

\begin{tabular}{|c|c|c|c|c|c|c|c|c|c|c|c|}
\hline Route & Class & Site & $\mathbf{1 9 9 5}$ & $\mathbf{1 9 9 6}$ & $\mathbf{1 9 9 7}$ & $\mathbf{1 9 9 8}$ & $\mathbf{1 9 9 9}$ & $\mathbf{2 0 0 0}$ & $\mathbf{2 0 0 1}$ & $\mathbf{2 0 0 2}$ & $\mathbf{2 0 0 3}$ \\
\hline I-64 & Rural & SITE 01 & 2019 & 1813 & 1782 & 1730 & 1491 & 1299 & 1227 & 1095 & 964 \\
\hline I-79 & Rural & SITE 05 & 2325 & 2624 & 2710 & 3136 & 2881 & 2967 & 3052 & 3145 & 3089 \\
\hline I-64 & Urban & SITE 26 & 3310 & 3880 & 4073 & 4277 & 4928 & 5090 & 4764 & 5093 & 4912 \\
\hline I-70 & Urban & SITE 29 & 6851 & 7101 & 7005 & 7733 & 8384 & 6852 & 8503 & 8424 & 8562 \\
\hline I-64 & Urban & SITE 42 & 2694 & 3740 & 4005 & 3358 & 4900 & 5451 & 6002 & 6797 & 7150 \\
\hline I-77 & Rural & SITE 47 & 2282 & 2262 & 2388 & 2441 & 2462 & 2928 & 2599 & 2142 & 2936 \\
\hline I-81 & Rural & SITE 50 & 2511 & 3680 & 5013 & 5440 & 7670 & 8359 & 9529 & 10699 & 11805 \\
\hline I-68 & Rural & SITE 53 & 1736 & 1227 & 1046 & 863 & 1665 & 1811 & 1957 & 2102 & 2576 \\
\hline
\end{tabular}

The values in the shaded boxes represent the AADTT estimated for the models

Table 4.3-Average Annual Growth Rates for Each Site

\begin{tabular}{|c|c|c|c|c|c|c|}
\hline Route & Class & Site & $\begin{array}{c}\text { Number of } \\
\text { Lanes }\end{array}$ & $\begin{array}{c}\text { Estimation } \\
\text { Year 2003 }\end{array}$ & Slope & $\begin{array}{c}\text { Average } \\
\text { Annual } \\
\text { Growth Rate }\end{array}$ \\
\hline I-64 & Rural & SITE 01 & 4 & 964 & -132.00 & $-13.69 \%$ \\
\hline I-79 & Rural & SITE 05 & 4 & 3223 & 86.00 & $2.67 \%$ \\
\hline I-64 & Urban & SITE 26 & 4 & 5297 & 204.00 & $3.85 \%$ \\
\hline I-70 & Urban & SITE 29 & 4 & 8575 & 215.00 & $2.51 \%$ \\
\hline I-64 & Urban & SITE 42 & 4 & 7105 & 551.00 & $7.76 \%$ \\
\hline I-77 & Rural & SITE 47 & 4 & 2704 & 53.00 & $1.96 \%$ \\
\hline I-81 & Rural & SITE 50 & 4 & 11869 & 1170.00 & $9.86 \%$ \\
\hline I-68 & Rural & SITE 53 & 4 & 2248 & 146.00 & $6.49 \%$ \\
\hline
\end{tabular}

Table 4.3 shows large differences in growth rates among sites, from a large negative value in Site01 to a positive large value in Site50. Because of the large dispersion in growth rates, sites were grouped by similar characteristics such as rural and urban sites in order to improve models based on their coefficient of regression and to 
obtain growth rates to better understand travel patters in rural, urban areas as well as patterns in light and heavy truck traffic (single/multi-unit trucks).

Linear regression models were conducted in order to predict truck traffic volume and growth rates. Models were based on two types of data, which are described below:

- The first type of data used AADTTs (Annual Average Daily Truck Traffic) for each site and truck classification per site and year. Annual Average Growth Rate Weighted was calculated for: all, rural, urban and each truck classification as well as for the two truck groups, single and multi-unit trucks.

- The second type of data was the year average of AADTT. Plotting these values in order to determine a unique linear regression model for all, rural, urban interstates; and for each truck classification as well. These models and the growth rates are shown in the course of this project. 


\subsubsection{Linear Regression Analysis using AADTT}

\subsubsection{Analysis for Sites}

\section{a) All Interstates}

Linear regression analysis was performed to estimate annual average growth rates (Table 4.4). Using AADTTs for each site (Table 4.2) to predict the Annual Average Growth Rate Weighted. The weight factor was estimated according to the total number of vehicles traveling during the nine years of the data collection. Therefore, each growth rate was multiplied by its weight factor and these values were added to obtain the weighted average. Results and the coefficient of variation are shown in Table 4.4.

Table 4.4-Average Annual Growth Rate Weighted-All Interstates

\begin{tabular}{|c|c|c|c|c|c|}
\hline Route & Class & Site & $\begin{array}{c}\text { Average annual } \\
\text { growth rate }\end{array}$ & Sum of trucks during years & weight/site \\
\hline I-64 & Rural & SITE 01 & $\mathbf{- 1 3 . 7 0 \%}$ & 13420 & 0.045 \\
\hline I-79 & Rural & SITE 05 & $\mathbf{2 . 6 5 \%}$ & 25929 & 0.088 \\
\hline I-64 & Urban & SITE 26 & $\mathbf{3 . 8 5 \%}$ & 40327 & 0.137 \\
\hline I-70 & Urban & SITE 29 & $\mathbf{2 . 5 1 \%}$ & 69415 & 0.235 \\
\hline I-64 & Urban & SITE 42 & $\mathbf{7 . 7 6 \%}$ & 44097 & 0.149 \\
\hline I-77 & Rural & SITE 47 & $\mathbf{1 . 9 5 \%}$ & 22440 & 0.076 \\
\hline I-81 & Rural & SITE 50 & $\mathbf{9 . 8 6 \%}$ & 64706 & 0.219 \\
\hline I-68 & Rural & SITE 53 & $\mathbf{6 . 4 9 \%}$ & 14983 & 0.051 \\
\hline
\end{tabular}

\begin{tabular}{|c|c|}
\hline Mean & $2.67 \%$ \\
\hline St. dev. & $7.19 \%$ \\
\hline $\begin{array}{c}\text { Coefficient of } \\
\text { Variation }\end{array}$ & $\mathbf{2 6 9 . 1 0 \%}$ \\
\hline
\end{tabular}

\begin{tabular}{|c|c|}
\hline $\begin{array}{c}\text { Class-weighted } \\
\text { Average annual } \\
\text { growth rate }\end{array}$ & $\mathbf{4 . 5 2 \%}$ \\
\hline
\end{tabular}

The coefficients of variation in Table 4.4 is a high number, it may be due to the negative value in Site01, which increase the dispersion among growth rates. For example 
whether the negative value is omitted in order to check the variability of the positive values, the coefficient of variation would be reduced to $60.82 \%$, which is lower but still high; therefore, more sample data would be required to reduce this coefficient, and to better estimate the growth rates in this group.

\section{b) Rural Interstates}

The analysis for rural interstate highways is similar to that performed for all interstate highways. Here, five sites were incorporated in order to estimate the annual average growth rate weighted. These results are shown in Table 4.5.

\section{Table 4.5- Average Annual Growth Rate Weighted—Rural Interstates}

\begin{tabular}{|c|c|c|c|c|c|}
\hline Route & Class & Site & $\begin{array}{c}\text { Average annual } \\
\text { growth rate }\end{array}$ & Sum of trucks during years & weight/site \\
\hline I-64 & Rural & SITE 01 & $\mathbf{- 1 3 . 7 0 \%}$ & 13420 & 0.095 \\
\hline I-79 & Rural & SITE 05 & $\mathbf{2 . 6 5 \%}$ & 25929 & 0.183 \\
\hline I-77 & Rural & SITE 47 & $\mathbf{1 . 9 5 \%}$ & 22440 & 0.159 \\
\hline I-81 & Rural & SITE 50 & $\mathbf{9 . 8 6 \%}$ & 64706 & 0.457 \\
\hline I-68 & Rural & SITE 53 & $\mathbf{6 . 4 9 \%}$ & 14983 & 0.106 \\
\hline
\end{tabular}

\begin{tabular}{|c|c|}
\hline Mean & $1.45 \%$ \\
\hline St. dev. & $9.05 \%$ \\
\hline $\begin{array}{c}\text { Coefficient of } \\
\text { variation }\end{array}$ & $\mathbf{6 2 3 . 4 3 \%}$ \\
\hline
\end{tabular}

\begin{tabular}{|c|c|}
\hline $\begin{array}{c}\text { Class-weighted } \\
\text { Average annual } \\
\text { growth rate }\end{array}$ & $\mathbf{4 . 6 9 \%}$ \\
\hline
\end{tabular}

Similar to the all interstate analysis, the coefficient of variation resulted to be a high number due to the negative value in Site01; therefore, more sample data would be required to reduce this coefficient. 


\section{c) Urban Interstates}

A similar computation was conducted for urban interstate highways. The three sites for urban interstates were used to estimate the annual average growth rate weighted. The results are shown in Table 4.6.

Table 4.6-Average Annual Growth Rate Weighted-Urban Interstates

\begin{tabular}{|c|c|c|c|c|c|}
\hline Route & Class & Site & $\begin{array}{c}\text { Average annual } \\
\text { growth rate }\end{array}$ & Sum of trucks during years & weight/site \\
\hline I-64 & Urban & SITE 26 & $3.85 \%$ & 40327 & 0.262 \\
\hline I-70 & Urban & SITE 29 & $2.51 \%$ & 69415 & 0.451 \\
\hline I-64 & Urban & SITE 42 & $7.76 \%$ & 44097 & 0.287 \\
\hline
\end{tabular}

\begin{tabular}{|c|c|}
\hline Mean & $4.71 \%$ \\
\hline St. dev. & $2.73 \%$ \\
\hline $\begin{array}{c}\text { Coefficient of } \\
\text { variation }\end{array}$ & $\mathbf{5 7 . 9 1 \%}$ \\
\hline
\end{tabular}

\begin{tabular}{|c|c|}
\hline $\begin{array}{c}\text { Class-weighted } \\
\text { Average annual } \\
\text { growth rate }\end{array}$ & $\mathbf{4 . 3 7 \%}$ \\
\hline
\end{tabular}

According to the results by sites, the most reliable growth rate is that of urban sites, with $57.91 \%$ coefficient of variation. This CV is lower than the rural and all sites analysis because Site01 is not included. The negative value in Site01 affects the coefficient of variation because it generates large gaps between the mean and growth rates. 


\subsubsection{Analysis for Each Truck Classification}

\section{a) All Interstates}

The results for each truck classification were somewhat similar to that for every site using their respective AADTT. Linear regression was conducted for every truck classification for each site during the nine years. Using these models, growth rates were estimated by the same procedure used for each site and truck classification: dividing the slope by the AADTT estimated for the year 2003, and obtaining the annual average growth rate weighted for each truck classification. The models for each truck classification and sites are shown in the Appendix A, and the growth rates are shown in Table 4.7.

Table 4.7-Annual Average Growth Rate for Each Truck Classification-All Interstates

\begin{tabular}{|c|r|r|r|r|r|r|r|r|}
\hline $\begin{array}{c}\text { Truck } \\
\text { Class }\end{array}$ & \multicolumn{1}{c|}{ Site01 } & \multicolumn{1}{c|}{ Site05 } & \multicolumn{1}{c|}{ Site26 } & \multicolumn{1}{c|}{ Site29 } & \multicolumn{1}{c|}{ Site42 } & \multicolumn{1}{c|}{ Site47 } & \multicolumn{1}{c|}{ Site50 } & \multicolumn{1}{c|}{ Site53 } \\
\hline TC4 & $6.23 \%$ & $6.21 \%$ & $7.99 \%$ & $5.51 \%$ & $6.63 \%$ & $10.40 \%$ & $13.00 \%$ & $10.58 \%$ \\
\hline TC5 & $-3.61 \%$ & $2.48 \%$ & $3.41 \%$ & $1.96 \%$ & $7.98 \%$ & $10.78 \%$ & $9.63 \%$ & $8.86 \%$ \\
\hline TC6 & $-45.34 \%$ & $2.63 \%$ & $1.75 \%$ & $-0.10 \%$ & $7.45 \%$ & $-12.12 \%$ & $12.12 \%$ & $5.78 \%$ \\
\hline TC7 & $-141.67 \%$ & $1.70 \%$ & $3.06 \%$ & $1.53 \%$ & $-12.54 \%$ & $-3.70 \%$ & $15.66 \%$ & $-38.72 \%$ \\
\hline TC8 & $-10.26 \%$ & $3.96 \%$ & $1.69 \%$ & $1.38 \%$ & $6.95 \%$ & $1.75 \%$ & $8.27 \%$ & $9.31 \%$ \\
\hline TC9 & $-15.45 \%$ & $2.75 \%$ & $4.38 \%$ & $3.66 \%$ & $8.09 \%$ & $0.80 \%$ & $10.60 \%$ & $6.46 \%$ \\
\hline TC10 & $-23.81 \%$ & $6.81 \%$ & $-0.63 \%$ & $9.95 \%$ & $12.75 \%$ & $10.58 \%$ & $17.16 \%$ & $6.85 \%$ \\
\hline TC11 & $-125.00 \%$ & $5.06 \%$ & $8.35 \%$ & $-4.42 \%$ & $69.68 \%$ & $-10.96 \%$ & $10.47 \%$ & $30.72 \%$ \\
\hline TC12 & $32.14 \%$ & $-6.25 \%$ & $-4.52 \%$ & $1.46 \%$ & $29.22 \%$ & $-12.50 \%$ & $11.90 \%$ & $-33.33 \%$ \\
\hline TC13 & $14.09 \%$ & $10.12 \%$ & $10.98 \%$ & $12.83 \%$ & $13.98 \%$ & $12.81 \%$ & $12.86 \%$ & $12.16 \%$ \\
\hline
\end{tabular}

Table 4.7 shows most of the negative values in Site 01. Large negative values are present beginning in Class 6, camping and recreational vehicles, through Class 11, five or less axle Multi-Trailer Trucks. The reader should understand that growth rates were based on the slope of the regression model, and on the truck traffic volume estimated in 
the last year of the study, 2003. Therefore, beginning in the year 2004, these growth rates are valid to predict truck traffic volume. In addition, negative growth rates larger than $100 \%$ are present in some truck classes, such as in truck classes 7 and 11 in Site01. Since these models have a negative slope, and AADTT estimated for the year 2003 is lower than the absolute value of the slope, these growth rates are negative and greater than $100 \%$, which means that no trucks from truck classes 7 and 11 are present in the year 2004 in Site01. Therefore, growth rates from these truck classes were discarded in the calculation of the annual average growth rate weighted.

Site01 is located on Interstate highway I-64, 1.2 miles west of WV20; therefore, this site has affected for the truck traffic volume from Raleigh County. This county is a coal producing area that has been affected in recent years by decline in its mining activity. According to the West Virginia Geological and Economic Survey, the total coal production for Raleigh County dropped from 10,200,390 tons in 1995 to 8,868,391 tons in 2002. This production decline may be one possible reason for the decrease in the heavy truck traffic volume in this site. Another reason, although this was not confirmable, may be a different choice of routes by the truck drivers with the same origin and destination, conceivably a shortcut to reduce transportation costs. In the absence of any additional traffic data, one could only assume that the costs incurred by the different route would be less than the previous route, Site01. A future study forecasting traffic volume on state highways or other roads may reveal increased volume of certain truck classes, which would explain the corresponding decrease in volume on the interstate route in question. 
Table 4.7 also reveals that Truck Class 13, Multi-Trailer Trucks, is the most stable truck class in all sites, having growth rates around 11\%.

\section{Annual Average Growth Rate Weighted}

The weighted growth rate average was calculated by multiplying the weight factor for each site and truck classification by its respective growth rate (Table 4.7), and these values were added to obtain the weighted growth rate average (because the total sum of the weight factors is equal to one) The weight factors were calculated as explained in Chapter 3.

Table 4.8-Average of AADTTs from 1995 to 2003 for Each Truck Classification and Site-All Interstates

\begin{tabular}{|c|c|c|c|c|c|c|c|c|}
\hline $\begin{array}{c}\text { Truck } \\
\text { Class }\end{array}$ & Site01 & Site05 & Site26 & Site29 & Site42 & Site47 & Site50 & Site53 \\
\hline TC4 & 37 & 30 & 38 & 76 & 62 & 58 & 66 & 16 \\
\hline TC5 & 147 & 239 & 424 & 409 & 425 & 282 & 449 & 117 \\
\hline TC6 & 66 & 103 & 234 & 190 & 171 & 57 & 184 & 48 \\
\hline TC7 & 20 & 27 & 26 & 16 & 24 & 3 & 22 & 12 \\
\hline TC8 & 84 & 162 & 256 & 276 & 333 & 132 & 340 & 69 \\
\hline TC9 & 1248 & 2290 & 3327 & 6410 & 3693 & 1912 & 5929 & 1235 \\
\hline TC10 & 14 & 30 & 92 & 103 & 97 & 23 & 67 & 19 \\
\hline TC11 & 34 & 53 & 80 & 467 & 164 & 117 & 474 & 41 \\
\hline TC12 & 4 & 8 & 8 & 69 & 19 & 14 & 65 & 3 \\
\hline TC13 & 12 & 12 & 39 & 72 & 95 & 27 & 22 & 6 \\
\hline
\end{tabular}

Table 4.8 shows the average of AADTTs during the years of the study, from 1995 to 2003, for every site and truck class. The following are some characteristics of truck traffic on interstate highways in West Virginia:

Most of the truck traffic volume occurs in Site29 (I-70) and Site50 (I-81) with 7397 and 6897 commercial vehicles traveling per day. 
Most of the truck traffic belongs to heavy truck vehicles (multi-unit trucks), falling into $80 \%$ of the total truck traffic.

The most prevailing truck vehicle on interstate highways in West Virginia belongs to class 9, which includes five-axle single trailer trucks with two units, one of which is a tractor or straight truck power unit.

Moreover, based on the results shown in Table 4.8, weight factors were calculated. The weight factors and the annual growth rate weighted are shown in Table 4.9 and Table 4.10, respectively. Regression models by site for each truck classification are reported in Appendix A.

\section{Table 4.9-Weight Table-All Interstates}

\begin{tabular}{|c|c|c|c|c|c|c|c|c|}
\hline $\begin{array}{c}\text { Truck } \\
\text { Class }\end{array}$ & Site01 & Site05 & Site26 & Site29 & Site42 & Site47 & Site50 & Site53 \\
\hline TC4 & 0.097 & 0.078 & 0.099 & 0.198 & 0.162 & 0.151 & 0.172 & 0.042 \\
\hline TC5 & 0.059 & 0.096 & 0.170 & 0.164 & 0.171 & 0.113 & 0.180 & 0.047 \\
\hline TC6 & 0.063 & 0.098 & 0.222 & 0.180 & 0.162 & 0.054 & 0.175 & 0.046 \\
\hline TC7 & 0.000 & 0.208 & 0.200 & 0.123 & 0.185 & 0.023 & 0.169 & 0.092 \\
\hline TC8 & 0.051 & 0.098 & 0.155 & 0.167 & 0.202 & 0.080 & 0.206 & 0.042 \\
\hline TC9 & 0.048 & 0.088 & 0.128 & 0.246 & 0.142 & 0.073 & 0.228 & 0.047 \\
\hline TC10 & 0.031 & 0.067 & 0.207 & 0.231 & 0.218 & 0.052 & 0.151 & 0.043 \\
\hline TC11 & 0.000 & 0.038 & 0.057 & 0.335 & 0.117 & 0.084 & 0.340 & 0.029 \\
\hline TC12 & 0.021 & 0.042 & 0.042 & 0.363 & 0.100 & 0.074 & 0.342 & 0.016 \\
\hline TC13 & 0.042 & 0.042 & 0.137 & 0.253 & 0.333 & 0.095 & 0.077 & 0.021 \\
\hline
\end{tabular}


Table 4.10—Annual Average Growth Rate Weighted—All Interstates

\begin{tabular}{|c|c|}
\hline Truck Class & $\begin{array}{c}\text { Class-Weighted } \\
\text { Average annual growth rate - (all) }\end{array}$ \\
\hline TC4 & $8.31 \%$ \\
\hline TC5 & $5.66 \%$ \\
\hline TC6 & $0.72 \%$ \\
\hline TC7 & $-2.17 \%$ \\
\hline TC8 & $3.99 \%$ \\
\hline TC9 & $4.89 \%$ \\
\hline TC10 & $8.08 \%$ \\
\hline TC11 & $10.92 \%$ \\
\hline TC12 & $6.30 \%$ \\
\hline TC13 & $12.88 \%$ \\
\hline
\end{tabular}

Table 4.10 shows annual average growth rates weighted. They represent the percent increase or decrease of truck traffic volume each year for each truck classification. Truck vehicles with one frame, three or four axles and eight or ten tires belong to truck class six and seven, respectively, which are the primary vehicle types used for coal mining material transport. As previously mentioned, the decline of the coal mining activity in West Virginia has possibly affected the traffic volume in certain areas for these truck classes.

\section{$\underline{\text { Precision Analysis }}$}

Precision analysis was performed using the average annual growth rate for each site and truck class (Table 4.7). The analysis was based on the computation of the coefficient of variation for each truck classification and site. The results are shown in Table 4.11. 
Table 4.11—Coefficient of Variation (CV) for Each Truck Class-All Interstates

\begin{tabular}{|c|c|c|c|}
\hline $\begin{array}{c}\text { Truck } \\
\text { Class }\end{array}$ & Mean & St. dev. & $\begin{array}{c}\text { Coefficient of } \\
\text { variation }\end{array}$ \\
\hline TC4 & 0.08 & 0.03 & $32.41 \%$ \\
\hline TC5 & 0.05 & 0.05 & $95.15 \%$ \\
\hline TC6 & -0.03 & 0.18 & $-526.94 \%$ \\
\hline TC7 & -0.05 & 0.17 & $-364.60 \%$ \\
\hline TC8 & 0.03 & 0.06 & $213.84 \%$ \\
\hline TC9 & 0.03 & 0.08 & $298.57 \%$ \\
\hline TC10 & 0.05 & 0.13 & $256.55 \%$ \\
\hline TC11 & 0.16 & 0.27 & $175.04 \%$ \\
\hline TC12 & 0.02 & 0.22 & $960.75 \%$ \\
\hline TC13 & 0.12 & 0.01 & $10.97 \%$ \\
\hline
\end{tabular}

As explained in the literature review large coefficients of variation are often associates with large gaps between growth rates. The standard deviation always is a positive number because it is based on the sum of squares deviations from the mean. However, negative growth rates generate negative mean, consequently negative CVs.

Table 4.11 shows high coefficients of variation, the exception is in Truck Class 4 and Truck Class 13, with coefficient of variation of $32.41 \%$ and $10.97 \%$ respectively. Therefore, the growth rates in these truck classes are more reliable in order to anticipate future truck traffic volume. As previously mentioned, high coefficient of variation may point out the presence of outliers in the sites analyzed. Therefore, truck class models with high CVs should be used with care in forecasting.

\section{b) Rural Interstates}

Similar to the analysis for all interstates, separate studies were performed for rural and urban sites. Using the five sites from rural interstate highways: 01, 05, 47, 50, and 53. 
Table 4.12 shows Annual Average Growth Rates in the sites of the study. The weight factors for rural and urban interstate highways were reported in Appendix B.

Table 4.12-Annual Average Growth Rate Weighted—Rural Interstate

\begin{tabular}{|c|c|}
\hline $\begin{array}{c}\text { Truck } \\
\text { Class }\end{array}$ & $\begin{array}{c}\text { Class-Weighted } \\
\text { Average annual } \\
\text { growth rate }- \text { (rural) }\end{array}$ \\
\hline TC4 & $9.89 \%$ \\
\hline TC5 & $6.86 \%$ \\
\hline TC6 & $-1.98 \%$ \\
\hline TC7 & $-1.33 \%$ \\
\hline TC8 & $4.40 \%$ \\
\hline TC9 & $4.71 \%$ \\
\hline TC10 & $9.11 \%$ \\
\hline TC11 & $7.60 \%$ \\
\hline TC12 & $6.14 \%$ \\
\hline TC13 & $12.56 \%$ \\
\hline
\end{tabular}

Rural sites also display negative growth rate values in truck class 6 and class 7 . As reported in the previous explanation, the traffic volume of these truck classes has been decreased.

\section{Precision Analysis}

Precision analysis was calculated based on the annual average growth rates for each truck class (Table 4.12). The coefficients of variation are showed in the following table. Table 4.13 corroborates that Class 13 is the most stable truck class traveling on rural interstate highways based on its low coefficient of variation of $11.75 \%$. 
Table 4.13- Coefficient of Variation in Every Site-Rural Interstates

\begin{tabular}{|c|c|c|c|}
\hline Truck Class & Mean & St. dev. & $\begin{array}{c}\text { Coefficient of } \\
\text { Variation }\end{array}$ \\
\hline TC4 & 0.09 & 0.03 & $32.05 \%$ \\
\hline TC5 & 0.06 & 0.06 & $108.14 \%$ \\
\hline TC6 & -0.07 & 0.23 & $-311.45 \%$ \\
\hline TC7 & -0.06 & 0.23 & $-369.02 \%$ \\
\hline TC8 & 0.03 & 0.08 & $300.33 \%$ \\
\hline TC9 & 0.01 & 0.10 & $961.56 \%$ \\
\hline TC10 & 0.04 & 0.16 & $450.63 \%$ \\
\hline TC11 & 0.09 & 0.17 & $194.97 \%$ \\
\hline TC12 & -0.02 & 0.25 & $-1544.69 \%$ \\
\hline TC13 & 0.12 & 0.01 & $11.75 \%$ \\
\hline
\end{tabular}

\section{c) Urban Interstates}

This analysis is similar to the one performed for rural interstates. Urban sites were used: 26,29 , and 42 .

Table 4.14-Annual Average Growth Rate Weighted-Urban Interstates

\begin{tabular}{|c|c|}
\hline Truck Class & $\begin{array}{c}\text { Class-Weighted } \\
\text { Average annual } \\
\text { growth rate }- \text { (urban) }\end{array}$ \\
\hline TC4 & $6.44 \%$ \\
\hline TC5 & $4.48 \%$ \\
\hline TC6 & $2.80 \%$ \\
\hline TC7 & $-2.98 \%$ \\
\hline TC8 & $3.62 \%$ \\
\hline TC9 & $5.06 \%$ \\
\hline TC10 & $7.55 \%$ \\
\hline TC11 & $14.11 \%$ \\
\hline TC12 & $6.46 \%$ \\
\hline TC13 & $13.01 \%$ \\
\hline
\end{tabular}

Table 4.14 shows that truck class 7 is decreasing not only in urban highways but also in rural interstate highways. Therefore, it corroborates that this commercial vehicle is decreasing activity on interstate highways in West Virginia and truck class 13 is the most stable growth truck class based on its coefficient of variation. 


\section{Precision Analysis}

Precision analysis was calculated based on the annual average growth rates for each truck class (Table 4.14). The coefficients of variation are showed in the following table.

Table 4.15- Coefficient of Variation in Every Site-Urban Interstates

\begin{tabular}{|c|c|c|c|}
\hline Truck Class & Mean & St. dev. & $\begin{array}{c}\text { Coefficient of } \\
\text { variation }\end{array}$ \\
\hline TC4 & 0.07 & 0.01 & $18.46 \%$ \\
\hline TC5 & 0.04 & 0.03 & $70.61 \%$ \\
\hline TC6 & 0.03 & 0.04 & $129.74 \%$ \\
\hline TC7 & -0.03 & 0.09 & $-324.40 \%$ \\
\hline TC8 & 0.03 & 0.03 & $93.85 \%$ \\
\hline TC9 & 0.05 & 0.02 & $44.22 \%$ \\
\hline TC10 & 0.07 & 0.07 & $95.95 \%$ \\
\hline TC11 & 0.25 & 0.40 & $161.44 \%$ \\
\hline TC12 & 0.09 & 0.18 & $206.41 \%$ \\
\hline TC13 & 0.13 & 0.02 & $11.99 \%$ \\
\hline
\end{tabular}

Coefficients of variation in rural and urban sites show lower values at the truck classes 4 and 13, similar finding reported in the previous analyses.

\subsubsection{Truck Groups: Single-Unit and Multi-Unit (4-7, 8-13)}

Truck classifications were grouped according to the number of axles: one single unit (4-7 vehicle classes) and multi-unit axle (8-13 vehicle classes). This analysis was conducted to better understand patterns of trucks traveling on interstate highways and to reduce the coefficient of variation in the models performed. These calculations were performed on all, rural and urban interstate highways. 


\section{a) All Interstates}

Table 4.16 shows growth rates for two groups of truck classification, single/multiunit axles. These rates were calculated using the AADTT of each group of truck classification. For example, in one site, the AADTTs between truck classifications 4 to 7 were added to obtain the AADTT for the single-unit group (TC4-TC7). After the AADTT for each site and group was determined, linear regression was performed to calculate the growth rates, dividing the slope by the estimate year 2003. A similar procedure was conducted for multi-unit trucks (TC8-TC13).

Table 4.16-Annual Average Growth Rates for Single and Multi-Unit Trucks for Each Site-All Interstates

\begin{tabular}{|c|r|r|r|r|r|r|r|r|}
\hline $\begin{array}{c}\text { Truck } \\
\text { Class }\end{array}$ & \multicolumn{1}{c|}{ Site01 } & \multicolumn{1}{c|}{ Site05 } & \multicolumn{1}{c|}{ Site26 } & \multicolumn{1}{c|}{ Site29 } & \multicolumn{1}{c|}{ Site42 } & \multicolumn{1}{c|}{ Site47 } & \multicolumn{1}{c|}{ Site50 } & \multicolumn{1}{c|}{ Site53 } \\
\hline TC4-TC7 & $-6.64 \%$ & $2.79 \%$ & $3.20 \%$ & $1.88 \%$ & $7.37 \%$ & $8.89 \%$ & $10.93 \%$ & $7.73 \%$ \\
\hline TC8-TC13 & $-15.54 \%$ & $2.63 \%$ & $3.97 \%$ & $2.57 \%$ & $7.82 \%$ & $0.19 \%$ & $9.73 \%$ & $6.30 \%$ \\
\hline
\end{tabular}

Table 4.16 shows negative growth rates in Site01, as reported in the previous analyses the highest negative growth rate of $-15 \%$ belongs to the heavy truck group, and a large dispersion in growth rates in both groups is found, between $-15 \%$ and $11 \%$.

\section{Annual Average Growth Rate Weighted}

AADTTs from single and multi-unit trucks were used to determine the weight factors. This is a similar analysis to perform with all, rural or urban site groups. The weight factor was the AADTT for one site in a group (e.g. single-unit) divided by the total sum of AADTT for all sites in the same group. Table 4.17 shows the weight factors. 
Table 4.17-Weight Table and Annual Average Growth Rate Weighted for Single and Multi-Unit Truck-All Interstates

\begin{tabular}{|c|c|c|c|c|c|c|c|c|c|}
\hline $\begin{array}{c}\text { Truck } \\
\text { Class }\end{array}$ & Site01 & Site05 & Site26 & Site29 & Site42 & Site47 & Site50 & Site53 & $\begin{array}{c}\text { Class-Weighted } \\
\text { Annual Average } \\
\text { Growth Rate - (all) }\end{array}$ \\
\hline TC4-TC7 & -0.004 & 0.003 & 0.006 & 0.003 & 0.012 & 0.009 & 0.019 & 0.004 & $5.12 \%$ \\
\hline TC8-TC13 & -0.007 & 0.002 & 0.005 & 0.006 & 0.011 & 0.000 & 0.022 & 0.003 & $4.32 \%$ \\
\hline
\end{tabular}

The annual average growth rates weighted for single and multi-unit trucks shown in Table 4.17 are smaller than those obtained in the previous analyses. These growth rates, around $4 \%$ are somewhat similar to the common growth rates used by DOTs for interstate highways.

\section{Precision Analysis}

The precision analysis was conducted based on annual average growth rates from single and multi-unit trucks on all interstate highways in West Virginia shown in Table 4.16. The coefficient of variation as previously mentioned measures the variation of growth rates from the mean in a group analyzed, in this case for the light (single-unit) and heavy truck (multi-unit) vehicle groups.

Table 4.18-AADTT for Each Truck Group (Single/Multi-Unit) and Coefficient of Variation in Every Site-All Interstates

\begin{tabular}{|c|c|c|c|}
\hline $\begin{array}{c}\text { Truck } \\
\text { Class }\end{array}$ & Mean & St. dev. & $\begin{array}{c}\text { Coefficient } \\
\text { of } \\
\text { Variation }\end{array}$ \\
\hline TC4-TC7 & 0.045 & 0.055 & $122.56 \%$ \\
\hline TC8-TC13 & 0.022 & 0.078 & $353.54 \%$ \\
\hline
\end{tabular}

As in the previous analyses, high values of coefficient of variation were found.

This is due to the considerable difference between the growth rates in this group 
analyzed, differences between growth rates from $2 \%$ to $10 \%$, and the negative growth rate value in Site 01 (around 7\%) generated high coefficients of variation.

\section{b) Rural Interstates}

Similar to the previous analyses, the analysis for rural and urban interstate highways was conducted. Table 4.19 shows annual average growth rate weighted for each truck group in rural interstate highways.

\section{Table 4.19-Weight Table and Annual Average Growth Rate Weighted for Single and Multi-Unit Truck-Rural Interstates}

\begin{tabular}{|c|c|c|c|c|c|c|}
\hline Truck Class & Site01 & Site05 & Site47 & Site50 & Site53 & $\begin{array}{c}\text { Class-Weighted } \\
\text { Annual Average } \\
\text { Growth Rate - (rural) }\end{array}$ \\
\hline TC4-TC7 & 0.136 & 0.201 & 0.202 & 0.364 & 0.097 & $6.18 \%$ \\
\hline TC8-TC13 & 0.097 & 0.177 & 0.154 & 0.477 & 0.095 & $4.24 \%$ \\
\hline
\end{tabular}

Somewhat similar growth factors were found in this analysis than the previous one with growth rates between $4 \%$ and $6 \%$ and higher growth rate for single-unit trucks than heavy trucks in rural interstates.

\section{Precision Analysis}

Precision analysis was conducted based on annual average growth rates from rural interstate highways in West Virginia shown in Table 4.16. These sites were used: Site 01, Site 05, Site 47, Site 50, and Site 53. 
Table 4.20-AADTT for Each Truck Group (Single/Multi-Unit) and Coefficient of Variation in Every Site-Rural Interstates

\begin{tabular}{|c|c|c|c|}
\hline Truck Class & Mean & St. dev. & $\begin{array}{c}\text { Coefficient of } \\
\text { Variation }\end{array}$ \\
\hline TC4-TC7 & 0.047 & 0.070 & $148.28 \%$ \\
\hline TC8-TC13 & 0.007 & 0.098 & $1471.56 \%$ \\
\hline
\end{tabular}

Coefficients of variation are high due to the large difference among growth rates in these sites from $-15 \%$ to $10 \%$.

\section{c) Urban Interstates}

Like the rural analysis, a similar one was conducted to urban sites. Table 4.21 shows annual average growth rates for single and multi-unit truck in urban interstate highways.

Table 4.21 - Weight Table and Annual Average Growth Rate Weighted for Single and Multi-Unit Truck—Urban Interstates

\begin{tabular}{|c|c|c|c|c|}
\hline Truck Class & Site26 & Site29 & Site42 & $\begin{array}{c}\text { Class-Weighted } \\
\text { Annual Average } \\
\text { Growth Rate - (urban) }\end{array}$ \\
\hline TC4-TC7 & 0.345 & 0.330 & 0.326 & $4.12 \%$ \\
\hline TC8-TC13 & 0.244 & 0.474 & 0.282 & $4.39 \%$ \\
\hline
\end{tabular}

Both groups, single and multi-unit trucks in urban interstates highways have similar growth rates around $4 \%$. These growth rates seem to be reasonable growth rates for both classes based on the common truck traffic growth rates used by DOT for interstate highways in the US. In addition, opposite to rural interstates, the annual growth rate weighted for heavy truck classes is higher than the light or single-unit truck vehicles. 


\section{Precision Analysis}

Precision analysis was conducted based on annual average growth rates from rural interstate highways in West Virginia shown in Table 4.16. These sites were used: Site 01, Site 26, Site 29, and Site 42.

\section{Table 4.22-AADTT for Each Truck Group (Single/Multi-Unit) and Coefficient of Variation in Every Site-Urban Interstates}

\begin{tabular}{|c|c|c|c|}
\hline Truck Class & Mean & St. dev. & $\begin{array}{c}\text { Coefficient of } \\
\text { variation }\end{array}$ \\
\hline TC4-TC7 & 0.042 & 0.029 & $69.08 \%$ \\
\hline TC8-TC13 & 0.048 & 0.027 & $56.74 \%$ \\
\hline
\end{tabular}

Table 4.22 shows lower values of CVs for single and multi-unit axles due to the fact that Site01 is not included. Models in these groups are the most reliable to predict future truck traffic volume. Truck traffic volume is increasing around $4.0 \%$ in single and multi-unit trucks.

\subsubsection{Linear Regression Analysis using Year Averaged AADTTs}

\subsubsection{Analysis for Sites}

Linear regression analysis was conducted using the average of AADTT for all sites in one year. In other words, AADTTs for all sites for the same year were averaged. For example, AADTTs for the year 1995 in all sites (Site01, Site05,...Site53) were averaged to obtain only one AADTT for this year, "1995". A similar procedure was conducted for the rest of the years. Therefore, nine AADTTs were obtained, one for each year, and then these values were plotted in a graph to determine their linear trend. The growth rate was determined by the slope and the estimated AADTT for the year 2003. 


\section{a) All Interstates}

Figure 4.1 shows the plot of AADTTs in a graph and their trend (linear curve).

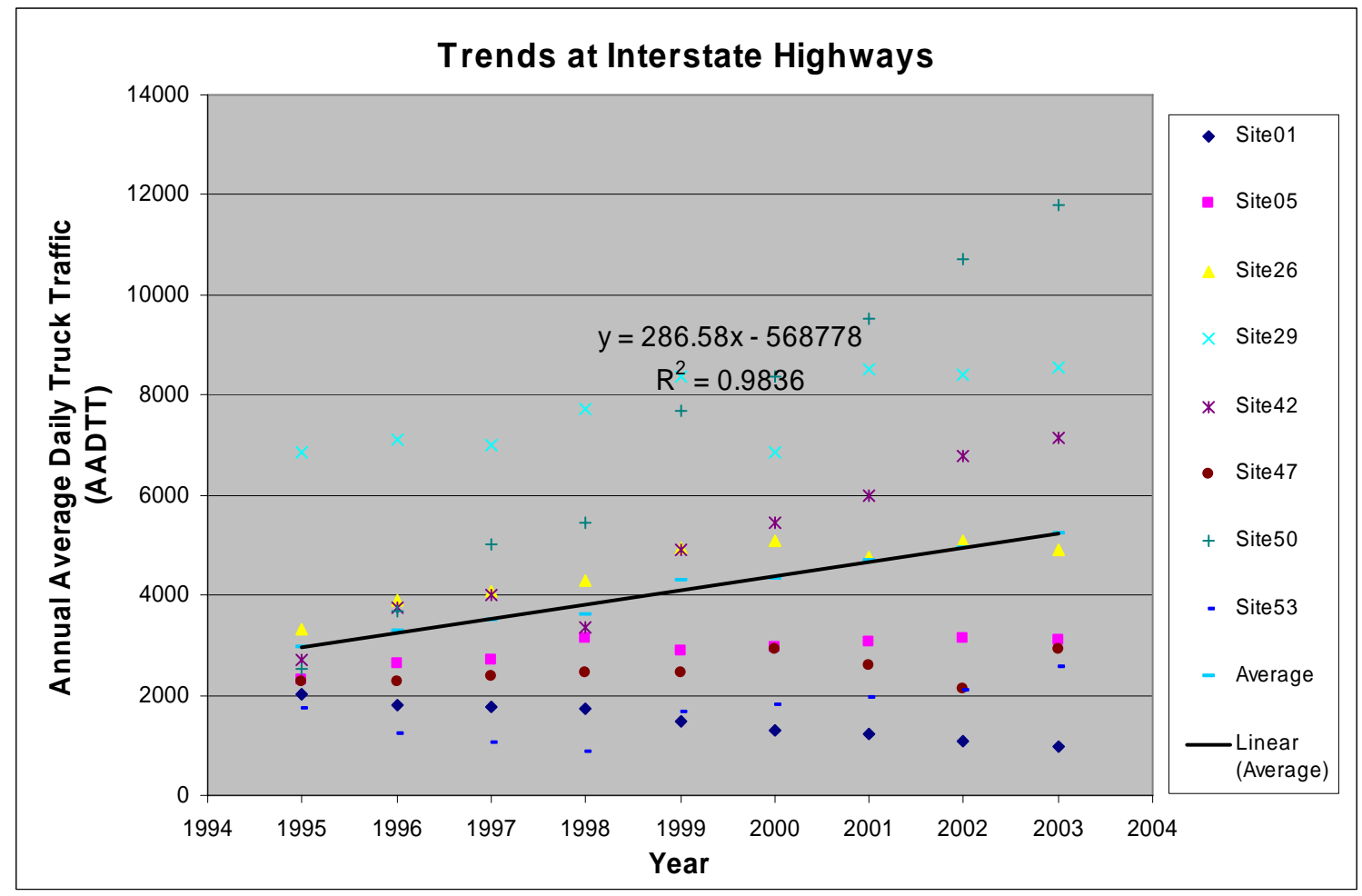

Figure 4.1—Trends at All Interstate Highways

(Equation 4.1)

$$
A A D T T=286.58 \times \text { year }-568778
$$

\begin{tabular}{|c|c|c|c|}
\hline Slope & Intercept & Estimate 2003 & Overall Growth Rate \\
\hline 286.58 & -568778 & 5248 & $\mathbf{5 . 4 6 \%}$ \\
\hline
\end{tabular}

Equation 4.1 could be used to estimate future truck traffic at interstate highways based on the AADTT year averaged. This is a reliable model based on its high coefficient of regression, around 1.0. Also, based on this model, from the slope and the AADTT predicted to the year 2003, an overall growth rate is estimated to be $5.46 \%$. 


\section{b) Rural Interstates}

Separate analysis for rural and urban interstate highways was conducted. Figure

4.2 shows the results for rural sites: Site01, Site05, Site47, Site50, and Site53.

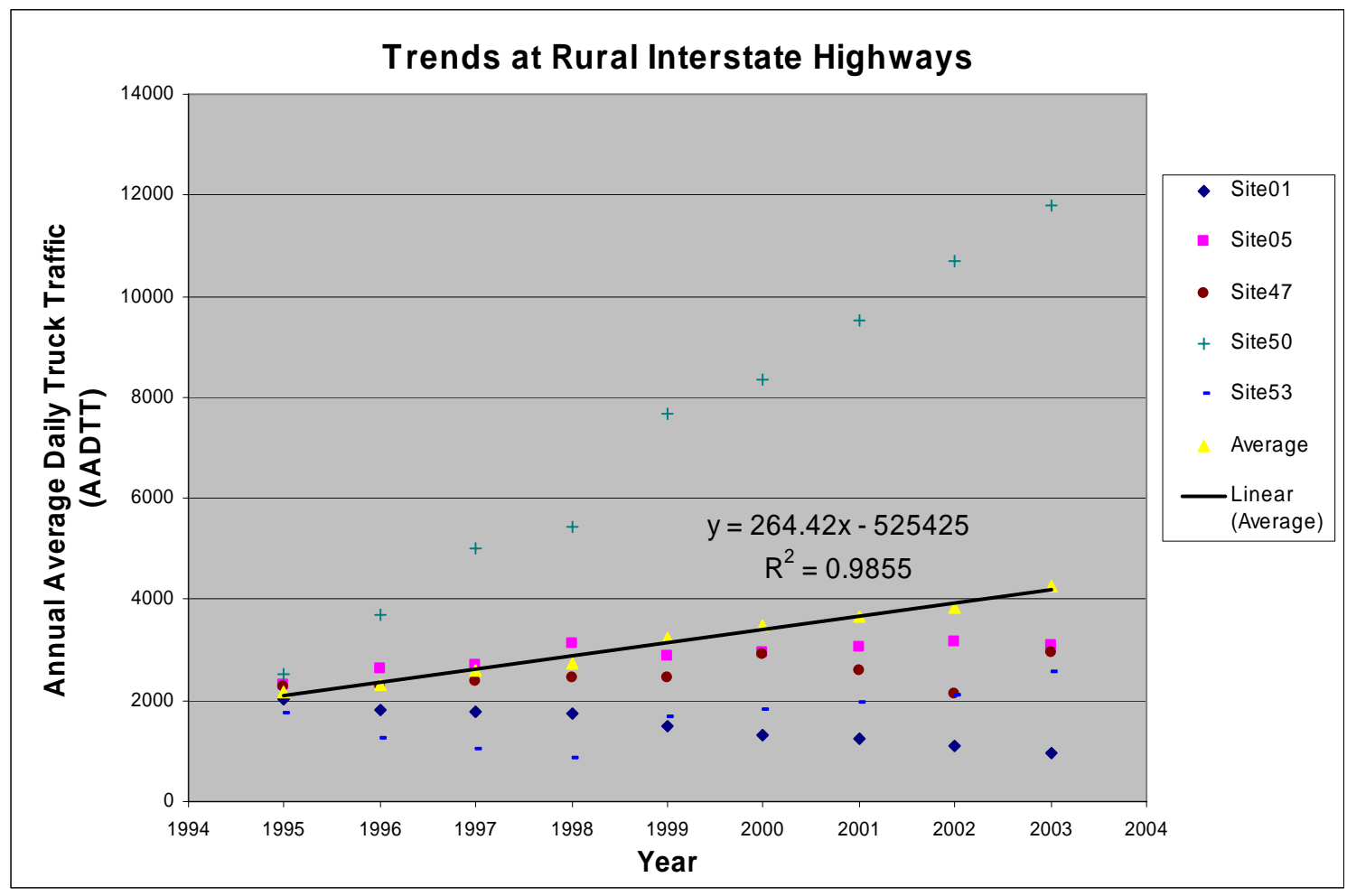

Figure 4.2-Trends at Rural Interstate Highways

(Equation 4.2)

$$
A A D T T=264.42 \times \text { year }-525425
$$

\begin{tabular}{|c|c|c|c|}
\hline Slope & Intercept & Estimate 2003 & Overall Growth Rate \\
\hline 264.42 & -525425 & 4201 & $\mathbf{6 . 2 9 \%}$ \\
\hline
\end{tabular}

Equation 4.2 was developed using the year averaged from rural sites. Based on this model, an overall growth rate was estimated to $6.29 \%$. 


\section{c) Urban Interstates}

Figure 4.3 shows the analysis for rural sites: Site26, Site29, and Site42.

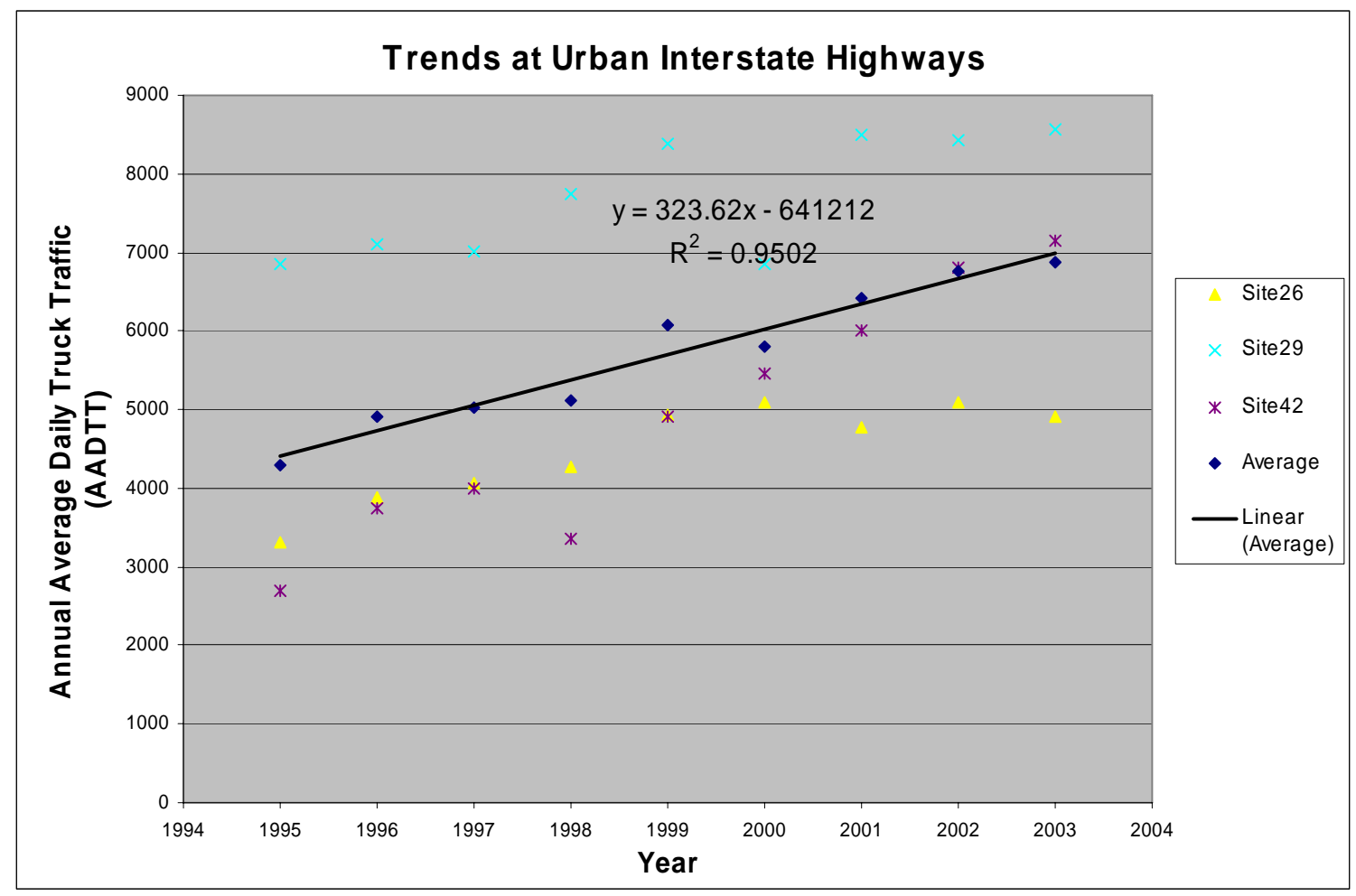

Figure 4.3-Trends at Urban Interstate Highways

(Equation 4.3)

$$
A A D T T=323.62 \times \text { year }-641212
$$

\begin{tabular}{|c|c|c|c|}
\hline Slope & Intercept & Estimate 2003 & Overall Growth Rate \\
\hline 323.62 & -641212 & 6992 & $\mathbf{4 . 6 3 \%}$ \\
\hline
\end{tabular}

Similar to the previous analysis, Equation 4.3 was developed and an overall growth rate estimated. Most reliable models were found using AADTT year averaged based on their coefficient of regression around one. Slight variations among overall growth rates were present, obtaining growth rate values between $4 \%$ and $6 \%$ in the three last analyses. 


\subsubsection{Analysis for Each Truck Classification}

Similar to the analysis for sites, a study for each truck classification was conducted. In this analysis, AADTTs for the same year and truck class were averaged. For example, the AADTTs for truck class four (TC4) for Site01, Site05.....Site53 from the year 1995 were averaged; thus, one AADTT for TC4 from this year (1995) was obtained. A similar analysis was conducted for the rest of the years. Therefore, for TC4, nine AADTTs were estimated and plotted in a graph to analyze the trend of the AADTTs in this truck classification in the course of the years. The following tables show regression models conducted for all of the sites in the study, rural and urban sites, as well as the analysis for single and multi-unit axle groups.

\section{a) All Interstates}

Similar to the analysis for sites, the average of the AADTTs for each truck class for all the sites for the same year was taken in order to develop a model for each truck class. These models and their coefficients of regression are shown in Table 4.23. 
Table 4.23-Linear Regression Models, Growth Rates and Coefficient of Regression $\left(R^{2}\right)$ for Each Truck Classification-All Interstate Highways

\begin{tabular}{|c|l|c|c|}
\hline Truck Class & \multicolumn{1}{|c|}{ Model } & $\begin{array}{c}\text { Overall Growth } \\
\text { Rate }\end{array}$ & $\mathbf{R}^{2}$ \\
\hline TC4 & Y=6X-12712 & $8.59 \%$ & 0.82 \\
\hline TC5 & Y=30X-59242 & $6.67 \%$ & 0.84 \\
\hline TC6 & Y=8X-16348 & $4.66 \%$ & 0.38 \\
\hline TC7 & Y=-0.12X+252 & $-0.64 \%$ & 0.01 \\
\hline TC8 & Y=15X-30170 & $5.51 \%$ & 0.68 \\
\hline TC9 & Y=342X-680161 & $6.89 \%$ & 0.66 \\
\hline TC10 & Y=10X-20358 & $9.65 \%$ & 0.66 \\
\hline TC11 & $\mathrm{Y}=52 \mathrm{X}-104051$ & $10.32 \%$ & 0.78 \\
\hline TC12 & $\mathrm{Y}=8 \mathrm{X}-15151$ & $10.61 \%$ & 0.83 \\
\hline TC13 & $\mathrm{Y}=11 \mathrm{X}-22612$ & $12.80 \%$ & 0.77 \\
\hline
\end{tabular}

Truck class 6 and 7 presents poor coefficients of regression on their models.

Therefore, these models should be use with caution. The low coefficients of regression is due to the large negative growth rate values in these truck classes in Site01, generating large differences between the mean of these truck classes compared to the rest.

\section{Truck Groups: Sinqle-Unit and Multi-Unit (4-7, 8-13)}

Analysis for single and multi-unit truck groups were performed using the sum of the average of the AADTTs from truck class 4 to class 7 and class 8 to class 13 for the same year was taken. Therefore, Average of AADDT for single and multi-unit trucks was obtained for the years in the study. Table 4.24 shows linear regression, the overall growth rate, which was based on the slope and the estimated year 2003, and the coefficient of regression for single and multi-unit truck groups. 
Table 4.24-Linear Regression Models, Growth Rates and Coefficient of Regression $\left(R^{2}\right)$ for Each Truck Classification-Single/Multi-Unit Trucks (All Interstates)

\begin{tabular}{|c|c|c|c|}
\hline Truck Class & Model & $\begin{array}{c}\text { Overall Growth } \\
\text { Rate }\end{array}$ & $\mathbf{R}^{2}$ \\
\hline TC4-TC7 & Y=44X-88050 & $6.19 \%$ & 0.77 \\
\hline TC8-TC13 & Y=352X-700272 & $6.46 \%$ & 0.62 \\
\hline
\end{tabular}

The impact of the negative growth rates from class 6 and 7 is lower in the above analysis. Single and multi-unit trucks show coefficients of regression of 0.77 and 0.62 , respectively, and similar positive growth rates around $6 \%$.

\section{b) Rural Interstates}

This analysis was conducted using the AADTTs from rural sites, they were averaged and plotted in order to develop their models. The models and coefficient of regression are shown in the following table.

Table 4.25-Linear Regression Models, Growth Rates and Coefficient of Regression $\left(R^{2}\right)$ for Each Truck Classification-Rural Interstate Highways

\begin{tabular}{|c|c|c|c|}
\hline Truck Class & Model & $\begin{array}{c}\text { Overall } \\
\text { Growth Rate }\end{array}$ & $\mathbf{R}^{\mathbf{2}}$ \\
\hline TC4 & Y=7X-13466 & $9.90 \%$ & 0.80 \\
\hline TC5 & Y=31X-60932 & $8.33 \%$ & 0.73 \\
\hline TC6 & Y=5X-9675 & $4.62 \%$ & 0.21 \\
\hline TC7 & Y=-0.05X+124 & $-0.35 \%$ & 0.00 \\
\hline TC8 & Y=14X-27004 & $6.54 \%$ & 0.46 \\
\hline TC9 & Y=207X-411461 & $6.37 \%$ & 0.31 \\
\hline TC10 & $\mathrm{Y}=6 \mathrm{X}-11092$ & $11.01 \%$ & 0.56 \\
\hline TC11 & $\mathrm{Y}=64 \mathrm{X}-128451$ & $11.87 \%$ & 0.77 \\
\hline TC12 & $\mathrm{Y}=9 \mathrm{X}-18751$ & $12.21 \%$ & 0.75 \\
\hline TC13 & $\mathrm{Y}=4 \mathrm{X}-7547$ & $11.79 \%$ & 0.91 \\
\hline
\end{tabular}


Table 4.25 shows small coefficients of regression from truck class 6 through 9 . The worst coefficient of regression (equal to zero) belongs to class 7 . Therefore, this model should not be used to estimate truck traffic volume.

\section{Truck Groups: Sinqle-Unit and Multi-Unit (4-7, 8-13)}

Analysis for single and multi-unit truck groups were performed using AADTTs for rural sites. Similar to the all interstates analysis the sum of the average of the AADTTs from truck class 4 to class 7 and class 8 to class 13 for the same year was taken. Table 4.26 shows the regression models for both groups and their growth rate based in the slope and the estimated year 2003.

Table 4.26-Linear Regression Models, Growth Rates and Coefficient of Regression $\left(R^{2}\right)$ for Each Truck Classification-Single/Multi-Unit Trucks (Rural Interstates)

\begin{tabular}{|c|c|c|c|}
\hline Truck Class & Model & $\begin{array}{c}\text { Overall } \\
\text { Growth Rate }\end{array}$ & $\mathbf{R}^{2}$ \\
\hline TC4-TC7 & $\mathrm{Y}=42 \mathrm{X}-83948$ & $7.58 \%$ & 0.66 \\
\hline TC8-TC13 & $\mathrm{Y}=215 \mathrm{X}-427859$ & $6.00 \%$ & 0.27 \\
\hline
\end{tabular}

The single-unit truck group seems to be the most reliable even though it includes class 6 and 7, which have the lowest coefficients of regression in previous analyses.

\section{c) Urban Interstates}

Similar to rural sites, this analysis was conducted using the AADTTs from urban sites; they were averaged in order to develop models for each truck class. Models and coefficient of regression are shown in the following table. 
Table 4.27-Linear Regression Models, Growth Rates and Coefficient of Regression $\left(R^{2}\right)$ for Each Truck Classification-Urban Interstate Highways

\begin{tabular}{|c|c|c|c|}
\hline Truck Class & Model & $\begin{array}{c}\text { Overall } \\
\text { Growth Rate }\end{array}$ & $\mathbf{R}^{\mathbf{2}}$ \\
\hline TC4 & $\mathrm{Y}=6 \mathrm{X}-11936$ & $7.34 \%$ & 0.71 \\
\hline TC5 & $\mathrm{Y}=22 \mathrm{X}-44500$ & $4.49 \%$ & 0.84 \\
\hline TC6 & $\mathrm{Y}=6 \mathrm{X}-12197$ & $2.80 \%$ & 0.45 \\
\hline TC7 & $\mathrm{Y}=-0.37 \mathrm{X}+754$ & $-1.84 \%$ & 0.04 \\
\hline TC8 & $\mathrm{Y}=12 \mathrm{X}-24410$ & $3.77 \%$ & 0.66 \\
\hline TC9 & $\mathrm{Y}=379 \mathrm{X}-753172$ & $6.18 \%$ & 0.82 \\
\hline TC10 & $\mathrm{Y}=11 \mathrm{X}-21791$ & $7.75 \%$ & 0.57 \\
\hline TC11 & $\mathrm{Y}=49 \mathrm{X}-98213$ & $9.21 \%$ & 0.49 \\
\hline TC12 & $\mathrm{Y}=7 \mathrm{X}-13746$ & $9.22 \%$ & 0.53 \\
\hline TC13 & $\mathrm{Y}=17 \mathrm{X}-34086$ & $12.96 \%$ & 0.87 \\
\hline
\end{tabular}

Table 4.27 shows better coefficients of regression than previous analyses; however, class 7 still carries a poor coefficient of regression, around zero.

\section{Truck Groups: Single-Unit and Multi-Unit (4-7, 8-13)}

Analysis for single and multi-unit truck groups were performed using AADTTs for urban sites. Similar to the rural interstates analysis the sum of the average of the AADTTs from truck class 4 to class 7 and class 8 to class 13 for the same year was taken. Table 4.26 shows the regression models for both groups and their growth rate based in the slope and the estimated year 2003.

Table 4.28-Linear Regression Models, Growth Rates and Coefficient of Regression $\left(R^{2}\right)$ for Each Truck Classification-Single/Multi-Unit Trucks (Urban Interstates)

\begin{tabular}{|c|c|c|c|}
\hline Truck Class & Model & $\begin{array}{c}\text { Overall } \\
\text { Growth Rate }\end{array}$ & $\mathbf{R}^{2}$ \\
\hline TC4-TC7 & Y=34X-67879 & $4.17 \%$ & 0.80 \\
\hline TC8-TC13 & Y=383X-761144 & $5.69 \%$ & 0.78 \\
\hline
\end{tabular}


Final conclusions from previous analyses are described below:

$>$ Urban sites are the most reliable group to be predicted.

Truck classes 6 through 9 display the lowest coefficient of regression on rural sites; however, growth rates on these classes can be used to further understand some changes on truck travel patterns.

Heavy truck traffic showed similar overall growth rates in all the three analyses performed: all, rural and urban interstates. Most of these similar growths are from class 10 to class 13 , which includes six or more axle single trailers through multi trailer consisting of three or more units.

Truck class 7 showed to be the worst model based on its coefficient of regression equal to zero. 


\subsection{Growth Factor}

Since the most important information is the most recent traffic counts, current growth rates were estimated for every site and for each truck classification. These rates were calculated using the last two years of data available with at least one year gap between them. The analysis for Sites in all, rural and urban interstate highways is reported in this chapter, and the analysis by each truck class and truck groups is documented in the Appendix D.

\subsubsection{Analysis for Sites}

\section{a) All Interstates}

Truck traffic growth rates and weight factors were estimated for all interstate highways using the growth factor method explained in Chapter 3. Table 4.29 shows truck traffic growth rates in all sites and their respective weight factors.

Table 4.29-Average Annual Growth Rates Weighted and Coefficient of Variation (CV) for Each Site-All Interstates

\begin{tabular}{|c|c|c|c|c|c|}
\hline Route & Class & Site & Growth Rate & $\begin{array}{c}\text { Sum of trucks in the } \\
\text { two years analyzed }\end{array}$ & weight/site \\
\hline I-64 & Rural & SITE 01 & $-13.35 \%$ & 3029 & 0.040 \\
\hline I-79 & Rural & SITE 05 & $-0.30 \%$ & 6225 & 0.083 \\
\hline I-64 & Urban & SITE 26 & $1.54 \%$ & 9676 & 0.129 \\
\hline I-70 & Urban & SITE 29 & $0.35 \%$ & 17065 & 0.227 \\
\hline I-64 & Urban & SITE 42 & $16.32 \%$ & 10508 & 0.140 \\
\hline I-77 & Rural & SITE 47 & $0.09 \%$ & 5864 & 0.078 \\
\hline I-81 & Rural & SITE 50 & $11.38 \%$ & 19475 & 0.259 \\
\hline I-68 & Rural & SITE 53 & $24.45 \%$ & 3439 & 0.046 \\
\hline
\end{tabular}

\begin{tabular}{|c|c|}
\hline $\begin{array}{c}\text { Class-Weighted } \\
\text { Average annual } \\
\text { growth rate - (all) }\end{array}$ & $6.06 \%$ \\
\hline
\end{tabular}

\begin{tabular}{|c|c|}
\hline Mean & $5.06 \%$ \\
\hline St. dev. & $11.77 \%$ \\
\hline $\begin{array}{c}\text { Coefficient of } \\
\text { variation }\end{array}$ & $\mathbf{2 3 2 . 5 9 \%}$ \\
\hline
\end{tabular}


The annual average growth rate weighted in Table 4.29 is higher than that obtained in the linear regression analysis. This is due to the large difference between the most current AADTTs, which were used to estimate the growth rate for each site. However, the coefficient of variation is somewhat similar to the regression analysis, which is a large value.

\section{b) Rural Interstates}

This analysis is similar to all interstate sites. Results are shown in table 4.30.

Table 4.30-Average Annual Growth Rates Weighted and Coefficient of Variation (CV) for Each Site-Rural Interstates

\begin{tabular}{|c|c|c|c|c|c|}
\hline Route & Class & Site & Growth Rate & $\begin{array}{c}\text { Sum of trucks in the two } \\
\text { years analyzed }\end{array}$ & weight/site \\
\hline I-64 & Rural & SITE 01 & $-13.35 \%$ & 3029 & 0.080 \\
\hline I-79 & Rural & SITE 05 & $-0.30 \%$ & 6225 & 0.164 \\
\hline I-77 & Rural & SITE 47 & $0.09 \%$ & 5864 & 0.154 \\
\hline I-81 & Rural & SITE 50 & $11.38 \%$ & 19475 & 0.512 \\
\hline I-68 & Rural & SITE 53 & $24.45 \%$ & 3439 & 0.090 \\
\hline
\end{tabular}

The annual average growth rate weighted in rural interstates is higher than the linear regression analysis; however, the coefficient of variation is somewhat similar to the linear regression analysis. 


\section{c) Urban Interstates}

Truck traffic growth rates and weight factors were estimated for urban interstate highways. Table 4.31 shows truck traffic growth rates in all sites and their respective weight factors.

Table 4.31-Average Annual Growth Rates Weighted and Coefficient of Variation (CV) for Each Site-Urban Interstates

\begin{tabular}{|c|c|c|c|c|c|}
\hline Route & Class & Site & Growth Rate & $\begin{array}{c}\text { Sum of trucks in the two } \\
\text { years analyzed }\end{array}$ & weight/site \\
\hline I-64 & Urban & SITE 26 & $1.54 \%$ & 9676 & 0.260 \\
\hline I-70 & Urban & SITE 29 & $0.35 \%$ & 17065 & 0.458 \\
\hline I-64 & Urban & SITE 42 & $16.32 \%$ & 10508 & 0.282 \\
\hline
\end{tabular}

\begin{tabular}{|c|c|}
\hline $\begin{array}{c}\text { Class-Weighted } \\
\text { Average annual } \\
\text { growth rate - (urban) }\end{array}$ & $5.16 \%$ \\
\hline
\end{tabular}

\begin{tabular}{|c|c|}
\hline Mean & $6.07 \%$ \\
\hline St. dev. & $8.90 \%$ \\
\hline $\begin{array}{c}\text { Coefficient of } \\
\text { variation }\end{array}$ & $\mathbf{1 4 6 . 6 0 \%}$ \\
\hline
\end{tabular}

As in the previous analysis the annual average growth rate weighted in urban interstates is higher than the linear regression analysis; however, the coefficients of variation in both analyses are high and display a slight variation. 


\subsection{Summary: Comparison among Annual Average Growth Rates}

\subsubsection{Annual Average Growth Rate for All, Rural and Urban Interstate Highways}

Table 4.32 shows that interstate highways on rural areas in West Virginia area increasing at a higher rate than urban areas. Also, the annual average growth rates in the three analyses are between $4.37 \%$ and $6.94 \%$; therefore, an overall growth rate can be established to be $5.00 \%$.

Table 4.32-Comparison of Annual Average Growth Rates (Weighted Average, Year Average Analysis and Growth Factor)

\begin{tabular}{|c|c|c|c|}
\hline \multirow{2}{*}{} & \multicolumn{3}{|c|}{ Annual Average Daily Truck Traffic Growth Rate } \\
\cline { 2 - 4 } & $\begin{array}{c}\text { Linear Regression } \\
\text { (weighted average) }\end{array}$ & $\begin{array}{c}\text { Overall } \\
\text { (Linear Regression) }\end{array}$ & Growth Factor \\
\hline All & $4.52 \%$ & $5.46 \%$ & $6.06 \%$ \\
\hline Rural & $4.69 \%$ & $6.29 \%$ & $6.94 \%$ \\
\hline Urban & $4.37 \%$ & $4.63 \%$ & $5.16 \%$ \\
\hline
\end{tabular}

It is important to note that annual average growth rates weighted in the growth factor method analysis are higher than the one performed by regression analysis; however, the coefficients of variation in both analyses are high and displayed a slight variation. 


\subsubsection{Analysis for Each Truck Classification}

Results from the analyses of truck classes in this study for all interstate highways were compared. Two linear regression analyses were conducted, using AADTTs and the year averaged of AADTTs. Results from linear regression and the growth factor method were compared and are documented in the following table:

Table 4.33-Comparison of Annual Average Growth Rate- All Interstate Highways

\begin{tabular}{|c|c|c|c|}
\hline \multirow{2}{*}{ ALL } & \multicolumn{4}{|c|}{ Annual Average Daily Truck Traffic Growth Rate } \\
\cline { 2 - 4 } & $\begin{array}{c}\text { Linear Regression } \\
\text { (weighted average) }\end{array}$ & $\begin{array}{c}\text { Overall } \\
\text { (Linear Regression) }\end{array}$ & Growth Factor \\
\hline TC4 & $8.31 \%$ & $8.59 \%$ & $15.44 \%$ \\
\hline TC5 & $5.66 \%$ & $6.67 \%$ & $10.81 \%$ \\
\hline TC6 & $0.72 \%$ & $4.66 \%$ & $8.76 \%$ \\
\hline TC7 & $-2.17 \%$ & $-0.64 \%$ & $11.55 \%$ \\
\hline TC8 & $3.99 \%$ & $5.51 \%$ & $8.79 \%$ \\
\hline TC9 & $4.89 \%$ & $6.89 \%$ & $6.05 \%$ \\
\hline TC10 & $8.08 \%$ & $9.65 \%$ & $23.34 \%$ \\
\hline TC11 & $10.92 \%$ & $10.32 \%$ & $4.14 \%$ \\
\hline TC12 & $6.30 \%$ & $10.61 \%$ & $6.43 \%$ \\
\hline TC13 & $12.88 \%$ & $12.80 \%$ & $20.49 \%$ \\
\hline
\end{tabular}

Truck class 9, which includes five-axle single trailer trucks consisting of two units, one of which is a tractor or straight truck power unit, seems to be the most stable truck class vehicle on interstate highways in West Virginia. Similar to the above table, results from rural sites were compared, and are reported in Table 4.34. 
Table 4.34-Comparison of Annual Average Growth Rates- Rural Interstate Highways

\begin{tabular}{|c|c|c|c|}
\hline \multirow{2}{*}{ Rural } & \multicolumn{4}{|c|}{ Annual Average Daily Truck Traffic Growth Rate } \\
\cline { 2 - 4 } & $\begin{array}{c}\text { Linear Regression } \\
\text { (weighted average) }\end{array}$ & $\begin{array}{c}\text { Overall } \\
\text { (Linear Regression) }\end{array}$ & Growth Factor \\
\hline TC4 & $9.89 \%$ & $9.90 \%$ & $9.66 \%$ \\
\hline TC5 & $6.86 \%$ & $8.33 \%$ & $12.04 \%$ \\
\hline TC6 & $-1.98 \%$ & $4.62 \%$ & $10.18 \%$ \\
\hline TC7 & $-1.33 \%$ & $-0.35 \%$ & $11.82 \%$ \\
\hline TC8 & $4.40 \%$ & $6.54 \%$ & $7.17 \%$ \\
\hline TC9 & $4.71 \%$ & $6.37 \%$ & $7.90 \%$ \\
\hline TC10 & $9.11 \%$ & $11.01 \%$ & $39.95 \%$ \\
\hline TC11 & $7.60 \%$ & $11.87 \%$ & $13.11 \%$ \\
\hline TC12 & $6.14 \%$ & $12.21 \%$ & $20.01 \%$ \\
\hline TC13 & $12.56 \%$ & $11.79 \%$ & $22.48 \%$ \\
\hline
\end{tabular}

Truck class 4, which includes buses, all vehicles manufactured as traditional passenger-carrying buses with two axles and six tires or three or more axles, displays the most constant growth rates in rural interstate highways. Table 4.34 shows truck class 4 growing at an overall rate of $10 \%$. Similar comparison for urban highways is shown below in Table 4.35 .

Table 4.35-Comparison of Annual Average Growth Rates- Urban Interstate Highways

\begin{tabular}{|c|c|c|c|}
\hline \multirow{2}{*}{ Urban } & \multicolumn{4}{|c|}{ Annual Average Daily Truck Traffic Growth Rate } \\
\cline { 2 - 4 } & $\begin{array}{c}\text { Linear Regression } \\
\text { (weighted average) }\end{array}$ & $\begin{array}{c}\text { Overall } \\
\text { (Linear Regression) }\end{array}$ & Growth Factor \\
\hline TC4 & $6.44 \%$ & $7.34 \%$ & $22.50 \%$ \\
\hline TC5 & $4.48 \%$ & $4.49 \%$ & $9.55 \%$ \\
\hline TC6 & $2.80 \%$ & $2.80 \%$ & $7.54 \%$ \\
\hline TC7 & $-2.98 \%$ & $-1.84 \%$ & $11.15 \%$ \\
\hline TC8 & $3.62 \%$ & $3.77 \%$ & $10.33 \%$ \\
\hline TC9 & $5.06 \%$ & $6.18 \%$ & $4.15 \%$ \\
\hline TC10 & $7.55 \%$ & $7.75 \%$ & $13.33 \%$ \\
\hline TC11 & $14.11 \%$ & $9.21 \%$ & $-5.53 \%$ \\
\hline TC12 & $6.46 \%$ & $9.22 \%$ & $-7.80 \%$ \\
\hline TC13 & $13.01 \%$ & $12.96 \%$ & $19.76 \%$ \\
\hline
\end{tabular}


Truck class 9 is the most stable truck class vehicle on urban interstate highways in West Virginia, growing at an overall rate of 5\%. As a general comment, results for Truck class 7 from all, rural and urban interstate highways displayed large disparity among growth rates. Also, in the regression analysis truck class seven showed coefficient of regression around zero. Therefore, models and growth rates for this truck class should be used with care in future forecasting.

\subsubsection{Truck Groups Single-Unit and Multi-Unit (4-7, 8-13)}

Results from the analyses of truck groups in this study for all interstate highways were compared. Two groups were performed; single and multi-unit trucks to be analyzed. Results from the linear regression and growth factor method were compared and are documented in Table 4.36 .

\section{Table 4.36-Comparison of Annual Average Growth Rates-- All Interstate Highways}

\begin{tabular}{|c|c|c|c|}
\hline \multirow{2}{*}{ All } & \multicolumn{3}{|c|}{ Annual Average Daily Truck Traffic Growth Rate } \\
\cline { 2 - 4 } & $\begin{array}{c}\text { Linear Regression } \\
\text { (weighted average) }\end{array}$ & $\begin{array}{c}\text { Overall } \\
\text { (Linear Regression) }\end{array}$ & Growth Factor \\
\hline TC4-TC7 & $5.12 \%$ & $6.19 \%$ & $10.58 \%$ \\
\hline TC8-TC13 & $4.32 \%$ & $6.46 \%$ & $5.47 \%$ \\
\hline
\end{tabular}

Heavy truck traffic (multi-unit trucks) is the most stable truck group on interstate highways in West Virginia based on its annual average growth rate in the three analyses. The growth rate for multi-unit trucks is between $4.32 \%$ and $6.46 \%$. Therefore, an overall annual growth rate for heavy traffic could be established to $5.00 \%$. 
Table 4.37 shows higher rates in single-unit trucks than heavy vehicles. Therefore, light truck traffic (single-unit trucks) is increasing at higher rate than heavy traffic in rural areas. Also, heavy truck traffic is increasing at an overall growth rate $5.00 \%$, similar finding reported in the previous analysis.

Table 4.37-Comparison of Annual Average Growth Rates-Rural Interstate Highways

\begin{tabular}{|c|c|c|c|}
\hline \multirow{2}{*}{ Rural } & \multicolumn{3}{|c|}{ Annual Average Daily Truck Traffic Growth Rate } \\
\cline { 2 - 4 } & $\begin{array}{c}\text { Linear Regression } \\
\text { (weighted average) }\end{array}$ & $\begin{array}{c}\text { Overall } \\
\text { (Linear Regression) }\end{array}$ & Growth Factor \\
\hline TC4-TC7 & $6.18 \%$ & $7.58 \%$ & $11.09 \%$ \\
\hline TC8-TC13 & $4.24 \%$ & $6.00 \%$ & $6.52 \%$ \\
\hline
\end{tabular}

Table 4.38 displays heavy traffic (multi-unit trucks) growing at an overall growth rate of $5.00 \%$. Unlike this result, an overall growth rate for single-unit trucks cannot be established based on both methods, because this truck group shows a large difference between the linear regression and growth factor method, a difference between $4.00 \%$ and $10.00 \%$.

Table 4.38-Comparison of Annual Average Growth Rates-Urban Interstate Highways

\begin{tabular}{|c|c|c|c|}
\hline \multirow{2}{*}{ Urban } & \multicolumn{3}{|c|}{ Annual Average Daily Truck Traffic Growth Rate } \\
\cline { 2 - 4 } & $\begin{array}{c}\text { Linear Regression } \\
\text { (weighted average) }\end{array}$ & $\begin{array}{c}\text { Overall } \\
\text { (Linear Regression) }\end{array}$ & Growth Factor \\
\hline TC4-TC7 & $4.12 \%$ & $4.17 \%$ & $10.06 \%$ \\
\hline TC8-TC13 & $4.39 \%$ & $5.69 \%$ & $4.41 \%$ \\
\hline
\end{tabular}




\section{CHAPTER 5}

\section{CONCLUSIONS AND RECOMMENDATIONS}

The purpose of this research was to forecast truck traffic volumes and truck traffic growth rates for interstate highways in West Virginia. Forecasting truck traffic is a vital duty in transportation planning in order to give the appropriate response due to the continuous changes in truck travel patterns on the highways system. Since interstate highways provide the highest level of service in the US highway system, it is valuable to understand and predict the variation in the roadways activity system to anticipate the improvements of new facilities and to understand the relationship of land use and transportation. Accurate and efficient forecasts of truck traffic are helpful in answering important questions for engineers and planners. Questions such as: Which roads carry large truck traffic volumes? What type of truck vehicle is increasing at a higher rate on interstate highways? Which roads carry light truck traffic volumes? These questions are answered in this study. In addition, this study shows truck travel patterns in separated studies for all, rural and urban interstate highways as well as for each type of truck vehicle.

Models and annual average growth rates forecasted in this study were derived by data collected from 1995 to 2003 from West Virginia's eight Permanent Automatic Traffic Recorders located in the following stations: Site 01, Site 05, Site 26, Site 29, Site 42, Site 47, Site 50, and Site 53. Data was tested for missing values, discrepancies and errors. They were removed based on observation of data and the use of a confidence interval. The confidence interval was based on the standard deviation and the mean of the 
data analyzed. This test was conducted in order to validate raw data from the count stations in order to develop models. Regression models and growth rates predicted in this study can be used throughout the Interstate Highways in West Virginia with a degree of confidence in the basis of their coefficient of regression

Limitations of this study are due to the errors and missing data found in the raw data, which affects the predicting capability in our sample data. This, consequently, also affected the results. Therefore, the factors derived by this study are limited in the way that they could only be used to compare with growth factors currently used by the West Virginia DOT in their designs, but these factors can also be used to further understand changes in future truck traffic patterns at interstate highways for each site and truck classification.

The two methods conducted to predict truck traffic (linear regression and growth factors) were compared. Linear regression models were proven to be the most confident technique used in the predicting analysis based on high values of the coefficient of regression present in the models developed. In addition, the use of the whole data available makes regression models stronger predictors than the growth factor method. The Growth factor technique showed results far away from the normal or reasonable values of growth rates for interstate highways. It probably occurs due to the use of two years data to develop the growth rate factors. As a final conclusion, linear regression analysis was established as the best predictor model technique to be used at interstate highways in West Virginia, giving an overall annual average growth rate of 5\%. 


\subsection{Findings}

- Annual average growth rates from the three methods conducted from all, rural and urban interstate highways display somewhat similar annual average growth rates between $4.37 \%$ and $6.94 \%$. Therefore, an overall growth rate at interstate highways in West Virginia can be established to be around $5.00 \%$.

- The best Models were found in the AADTT year averaged analysis based on their high coefficient of regression around 0.95.

- The best models for each truck classification are found in Site50, and the worst models in Site29 (only truck class 9 and 10 could be predicted) based on coefficients of regression and the difference between real AADTT and the predicted one (Appendix C).

- Truck class 13 seems to be the most reliable truck class to be predicted on the basis of its coefficient of variation around $12 \%$.

- Site01 showed negative annual average truck traffic growth rates. As shown in Table 4.7, heavy truck classes are reducing their travel activity in this site. As previously reported, the decline in the coal mining production, in addition to a possible change in route choice, could be affecting the travel patterns of the heavy truck classes. 
- Growth rates weighted in the growth factor method were higher than the one performed by regression analysis; however, the coefficients of variation in both analyses are high and display a slight variation.

\subsection{Further Work}

- More counts should be collected throughout the state, to ensure robust models. Additional data would also help to increase the accuracy of the proposed method and would better enable engineers to differentiate between locally generated and through traffic.

- Although the preliminary results obtained through this study are promising in terms of the proposed methodology, it is recognized that a much larger set of counts should be considered, in order to obtain more sound statistical models and more accurate results. 


\section{REFERENCE LIST}

Barrett Monica L; Graves, Clark, Allen, David L; Pigman, Jerry G. Kentucky Transportation Center. Analysis of Traffic Growth. Research Report. KTC 0115/SPR-213-00-1F. University of Kentucky. August 2001.

Dixon, Michael. The effects of errors in annual average daily traffic forecasting: Study of Highways in rural Idaho. Final Report. National Institute for advance Transportation. September 2004.

Federal Highway Administration, Traffic Monitoring Guide, Office of Highway Policy Information, Washington, D.C., January 2001.

Federal Highway Administration. Guidebook on Statewide Travel Forecasting. March 1999.

Gargett, David; Cosgrove, David. Predicting Traffic Growth in Australian Cities. Bureau of Transport and Regional Economics, Canberra. Paper for the Australasian Transport Research Forum, 29 September-1 October, Adelaide.

Hallenbeck, Rice, Cornell-Martinez, and Smith, "Vehicle Volume Distributions by Classification," FHWA-PL-97-025, June 1997.

Hallmark, Shauna L; Lamptey, Stephen. Evaluation of Different Methods to Calculate Heavy-Truck VMT. Midwest Transportation Consortium, Project 200202. Final report, December 2004.

Highway Performance Monitoring System Field Book. http://www.fhwa.dot.gov/ohim/hpmsmanl/hpms.htm\accessed July 18, 2005.

Rebovich, Andrew J. An Evaluation of Statewide Truck Forecasting Methods. College of Engineering and Mineral Resources at West Virginia University, 2004.

The West Virginia Geological and Economic Survey-- Summary Data and Statistics: Coal Production Data, By County Drilling Activity Reported in 2001 http://www.wvgs.wvnet.edu/www/datastat/dataclco.htmlaccessed January 18, 2006

US Department of Transportation. Freight Management and Operations. http://www.ops.fhwa.dot.gov/freight/freight_analysis/state_info/west_virginia/wv .htm $\backslash$ accessed June 10, 2005.

Wright, T., Hu, P., Young, J., and Lu, A, "Variability in Traffic Monitoring Data, Final Summary report," Oak Ridge National Laboratory for the US Department of 
Zhao, Fang; Chung, Soon. Estimation of Annual Average Daily Traffic in a Florida County Using GIS and Regression. Transportation Research Board, TRB Paper 01-3440. 2001. 


\section{APPENDICES}

APPENDIX A

Linear Regression Models for Each Truck Classification for Each Site

\section{$\underline{\text { Rural Interstate Highways }}$}

\begin{tabular}{|c|c|c|c|}
\hline $\begin{array}{c}\text { Truck } \\
\text { Class }\end{array}$ & Site 01 & Site 05 & Site 47 \\
\hline TC4 & $\mathrm{Y}=3.43 \mathrm{X}-6812$ & $\mathrm{Y}=2.4 \mathrm{X}-4773$ & $\mathrm{Y}=8.77 \mathrm{X}-17475$ \\
\hline TC5 & $\mathrm{Y}=-4.46 \mathrm{X}+9051$ & $\mathrm{Y}=6.5 \mathrm{X}-12758$ & $\mathrm{Y}=44.97 \mathrm{X}-89651$ \\
\hline TC6 & $\mathrm{Y}=-8.89 \mathrm{X}+17818$ & $\mathrm{Y}=2.99 \mathrm{X}-5871$ & $\mathrm{Y}=-5.07 \mathrm{X}+10190$ \\
\hline TC7 & $\mathrm{Y}=-3.4 \mathrm{X}+6813$ & $\mathrm{Y}=0.49 \mathrm{X}-948$ & $\mathrm{Y}=-0.1 \mathrm{X}+203$ \\
\hline TC8 & $\mathrm{Y}=-5.6 \mathrm{X}+11271$ & $\mathrm{Y}=7.45 \mathrm{X}-14736$ & $\mathrm{Y}=2.43 \mathrm{X}-4735$ \\
\hline TC9 & $\mathrm{Y}=-106.43 \mathrm{X}+213865$ & $\mathrm{Y}=69.65 \mathrm{X}-136968$ & $\mathrm{Y}=15.77 \mathrm{X}-29621$ \\
\hline TC10 & $\mathrm{Y}=-1.43 \mathrm{X}+2867$ & $\mathrm{Y}=2.68 \mathrm{X}-5335$ & $\mathrm{Y}=3.53 \mathrm{X}-7044$ \\
\hline TC11 & $\mathrm{Y}=-5 \mathrm{X}+10019$ & $\mathrm{Y}=4 \mathrm{X}-7933$ & $\mathrm{Y}=-8 \mathrm{X}+16097$ \\
\hline TC12 & $\mathrm{Y}=-1.5 \mathrm{X}+3000$ & $\mathrm{Y}=-0.33 \mathrm{X}+673$ & $\mathrm{Y}=-1 \mathrm{X}+2011$ \\
\hline TC13 & $\mathrm{Y}=6.23 \mathrm{X}-12432$ & $\mathrm{Y}=1.84 \mathrm{X}-3670$ & $\mathrm{Y}=5.53 \mathrm{X}-11040$ \\
\hline
\end{tabular}

\begin{tabular}{|c|c|c|}
\hline $\begin{array}{c}\text { Truck } \\
\text { Class }\end{array}$ & Site 50 & Site 53 \\
\hline TC4 & $\mathrm{Y}=16.6 \mathrm{X}-33127$ & $\mathrm{Y}=3.29 \mathrm{X}-6569$ \\
\hline TC5 & $\mathrm{Y}=67.66 \mathrm{X}-134826$ & $\mathrm{Y}=17.92 \mathrm{X}-35693$ \\
\hline TC6 & $\mathrm{Y}=40.75 \mathrm{X}-81280$ & $\mathrm{Y}=3.83 \mathrm{X}-7600$ \\
\hline TC7 & $\mathrm{Y}=8.25 \mathrm{X}-16478$ & $\mathrm{Y}=-1.57 \mathrm{X}+3145$ \\
\hline TC8 & $\mathrm{Y}=40.76 \mathrm{X}-81147$ & $\mathrm{Y}=11.56 \mathrm{X}-23033$ \\
\hline TC9 & $\mathrm{Y}=1043.51 \mathrm{X}-2080300$ & $\mathrm{Y}=115.19 \mathrm{X}-228937$ \\
\hline TC10 & $\mathrm{Y}=32.11 \mathrm{X}-64126$ & $\mathrm{Y}=1.93 \mathrm{X}-3834$ \\
\hline TC11 & $\mathrm{Y}=104 \mathrm{X}-207318$ & $\mathrm{Y}=-13.43 \mathrm{X}+26854$ \\
\hline TC12 & $\mathrm{Y}=19 \mathrm{X}-37897$ & $\mathrm{Y}=-0.36 \mathrm{X}+716$ \\
\hline TC13 & $\mathrm{Y}=5.53 \mathrm{X}-11034$ & $\mathrm{Y}=1.73 \mathrm{X}-3444$ \\
\hline
\end{tabular}

Noted: "X" is the independent variable Time Period, for example: 2004, 2005, 2006 and so on. " $\mathrm{Y}$ " is the Annual Average Daily Truck Traffic to be predicted 


\section{Urban Interstate Highways}

\begin{tabular}{|c|c|c|c|}
\hline $\begin{array}{c}\text { Truck } \\
\text { Class }\end{array}$ & Site 26 & Site 29 & Site 42 \\
\hline TC4 & $\mathrm{Y}=4.5 \mathrm{X}-8957$ & $\mathrm{Y}=5.2 \mathrm{X}-10326$ & $\mathrm{Y}=5.53 \mathrm{X}-10995$ \\
\hline TC5 & $\mathrm{Y}=16.74 \mathrm{X}-33038$ & $\mathrm{Y}=8.61 \mathrm{X}-16801$ & $\mathrm{Y}=48.71 \mathrm{X}-96948$ \\
\hline TC6 & $\mathrm{Y}=4.41 \mathrm{X}-8587$ & $\mathrm{Y}=-0.19 \mathrm{X}+571$ & $\mathrm{Y}=17.74 \mathrm{X}-35300$ \\
\hline TC7 & $\mathrm{Y}=0.91 \mathrm{X}-1799$ & $\mathrm{Y}=0.26 \mathrm{X}-507$ & $\mathrm{Y}=-2.07 \mathrm{X}+4167$ \\
\hline TC8 & $\mathrm{Y}=4.63 \mathrm{X}-9000$ & $\mathrm{Y}=4 \mathrm{X}-7722$ & $\mathrm{Y}=31.45 \mathrm{X}-62539$ \\
\hline TC9 & $\mathrm{Y}=176.5 \mathrm{X}-349497$ & $\mathrm{Y}=269.18 \mathrm{X}-531812$ & $\mathrm{Y}=431.29 \mathrm{X}-858550$ \\
\hline TC10 & $\mathrm{Y}=-0.57 \mathrm{X}+1222$ & $\mathrm{Y}=15.76 \mathrm{X}-31413$ & $\mathrm{Y}=23.99 \mathrm{X}-47873$ \\
\hline TC11 & $\mathrm{Y}=14.23 \mathrm{X}-28334$ & $\mathrm{Y}=-16.6 \mathrm{X}+33626$ & $\mathrm{Y}=-36 \mathrm{X}+72056$ \\
\hline TC12 & $\mathrm{Y}=-0.27 \mathrm{X}+545$ & $\mathrm{Y}=1.1 \mathrm{X}-2128$ & $\mathrm{Y}=-7.5 \mathrm{X}+14997$ \\
\hline TC13 & $\mathrm{Y}=7.67 \mathrm{X}-15301$ & $\mathrm{Y}=16.64 \mathrm{X}-33206$ & $\mathrm{Y}=28.21 \mathrm{X}-56295$ \\
\hline
\end{tabular}




\section{APPENDIX B}

\section{Annual Average Growth rates and weight factors for each truck classification on rural and urban interstate highways.}

\section{Rural Interstates}

\section{Annual Average Growth Rate}

\begin{tabular}{|c|r|r|r|r|r|}
\hline Truck Class & \multicolumn{1}{|c|}{ Site01 } & \multicolumn{1}{c|}{ Site05 } & \multicolumn{1}{c|}{ Site47 } & \multicolumn{1}{c|}{ Site50 } & \multicolumn{1}{c|}{ Site53 } \\
\hline TC4 & $6.23 \%$ & $6.21 \%$ & $10.40 \%$ & $13.00 \%$ & $10.58 \%$ \\
\hline TC5 & $-3.61 \%$ & $2.48 \%$ & $10.78 \%$ & $9.63 \%$ & $8.86 \%$ \\
\hline TC6 & $-45.34 \%$ & $2.63 \%$ & $-12.12 \%$ & $12.12 \%$ & $5.78 \%$ \\
\hline TC7 & $-141.67 \%$ & $1.70 \%$ & $-3.70 \%$ & $15.66 \%$ & $-38.72 \%$ \\
\hline TC8 & $-10.26 \%$ & $3.96 \%$ & $1.75 \%$ & $8.27 \%$ & $9.31 \%$ \\
\hline TC9 & $-15.45 \%$ & $2.75 \%$ & $0.80 \%$ & $10.60 \%$ & $6.46 \%$ \\
\hline TC10 & $-23.81 \%$ & $6.81 \%$ & $10.58 \%$ & $17.16 \%$ & $6.85 \%$ \\
\hline TC11 & $-125.00 \%$ & $5.06 \%$ & $-10.96 \%$ & $10.47 \%$ & $30.72 \%$ \\
\hline TC12 & $32.14 \%$ & $-6.25 \%$ & $-12.50 \%$ & $11.90 \%$ & $-33.33 \%$ \\
\hline TC13 & $14.09 \%$ & $10.12 \%$ & $12.81 \%$ & $12.86 \%$ & $12.16 \%$ \\
\hline
\end{tabular}

Weight Table

\begin{tabular}{|c|c|c|c|c|c|}
\hline Truck Class & Site01 & Site05 & Site47 & Site50 & Site53 \\
\hline TC4 & 0.179 & 0.145 & 0.280 & 0.319 & 0.077 \\
\hline TC5 & 0.119 & 0.194 & 0.229 & 0.364 & 0.095 \\
\hline TC6 & 0.144 & 0.225 & 0.124 & 0.402 & 0.105 \\
\hline TC7 & 0.000 & 0.422 & 0.047 & 0.344 & 0.188 \\
\hline TC8 & 0.107 & 0.206 & 0.168 & 0.432 & 0.088 \\
\hline TC9 & 0.099 & 0.182 & 0.152 & 0.470 & 0.098 \\
\hline TC10 & 0.092 & 0.196 & 0.150 & 0.438 & 0.124 \\
\hline TC11 & 0.000 & 0.077 & 0.171 & 0.692 & 0.060 \\
\hline TC12 & 0.043 & 0.085 & 0.149 & 0.691 & 0.032 \\
\hline TC13 & 0.152 & 0.152 & 0.342 & 0.278 & 0.076 \\
\hline
\end{tabular}

Average Annual Growth Rates for Single and Multi-Unit Trucks

\begin{tabular}{|c|c|c|c|c|c|}
\hline Truck Class & Site01 & Site05 & Site47 & \multicolumn{1}{c|}{ Site50 } & Site53 \\
\hline TC4-TC7 & $-6.64 \%$ & $2.79 \%$ & $8.89 \%$ & $10.93 \%$ & $7.73 \%$ \\
\hline TC8-TC13 & $-15.54 \%$ & $2.63 \%$ & $0.19 \%$ & $9.73 \%$ & $6.30 \%$ \\
\hline
\end{tabular}




\section{$\underline{\text { Urban }}$}

\section{Annual Average Growth Rate}

\begin{tabular}{|c|r|r|r|}
\hline Truck Class & \multicolumn{1}{|c|}{ Site26 } & \multicolumn{1}{c|}{ Site29 } & \multicolumn{1}{c|}{ Site42 } \\
\hline TC4 & $7.99 \%$ & $5.51 \%$ & $6.63 \%$ \\
\hline TC5 & $3.41 \%$ & $1.96 \%$ & $7.98 \%$ \\
\hline TC6 & $1.75 \%$ & $-0.10 \%$ & $7.45 \%$ \\
\hline TC7 & $3.06 \%$ & $1.53 \%$ & $-12.54 \%$ \\
\hline TC8 & $1.69 \%$ & $1.38 \%$ & $6.95 \%$ \\
\hline TC9 & $4.38 \%$ & $3.66 \%$ & $8.09 \%$ \\
\hline TC10 & $-0.63 \%$ & $9.95 \%$ & $12.75 \%$ \\
\hline TC11 & $8.35 \%$ & $-4.42 \%$ & $69.68 \%$ \\
\hline TC12 & $-4.52 \%$ & $1.46 \%$ & $29.22 \%$ \\
\hline TC13 & $10.98 \%$ & $12.83 \%$ & $13.98 \%$ \\
\hline
\end{tabular}

Weight Table

\begin{tabular}{|c|c|c|c|}
\hline Truck Class & Site26 & Site29 & \multicolumn{1}{c|}{ Site42 } \\
\hline TC4 & 0.216 & 0.432 & 0.352 \\
\hline TC5 & 0.337 & 0.325 & 0.338 \\
\hline TC6 & 0.393 & 0.319 & 0.287 \\
\hline TC7 & 0.394 & 0.242 & 0.364 \\
\hline TC8 & 0.296 & 0.319 & 0.385 \\
\hline TC9 & 0.248 & 0.477 & 0.275 \\
\hline TC10 & 0.315 & 0.353 & 0.332 \\
\hline TC11 & 0.113 & 0.657 & 0.231 \\
\hline TC12 & 0.083 & 0.719 & 0.198 \\
\hline TC13 & 0.189 & 0.350 & 0.461 \\
\hline
\end{tabular}

\section{Annual Average Growth Rates for Single and Multi-Unit Trucks}

\begin{tabular}{|c|c|c|c|}
\hline Truck Class & Site26 & Site29 & Site42 \\
\hline TC4-TC7 & $3.20 \%$ & $1.88 \%$ & $7.37 \%$ \\
\hline TC8-TC13 & $3.97 \%$ & $2.57 \%$ & $7.82 \%$ \\
\hline
\end{tabular}




\section{APPENDIX C}

Differences between Real and Predicted AADTTs conducted to the last year of AADTT available.

\begin{tabular}{|c|c|c|c|c|cc|}
\hline Route & Class & Site & 2003 & Predicted 2003 & $\mathrm{R}^{2}$ & Differences \\
\hline I-64 & Rural & SITE 01 & ---- & 964 & 0.88 & ---- \\
\hline I-79 & Rural & SITE 05 & 3089 & 3223 & 0.63 & $-4.34 \%$ \\
\hline I-64 & Urban & SITE 26 & 4912 & 5297 & 0.75 & $-7.83 \%$ \\
\hline I-70 & Urban & SITE 29 & 8562 & 8575 & 0.51 & $-0.15 \%$ \\
\hline I-64 & Urban & SITE 42 & 7150 & 7105 & 0.90 & $0.63 \%$ \\
\hline I-77 & Rural & SITE 47 & 2936 & 2704 & 0.15 & $7.90 \%$ \\
\hline I-81 & Rural & SITE 50 & 11805 & 11869 & 0.98 & $-0.54 \%$ \\
\hline I-68 & Rural & SITE 53 & 2576 & 2248 & 0.41 & $12.72 \%$ \\
\hline
\end{tabular}

Differences between Real and Predicted AADTTs conducted to the last year of AADTT available for each truck classification in each site.

Site01-- Functional Classes

\begin{tabular}{|c|c|c|c|c|}
\hline Truck Class & $\mathbf{2 0 0 0}$ & Estimated 2000 & $\mathbf{R}^{\mathbf{2}}$ & Difference \\
\hline TC4 & 23 & 44.71 & 0.03 & $94.41 \%$ \\
\hline TC5 & 106 & 136.97 & 0.02 & $29.22 \%$ \\
\hline TC6 & 41 & 46.26 & 0.80 & $12.82 \%$ \\
\hline TC7 & 13 & 12.60 & 0.85 & $3.08 \%$ \\
\hline TC8 & 62 & 71.40 & 0.34 & $15.16 \%$ \\
\hline TC9 & 1017 & 1008.29 & 0.94 & $0.86 \%$ \\
\hline TC10 & 12 & 10.29 & 0.44 & $14.29 \%$ \\
\hline TC11 & --- & 19.00 & 0.68 & --- \\
\hline TC12 & --- & -0.17 & 0.96 & --- \\
\hline TC13 & 25 & 25.51 & 0.93 & $2.06 \%$ \\
\hline
\end{tabular}

\begin{tabular}{|l|r|c|c|r|}
\hline Truck Class & $\mathbf{2 0 0 0}$ & Estimated 2000 & $\mathbf{R}^{2}$ & Difference \\
\hline TC4-TC7 & 183 & 241 & 0.06 & $31.44 \%$ \\
\hline TC8-TC13 & 1116 & 1119 & 0.96 & $0.24 \%$ \\
\hline
\end{tabular}

$* \mathrm{R}^{2}<0.6$ and Differences $>10 \%$ are shaded 
Site05-- Functional Classes

\begin{tabular}{|c|c|c|c|c|}
\hline Truck Class & $\mathbf{2 0 0 3}$ & Estimated 2003 & $\mathbf{R}^{2}$ & Difference \\
\hline TC4 & 36 & 38.66 & 0.83 & $7.38 \%$ \\
\hline TC5 & 240 & 262.00 & 0.59 & $9.17 \%$ \\
\hline TC6 & 108 & 113.71 & 0.60 & $5.28 \%$ \\
\hline TC7 & 29 & 28.71 & 0.12 & $1.01 \%$ \\
\hline TC8 & 160 & 188.33 & 0.56 & $17.71 \%$ \\
\hline TC9 & 2461 & 2533.51 & 0.64 & $2.95 \%$ \\
\hline TC10 & 40 & 39.39 & 1.00 & $1.52 \%$ \\
\hline TC11 & --- & 79.00 & 1.00 & --- \\
\hline TC12 & --- & 5.33 & 1.00 & --- \\
\hline TC13 & 15 & 18.20 & 0.85 & $21.30 \%$ \\
\hline
\end{tabular}

\begin{tabular}{|l|r|c|c|r|}
\hline Truck Class & $\mathbf{2 0 0 3}$ & Estimated 2003 & $\mathbf{R}^{\mathbf{2}}$ & Difference \\
\hline TC4-TC7 & 413 & 443 & 0.64 & $7.28 \%$ \\
\hline TC8-TC13 & 2676 & 2780 & 0.62 & $3.89 \%$ \\
\hline
\end{tabular}

Site26-- Functional Classes

\begin{tabular}{|c|c|c|c|c|}
\hline Truck Class & $\mathbf{2 0 0 3}$ & Estimated 2003 & $\mathbf{R}^{\mathbf{2}}$ & Difference \\
\hline TC4 & 59 & 56.33 & 0.71 & $4.52 \%$ \\
\hline TC5 & 495 & 490.79 & 0.83 & $0.85 \%$ \\
\hline TC6 & 250 & 251.99 & 0.22 & $0.79 \%$ \\
\hline TC7 & 29 & 29.82 & 0.86 & $2.82 \%$ \\
\hline TC8 & 269 & 274.69 & 0.75 & $2.11 \%$ \\
\hline TC9 & 3676 & 4033.00 & 0.74 & $9.71 \%$ \\
\hline TC10 & 83 & 89.41 & 0.03 & $7.72 \%$ \\
\hline TC11 & --- & 170.46 & 0.84 & --- \\
\hline TC12 & --- & 5.96 & 0.94 & --- \\
\hline TC13 & 51 & 69.86 & 0.59 & $36.98 \%$ \\
\hline
\end{tabular}

\begin{tabular}{|l|r|r|c|r|}
\hline Truck Class & $\mathbf{2 0 0 3}$ & Estimated 2003 & $\mathbf{R}^{2}$ & Difference \\
\hline TC4-TC7 & 833 & 829 & 0.75 & $0.49 \%$ \\
\hline TC8-TC13 & 4079 & 4468 & 0.72 & $9.53 \%$ \\
\hline
\end{tabular}

$* \mathrm{R}^{2}<0.6$ and Differences $>10 \%$ are shaded 
Site29-- Functional Classes

\begin{tabular}{|l|r|r|c|c|}
\hline Truck Class & $\mathbf{2 0 0 3}$ & Estimated 2003 & $\mathbf{R}^{2}$ & Difference \\
\hline TC4 & 122 & 94.33 & 0.44 & $22.68 \%$ \\
\hline TC5 & 467 & 439.25 & 0.43 & $5.94 \%$ \\
\hline TC6 & 194 & 189.08 & 0.00 & $2.53 \%$ \\
\hline TC7 & 21 & 17.17 & 0.07 & $18.25 \%$ \\
\hline TC8 & 332 & 290.25 & 0.12 & $12.58 \%$ \\
\hline TC9 & 7160 & 7352.25 & 0.70 & $2.69 \%$ \\
\hline TC10 & 159 & 158.42 & 0.91 & $0.37 \%$ \\
\hline TC11 & --- & 375.70 & 0.49 & \\
\hline TC12 & --- & 75.30 & 0.10 & \\
\hline TC13 & 107 & 129.75 & 0.75 & $21.26 \%$ \\
\hline
\end{tabular}

\begin{tabular}{|l|r|r|c|r|}
\hline Truck Class & $\mathbf{2 0 0 3}$ & Estimated 2003 & $\mathbf{R}^{\mathbf{2}}$ & Difference \\
\hline TC4-TC7 & 804 & 740 & 0.37 & $7.98 \%$ \\
\hline TC8-TC13 & 7758 & 7835 & 0.49 & $0.99 \%$ \\
\hline
\end{tabular}

Site42-- Functional Classes

\begin{tabular}{|c|c|c|c|c|}
\hline Truck Class & $\mathbf{2 0 0 3}$ & Estimated 2003 & $\mathbf{R}^{\mathbf{2}}$ & Difference \\
\hline TC4 & 83 & 83.42 & 0.99 & $0.50 \%$ \\
\hline TC5 & 629 & 610.28 & 0.96 & $2.98 \%$ \\
\hline TC6 & 253 & 238.02 & 0.81 & $5.92 \%$ \\
\hline TC7 & 21 & 16.53 & 0.25 & $21.31 \%$ \\
\hline TC8 & 496 & 452.30 & 0.82 & $8.81 \%$ \\
\hline TC9 & 5256 & 5331.72 & 0.91 & $1.44 \%$ \\
\hline TC10 & 184 & 188.18 & 0.91 & $2.27 \%$ \\
\hline TC11 & --- & -51.67 & 0.62 & --- \\
\hline TC12 & --- & -25.67 & 0.96 & --- \\
\hline TC13 & 228 & 201.78 & 0.89 & $11.50 \%$ \\
\hline
\end{tabular}

\begin{tabular}{|l|r|r|c|r|}
\hline Truck Class & $\mathbf{2 0 0 3}$ & Estimated 2003 & $\mathbf{R}^{2}$ & Difference \\
\hline TC4-TC7 & 986 & 948 & 0.91 & $3.83 \%$ \\
\hline TC8-TC13 & 6164 & 6157 & 0.90 & $0.11 \%$ \\
\hline
\end{tabular}

$* \mathrm{R}^{2}<0.6$ and Differences $>10 \%$ are shaded 
Site47-- Functional Classes

\begin{tabular}{|c|c|c|c|c|}
\hline Truck Class & $\mathbf{2 0 0 3}$ & Estimated 2003 & $\mathbf{R}^{2}$ & Difference \\
\hline TC4 & 83 & 84.30 & 0.77 & $1.57 \%$ \\
\hline TC5 & 429 & 417.30 & 0.73 & $2.73 \%$ \\
\hline TC6 & 59 & 41.80 & 0.56 & $29.15 \%$ \\
\hline TC7 & 3 & 2.70 & 0.15 & $10.00 \%$ \\
\hline TC8 & 155 & 138.90 & 0.18 & $10.39 \%$ \\
\hline TC9 & 2125 & 1959.70 & 0.01 & $7.78 \%$ \\
\hline TC10 & 35 & 33.40 & 0.68 & $4.57 \%$ \\
\hline TC11 & --- & 73.00 & 1.00 & --- \\
\hline TC12 & --- & 8.00 & 1.00 & --- \\
\hline TC13 & 47 & 43.20 & 0.96 & $8.09 \%$ \\
\hline
\end{tabular}

\begin{tabular}{|l|r|r|c|r|}
\hline Truck Class & $\mathbf{2 0 0 3}$ & Estimated 2003 & $\mathbf{R}^{\mathbf{2}}$ & Difference \\
\hline TC4-TC7 & 574 & 546 & 0.73 & $4.86 \%$ \\
\hline TC8-TC13 & 2362 & 2158 & 0.0008 & $8.63 \%$ \\
\hline
\end{tabular}

Site50-- Functional Classes

\begin{tabular}{|c|c|c|c|c|}
\hline Truck Class & $\mathbf{2 0 0 3}$ & Estimated 2003 & $\mathbf{R}^{\mathbf{2}}$ & Difference \\
\hline TC4 & 132 & 127.76 & 0.95 & $3.21 \%$ \\
\hline TC5 & 712 & 702.73 & 0.98 & $1.30 \%$ \\
\hline TC6 & 342 & 336.30 & 0.99 & $1.67 \%$ \\
\hline TC7 & 54 & 52.70 & 0.98 & $2.41 \%$ \\
\hline TC8 & 493 & 493.10 & 0.98 & $0.02 \%$ \\
\hline TC9 & 9830 & 9842.40 & 0.98 & $0.13 \%$ \\
\hline TC10 & 199 & 187.16 & 0.92 & $5.95 \%$ \\
\hline TC11 & --- & 993.67 & 0.89 & --- \\
\hline TC12 & --- & 159.67 & 0.87 & --- \\
\hline TC13 & 43 & 42.99 & 1.00 & $0.03 \%$ \\
\hline
\end{tabular}

\begin{tabular}{|l|c|r|c|r|}
\hline Truck Class & $\mathbf{2 0 0 3}$ & Estimated 2003 & $\mathbf{R}^{\mathbf{2}}$ & Difference \\
\hline TC4-TC7 & 1240 & 1220 & 0.98 & $1.65 \%$ \\
\hline TC8-TC13 & 10565 & 10649 & 0.97 & $0.80 \%$ \\
\hline
\end{tabular}

$* \mathrm{R}^{2}<0.6$ and Differences $>10 \%$ are shaded 
Site53-- Functional Classes

\begin{tabular}{|c|c|c|c|c|}
\hline Truck Class & $\mathbf{2 0 0 3}$ & Estimated 2003 & $\mathbf{R}^{2}$ & Difference \\
\hline TC4 & 34 & 31.15 & 0.82 & $8.38 \%$ \\
\hline TC5 & 225 & 202.37 & 0.69 & $10.06 \%$ \\
\hline TC6 & 79 & 66.18 & 0.23 & $16.23 \%$ \\
\hline TC7 & 9 & 4.05 & 0.25 & $55.00 \%$ \\
\hline TC8 & 141 & 124.17 & 0.62 & $11.94 \%$ \\
\hline TC9 & 2040 & 1782.39 & 0.41 & $12.63 \%$ \\
\hline TC10 & 32 & 28.16 & 0.47 & $12.01 \%$ \\
\hline TC11 & --- & -43.71 & 1.00 & --- \\
\hline TC12 & --- & 1.07 & 0.89 & --- \\
\hline TC13 & 16 & 14.20 & 0.76 & $11.24 \%$ \\
\hline
\end{tabular}

\begin{tabular}{|l|r|r|c|r|}
\hline Truck Class & $\mathbf{2 0 0 3}$ & Estimated 2003 & $\mathbf{R}^{\mathbf{2}}$ & Difference \\
\hline TC4-TC7 & 347 & 304 & 0.51 & $12.46 \%$ \\
\hline TC8-TC13 & 2229 & 1945 & 0.39 & $12.76 \%$ \\
\hline
\end{tabular}

$* \mathrm{R}^{2}<0.6$ and Differences $>10 \%$ are shaded 


\title{
APPENDIX D
}

\author{
Growth Factor Analysis
}

\section{$\underline{\text { Analysis for Each Truck Classification }}$}

\section{$\underline{\text { All Interstates }}$}

$\underline{\text { Average Annual Growth Rates for Each Truck Classification-All Interstates }}$

\begin{tabular}{|c|r|r|r|r|r|r|r|c|}
\hline Truck Class & \multicolumn{1}{|c|}{ Site01 } & \multicolumn{1}{c|}{ Site05 } & \multicolumn{1}{c|}{ Site26 } & \multicolumn{1}{c|}{ Site29 } & \multicolumn{1}{c|}{ Site42 } & \multicolumn{1}{c|}{ Site47 } & Site50 & Site53 \\
\hline TC4 & $-49.16 \%$ & $2.38 \%$ & $26.28 \%$ & $30.17 \%$ & $8.98 \%$ & $29.75 \%$ & $30.15 \%$ & $33.56 \%$ \\
\hline TC5 & $-30.11 \%$ & $-0.41 \%$ & $7.42 \%$ & $6.21 \%$ & $14.76 \%$ & $29.18 \%$ & $16.02 \%$ & $27.42 \%$ \\
\hline TC6 & $-26.06 \%$ & $-0.55 \%$ & $3.36 \%$ & $1.85 \%$ & $19.23 \%$ & $3.64 \%$ & $21.10 \%$ & $27.99 \%$ \\
\hline TC7 & $-12.55 \%$ & $-2.55 \%$ & $3.64 \%$ & $14.56 \%$ & $21.29 \%$ & $0.00 \%$ & $33.50 \%$ & $24.57 \%$ \\
\hline TC8 & $-22.04 \%$ & $0.77 \%$ & $1.72 \%$ & $10.89 \%$ & $16.11 \%$ & $7.15 \%$ & $9.65 \%$ & $34.53 \%$ \\
\hline TC9 & $-6.97 \%$ & $0.01 \%$ & $1.29 \%$ & $-0.92 \%$ & $16.33 \%$ & $-4.63 \%$ & $13.24 \%$ & $24.17 \%$ \\
\hline TC10 & $15.47 \%$ & $9.00 \%$ & $-11.93 \%$ & $8.13 \%$ & $42.79 \%$ & $3.03 \%$ & $64.77 \%$ & $26.19 \%$ \\
\hline TC11 & $-14.58 \%$ & $7.87 \%$ & $8.97 \%$ & $-3.22 \%$ & $-21.98 \%$ & $-6.63 \%$ & $23.77 \%$ & $-27.89 \%$ \\
\hline TC12 & $-29.29 \%$ & $-4.35 \%$ & $-4.35 \%$ & $-0.74 \%$ & $-34.96 \%$ & $-7.17 \%$ & $32.66 \%$ & $-9.14 \%$ \\
\hline TC13 & $25.00 \%$ & $10.76 \%$ & $-23.44 \%$ & $-3.12 \%$ & $64.38 \%$ & $20.29 \%$ & $19.62 \%$ & $51.57 \%$ \\
\hline
\end{tabular}

* Shaded boxes show negative growth rates

Weight Table and Average Annual Growth Rates Weighted for Each Truck $\underline{\text { Classification-All Interstates }}$

\begin{tabular}{|c|c|c|c|c|c|c|c|c|c|}
\hline $\begin{array}{c}\text { Truck } \\
\text { Class }\end{array}$ & Site01 & Site05 & Site26 & Site29 & Site42 & Site47 & Site50 & Site53 & $\begin{array}{c}\text { Class-Weighted } \\
\text { Annual Average } \\
\text { Growth Rate - (All) }\end{array}$ \\
\hline TC4 & 0.118 & 0.072 & 0.101 & 0.205 & 0.145 & 0.128 & 0.188 & 0.044 & $15.44 \%$ \\
\hline TC5 & 0.058 & 0.087 & 0.166 & 0.158 & 0.169 & 0.112 & 0.198 & 0.052 & $10.81 \%$ \\
\hline TC6 & 0.051 & 0.096 & 0.213 & 0.168 & 0.158 & 0.049 & 0.220 & 0.045 & $8.76 \%$ \\
\hline TC7 & 0.099 & 0.205 & 0.185 & 0.122 & 0.096 & 0.020 & 0.234 & 0.040 & $11.55 \%$ \\
\hline TC8 & 0.045 & 0.087 & 0.146 & 0.166 & 0.201 & 0.077 & 0.230 & 0.048 & $8.79 \%$ \\
\hline TC9 & 0.037 & 0.082 & 0.122 & 0.242 & 0.129 & 0.077 & 0.265 & 0.046 & $6.05 \%$ \\
\hline TC10 & 0.019 & 0.059 & 0.169 & 0.263 & 0.192 & 0.060 & 0.201 & 0.037 & $23.34 \%$ \\
\hline TC11 & 0.022 & 0.037 & 0.068 & 0.310 & 0.104 & 0.082 & 0.346 & 0.031 & $4.14 \%$ \\
\hline TC12 & 0.023 & 0.039 & 0.039 & 0.352 & 0.097 & 0.070 & 0.360 & 0.018 & $6.43 \%$ \\
\hline TC13 & 0.050 & 0.029 & 0.167 & 0.267 & 0.299 & 0.089 & 0.077 & 0.022 & $20.49 \%$ \\
\hline
\end{tabular}


Coefficient of Variation for Each Truck Classification based on AADTTs-All $\underline{\text { Interstates }}$

\begin{tabular}{|c|c|c|c|}
\hline Truck Class & Mean & St. dev. & $\begin{array}{c}\text { Coefficient of } \\
\text { Variation }\end{array}$ \\
\hline TC4 & 0.140 & 0.279 & $199.18 \%$ \\
\hline TC5 & 0.088 & 0.187 & $212.65 \%$ \\
\hline TC6 & 0.063 & 0.168 & $266.49 \%$ \\
\hline TC7 & 0.103 & 0.157 & $152.02 \%$ \\
\hline TC8 & 0.073 & 0.159 & $216.54 \%$ \\
\hline TC9 & 0.053 & 0.112 & $210.11 \%$ \\
\hline TC10 & 0.197 & 0.244 & $123.73 \%$ \\
\hline TC11 & -0.042 & 0.173 & $-410.80 \%$ \\
\hline TC12 & -0.072 & 0.204 & $-284.44 \%$ \\
\hline TC13 & 0.206 & 0.280 & $135.78 \%$ \\
\hline
\end{tabular}

\section{$\underline{\text { Rural Interstates }}$}

Average Annual Growth Rates for Each Truck Classification-Rural Interstates

\begin{tabular}{|c|c|c|r|r|c|}
\hline Truck Class & Site01 & Site05 & Site47 & Site50 & Site53 \\
\hline TC4 & $-49.16 \%$ & $2.38 \%$ & $29.75 \%$ & $30.15 \%$ & $33.56 \%$ \\
\hline TC5 & $-30.11 \%$ & $-0.41 \%$ & $29.18 \%$ & $16.02 \%$ & $27.42 \%$ \\
\hline TC6 & $-26.06 \%$ & $-0.55 \%$ & $3.64 \%$ & $21.10 \%$ & $27.99 \%$ \\
\hline TC7 & $-12.55 \%$ & $-2.55 \%$ & $0.00 \%$ & $33.50 \%$ & $24.57 \%$ \\
\hline TC8 & $-22.04 \%$ & $0.77 \%$ & $7.15 \%$ & $9.65 \%$ & $34.53 \%$ \\
\hline TC9 & $-6.97 \%$ & $0.01 \%$ & $-4.63 \%$ & $13.24 \%$ & $24.17 \%$ \\
\hline TC10 & $15.47 \%$ & $9.00 \%$ & $3.03 \%$ & $64.77 \%$ & $26.19 \%$ \\
\hline TC11 & $-14.58 \%$ & $7.87 \%$ & $-6.63 \%$ & $23.77 \%$ & $-27.89 \%$ \\
\hline TC12 & $-29.29 \%$ & $-4.35 \%$ & $-7.17 \%$ & $32.66 \%$ & $-9.14 \%$ \\
\hline TC13 & $25.00 \%$ & $10.76 \%$ & $20.29 \%$ & $19.62 \%$ & $51.57 \%$ \\
\hline
\end{tabular}


Weight Table and Average Annual Growth Rates Weighted for Each Truck Classification-Rural Interstates

\begin{tabular}{|c|r|r|r|r|r|c|}
\hline $\begin{array}{c}\text { Truck } \\
\text { Class }\end{array}$ & \multicolumn{1}{|c|}{ Site01 } & \multicolumn{1}{c|}{ Site05 } & \multicolumn{1}{c|}{ Site47 } & \multicolumn{1}{c|}{ Site50 } & \multicolumn{1}{c|}{ Site53 } & $\begin{array}{c}\text { Class-Weighted } \\
\text { Annual Average } \\
\text { Growth Rate-(Rural) }\end{array}$ \\
\hline TC4 & 0.196 & 0.128 & 0.291 & 0.312 & 0.074 & $9.66 \%$ \\
\hline TC5 & 0.104 & 0.165 & 0.282 & 0.355 & 0.094 & $12.04 \%$ \\
\hline TC6 & 0.113 & 0.213 & 0.089 & 0.486 & 0.099 & $10.18 \%$ \\
\hline TC7 & 0.174 & 0.314 & 0.029 & 0.413 & 0.070 & $11.82 \%$ \\
\hline TC8 & 0.090 & 0.204 & 0.156 & 0.456 & 0.095 & $7.17 \%$ \\
\hline TC9 & 0.075 & 0.168 & 0.121 & 0.543 & 0.094 & $7.90 \%$ \\
\hline TC10 & 0.049 & 0.178 & 0.143 & 0.531 & 0.099 & $39.95 \%$ \\
\hline TC11 & 0.043 & 0.071 & 0.157 & 0.689 & 0.040 & $13.11 \%$ \\
\hline TC12 & 0.035 & 0.075 & 0.136 & 0.724 & 0.030 & $20.01 \%$ \\
\hline TC13 & 0.172 & 0.147 & 0.336 & 0.269 & 0.076 & $22.48 \%$ \\
\hline
\end{tabular}

Coefficient of Variation for Each Truck Classification based on AADTTs-Rural $\underline{\text { Interstates }}$

\begin{tabular}{|c|c|c|c|}
\hline Truck Class & mean & St. dev. & $\begin{array}{c}\text { Coefficient of } \\
\text { Variation }\end{array}$ \\
\hline TC3 & 0.093 & 0.350 & $375.18 \%$ \\
\hline TC4 & 0.084 & 0.246 & $291.68 \%$ \\
\hline TC5 & 0.052 & 0.211 & $404.33 \%$ \\
\hline TC6 & 0.086 & 0.195 & $226.89 \%$ \\
\hline TC7 & 0.060 & 0.203 & $336.97 \%$ \\
\hline TC8 & 0.052 & 0.132 & $255.50 \%$ \\
\hline TC9 & 0.237 & 0.245 & $103.47 \%$ \\
\hline TC10 & -0.035 & 0.200 & $-573.21 \%$ \\
\hline TC11 & -0.035 & 0.225 & $-649.71 \%$ \\
\hline TC12 & 0.254 & 0.155 & $60.84 \%$ \\
\hline TC13 & 44.20 & 24.42 & $55.24 \%$ \\
\hline
\end{tabular}




\section{$\underline{\text { Urban Interstates }}$}

Average Annual Growth Rates for Each Truck Classification-Urban Interstates

\begin{tabular}{|c|r|r|r|}
\hline Truck Class & \multicolumn{1}{|c|}{ Site26 } & \multicolumn{1}{c|}{ Site29 } & \multicolumn{1}{c|}{ Site42 } \\
\hline TC4 & $26.28 \%$ & $30.17 \%$ & $8.98 \%$ \\
\hline TC5 & $7.42 \%$ & $6.21 \%$ & $14.76 \%$ \\
\hline TC6 & $3.36 \%$ & $1.85 \%$ & $19.23 \%$ \\
\hline TC7 & $3.64 \%$ & $14.56 \%$ & $21.29 \%$ \\
\hline TC8 & $1.72 \%$ & $10.89 \%$ & $16.11 \%$ \\
\hline TC9 & $1.29 \%$ & $-0.92 \%$ & $16.33 \%$ \\
\hline TC10 & $-11.93 \%$ & $8.13 \%$ & $42.79 \%$ \\
\hline TC11 & $8.97 \%$ & $-3.22 \%$ & $-21.98 \%$ \\
\hline TC12 & $-4.35 \%$ & $-0.74 \%$ & $-34.96 \%$ \\
\hline TC13 & $-23.44 \%$ & $-3.12 \%$ & $64.38 \%$ \\
\hline
\end{tabular}

Weight Table and Average Annual Growth Rates Weighted for Each Truck Classification-Urban Interstates

\begin{tabular}{|c|c|c|c|c|}
\hline $\begin{array}{c}\text { Truck } \\
\text { Class }\end{array}$ & Site26 & Site29 & Site42 & $\begin{array}{c}\text { Class-Weighted } \\
\text { Annual Average } \\
\text { Growth Rate-(Urban) }\end{array}$ \\
\hline TC4 & 0.212 & 0.429 & 0.358 & $22.50 \%$ \\
\hline TC5 & 0.311 & 0.290 & 0.399 & $9.55 \%$ \\
\hline TC6 & 0.363 & 0.285 & 0.351 & $7.54 \%$ \\
\hline TC7 & 0.424 & 0.280 & 0.295 & $11.15 \%$ \\
\hline TC8 & 0.264 & 0.295 & 0.441 & $10.33 \%$ \\
\hline TC9 & 0.226 & 0.448 & 0.326 & $4.15 \%$ \\
\hline TC10 & 0.219 & 0.359 & 0.421 & $13.33 \%$ \\
\hline TC11 & 0.137 & 0.645 & 0.217 & $-5.53 \%$ \\
\hline TC12 & 0.079 & 0.753 & 0.168 & $-7.80 \%$ \\
\hline TC13 & 0.185 & 0.299 & 0.516 & $19.76 \%$ \\
\hline
\end{tabular}


Coefficient of Variation for Each Truck Classification based on AADTTs-Urban Interstate

\begin{tabular}{|c|c|c|c|}
\hline Truck Class & Mean & St. dev. & $\begin{array}{c}\text { Coefficient of } \\
\text { Variation }\end{array}$ \\
\hline TC4 & 0.218 & 0.113 & $51.73 \%$ \\
\hline TC5 & 0.095 & 0.046 & $48.91 \%$ \\
\hline TC6 & 0.081 & 0.096 & $118.13 \%$ \\
\hline TC7 & 0.132 & 0.089 & $67.68 \%$ \\
\hline TC8 & 0.096 & 0.073 & $76.14 \%$ \\
\hline TC9 & 0.056 & 0.094 & $168.68 \%$ \\
\hline TC10 & 0.130 & 0.277 & $212.99 \%$ \\
\hline TC11 & -0.054 & 0.156 & $-288.20 \%$ \\
\hline TC12 & -0.133 & 0.188 & $-140.83 \%$ \\
\hline TC13 & 0.126 & 0.460 & $364.64 \%$ \\
\hline
\end{tabular}




\section{Analysis by Truck Groups (TC4-TC7, TC8-TC13)}

\section{All Interstates}

Average Annual Growth Rates for Single and Multi-Unit Trucks for Each Site-All $\underline{\text { Interstates }}$

\begin{tabular}{|c|c|c|c|c|c|c|c|c|}
\hline Truck Class & Site01 & Site05 & Site26 & \multicolumn{1}{c|}{ Site29 } & Site42 & Site47 & Site50 & Site53 \\
\hline TC4-TC7 & $-32.19 \%$ & $-0.38 \%$ & $7.04 \%$ & $8.02 \%$ & $15.34 \%$ & $25.13 \%$ & $19.16 \%$ & $28.00 \%$ \\
\hline TC8-TC13 & $-8.47 \%$ & $-0.29 \%$ & $0.52 \%$ & $-0.36 \%$ & $16.48 \%$ & $-3.58 \%$ & $10.62 \%$ & $23.95 \%$ \\
\hline
\end{tabular}

Weight Table and Annual Average Growth Rate weighted for Single and Multi-Unit Truck-All Interstates

\begin{tabular}{|c|c|c|c|c|c|c|c|c|c|}
\hline $\begin{array}{c}\text { Truck } \\
\text { Class }\end{array}$ & Site01 & Site05 & Site26 & Site29 & Site42 & Site47 & Site50 & Site53 & $\begin{array}{c}\text { Class-Weighted } \\
\text { Annual Average } \\
\text { Growth Rate - (All) }\end{array}$ \\
\hline TC4-TC7 & 0.064 & 0.092 & 0.171 & 0.164 & 0.161 & 0.095 & 0.204 & 0.049 & $10.58 \%$ \\
\hline TC8-TC13 & 0.036 & 0.080 & 0.122 & 0.242 & 0.135 & 0.077 & 0.264 & 0.045 & $5.47 \%$ \\
\hline
\end{tabular}

AADTT for Each Truck Group (Single/Multi-Unit) and Coefficient of Variation in Every $\underline{\text { Site-All Interstates }}$

\begin{tabular}{|c|c|c|c|}
\hline $\begin{array}{c}\text { Truck } \\
\text { Class }\end{array}$ & Mean & St. dev. & $\begin{array}{c}\text { Coefficient } \\
\text { of } \\
\text { Variation }\end{array}$ \\
\hline TC4-TC7 & 0.088 & 0.191 & $217.91 \%$ \\
\hline TC8-TC13 & 0.049 & 0.110 & $227.31 \%$ \\
\hline
\end{tabular}




\section{Rural Interstate}

Average Annual Growth Rates for Single and Multi-Unit Trucks for Each Site-Rural $\underline{\text { Interstates }}$

\begin{tabular}{|c|c|c|c|c|c|}
\hline Truck Class & Site01 & Site05 & Site47 & Site50 & Site53 \\
\hline TC3-TC7 & $-32.19 \%$ & $-0.38 \%$ & $25.13 \%$ & $19.16 \%$ & $28.00 \%$ \\
\hline TC8-TC13 & $-8.47 \%$ & $-0.29 \%$ & $-3.58 \%$ & $10.62 \%$ & $23.95 \%$ \\
\hline
\end{tabular}

Weight Table and Annual Average Growth Rate Weighted for Single and Multi-Unit Truck-Rural Interstates

\begin{tabular}{|c|c|c|c|c|c|c|}
\hline Truck Class & Site01 & Site05 & Site47 & Site50 & Site53 & $\begin{array}{c}\text { Class-Weighted } \\
\text { Annual Average } \\
\text { Growth Rate - (Rural) }\end{array}$ \\
\hline TC4-TC7 & 0.127 & 0.182 & 0.189 & 0.405 & 0.098 & $11.09 \%$ \\
\hline TC8-TC13 & 0.073 & 0.159 & 0.153 & 0.526 & 0.089 & $6.52 \%$ \\
\hline
\end{tabular}

AADTT for Each Truck Group (Single/Multi-Unit) and Coefficient of Variation in Every $\underline{\text { Site-Rural Interstates }}$

\begin{tabular}{|c|c|c|c|}
\hline $\begin{array}{c}\text { Truck } \\
\text { Class }\end{array}$ & Mean & St. dev. & $\begin{array}{c}\text { Coefficient } \\
\text { of } \\
\text { Variation }\end{array}$ \\
\hline TC3-TC7 & 0.079 & 0.250 & $314.99 \%$ \\
\hline TC8-TC13 & 0.044 & 0.130 & $291.49 \%$ \\
\hline
\end{tabular}




\section{$\underline{\text { Urban Interstates }}$}

Average Annual Growth Rates for Single and Multi-Unit Trucks for Each Site-Urban Interstates

\begin{tabular}{|c|c|c|c|}
\hline Truck Class & Site26 & Site29 & Site42 \\
\hline TC4-TC7 & $7.04 \%$ & $8.02 \%$ & $15.34 \%$ \\
\hline TC8-TC13 & $0.52 \%$ & $-0.36 \%$ & $16.48 \%$ \\
\hline
\end{tabular}

Weight Table and Annual Average Growth Rate Weighted for Single and Multi-Unit Truck-Urban Interstates

\begin{tabular}{|c|c|c|c|c|}
\hline Truck Class & Site26 & Site29 & Site42 & $\begin{array}{c}\text { Class-Weighted } \\
\text { Annual Average } \\
\text { Growth Rate-(Urban) }\end{array}$ \\
\hline TC4-TC7 & 0.345 & 0.330 & 0.325 & $10.06 \%$ \\
\hline TC8-TC13 & 0.244 & 0.486 & 0.271 & $4.41 \%$ \\
\hline
\end{tabular}

AADTT for Each Truck Group (Single/Multi-Unit) and Coefficient of Variation in Every $\underline{\text { Site-Urban Interstates }}$

\begin{tabular}{|c|c|c|c|}
\hline Truck Class & Mean & St. dev. & $\begin{array}{c}\text { Coefficient of } \\
\text { Variation }\end{array}$ \\
\hline TC4-TC7 & 0.101 & 0.045 & $44.74 \%$ \\
\hline TC8-TC13 & 0.055 & 0.095 & $170.89 \%$ \\
\hline
\end{tabular}

